\title{
LA INVESTIGACIÓN BIBLIOTECOLÓGICA: problemas para su enseñanza y aprendizaje
}

Jaime Ríos Ortega

C O OR D I A D O R

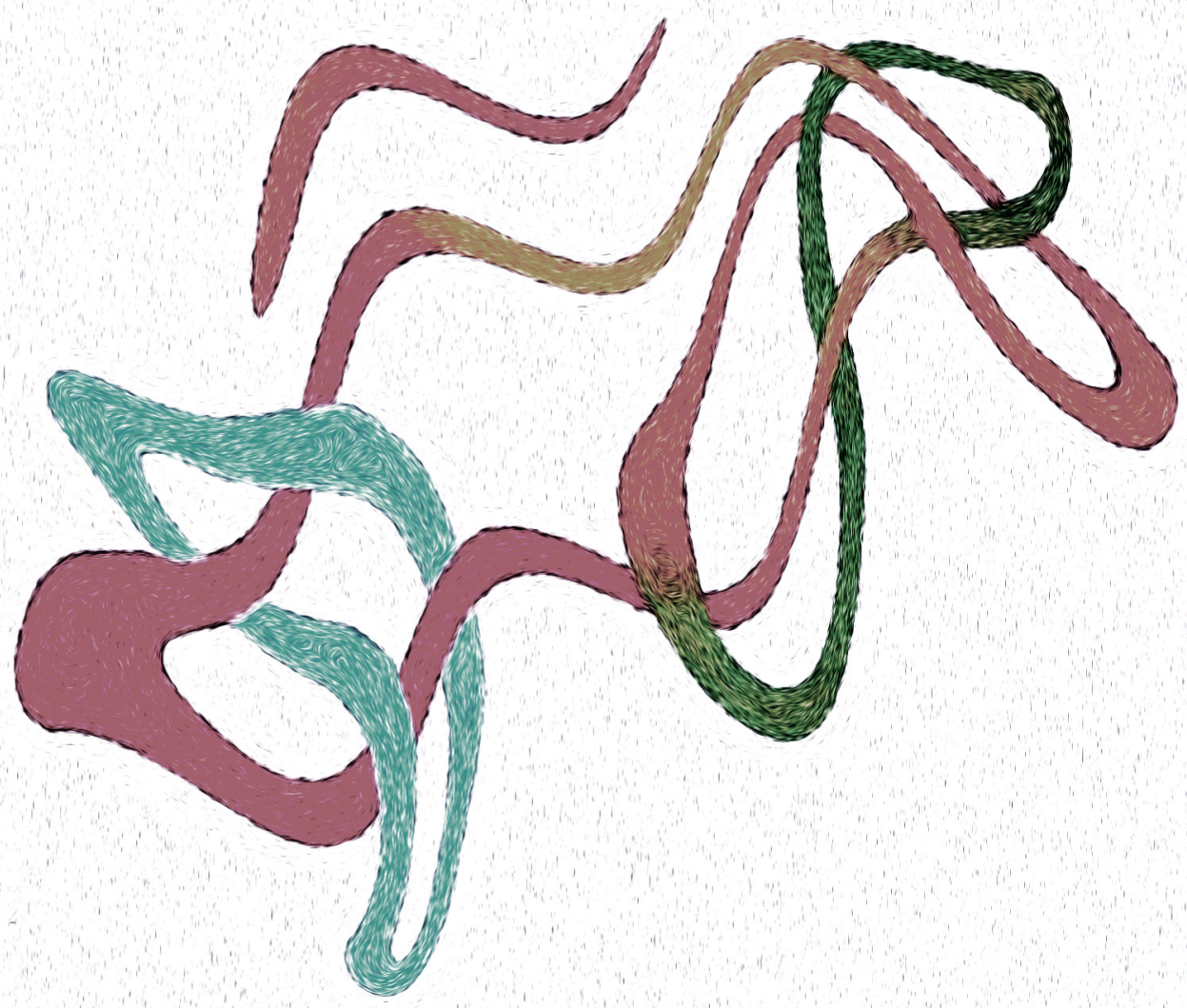




\section{La presente obra está bajo una licencia de:}

\section{http://creativecommons.org/licenses/by-nc-sa/3.0/deed.es MX}

\section{Atribución-No Comercial-Licenciamiento Reciproco 3.0 Unported}

Eres libre de:

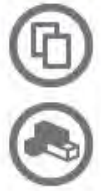

copiar, distribuir y comunicar públicamente la obra

hacer obras derivadas

Bajo las condiciones siguientes:

Atribución - Debes reconocer la autoría de la obra en los términos

especificados por el propio autor o licenciante.

No comercial - No puedes utilizar esta obra para fines comerciales.

Licenciamiento Recíproco - Si alteras, transformas o creas una obra a

partir de esta obra, solo podrás distribuir la obra resultante bajo una licencia

igual a ésta.

\section{Esto es un resumen fácilmente legible del: texto legal (de la licencia completa)}

En los casos que sea usada la presente obra, deben respetarse los términos especificados en esta licencia.
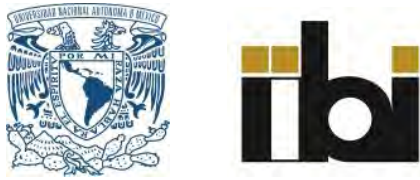
La investigación bibliotecológica: problemas para su enseñanza y aprendizaje 
COLECCIÓN

DidÁctica de LA BIBLIOTECOLOGía

Instituto de Investigaciones Bibliotecológicas y de la Información 


\title{
La investigación bibliotecológica: problemas para su enseñanza y aprendizaje
}

\author{
Coordinador \\ Jaime Ríos Ortega
}

Universidad Nacional Autónoma de México 2016 


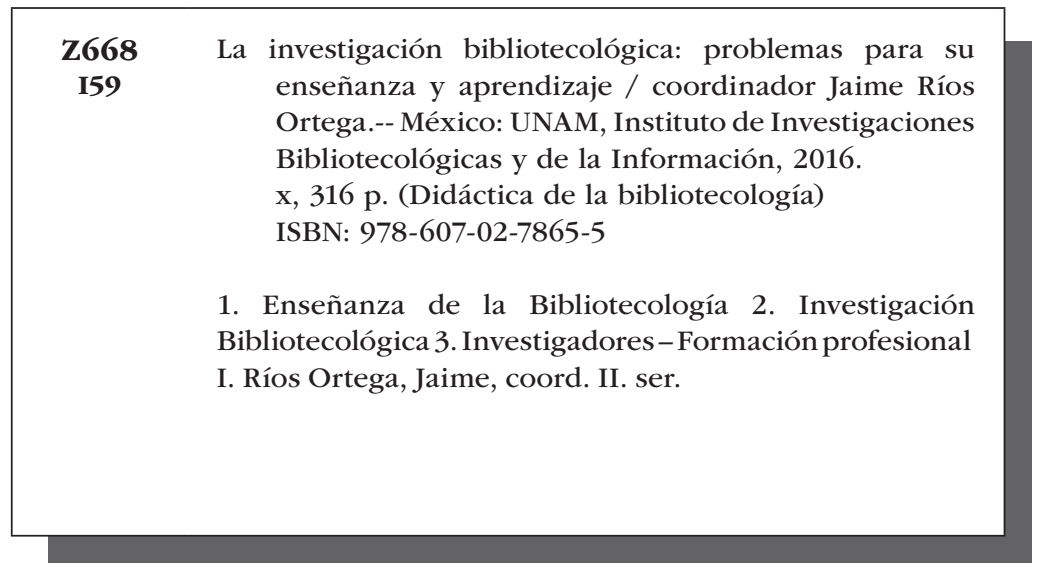

Diseño de portada: Mario Ocampo Chávez

Primera edición 2016

DR (C) Universidad Nacional Autónoma de México

Ciudad Universitaria, 04510, México D.F.

Impreso y hecho en México

ISBN: 978-607-02-7865-5 


\section{Contenido}

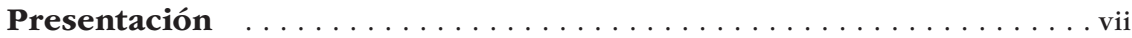

Jaime Ríos Ortega

APRENDIZAJE BASADO EN PROBLEMAS Y ORGANIZADO EN PROYECTOS. LA EXPERIENCIA DE LA LICENCIATURA EN BIBLIOTECOLOGÍA PEDAGÓGICA DE LA UNIVERSIDAD NACIONAL, COSTA RICA . . . . . . . . . . . . . . . . 1 Nidia Rojas Morales

APRENDIZAJE DE LA METODOLOGÍA DE INVESTIGACIÓN EN

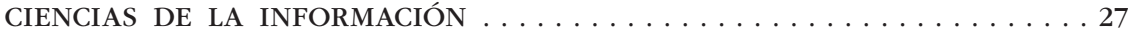
Rosa María Martínez Rider

¿CÓMO ENSEÑAR A INVESTIGAR EN BIBLIOTECOLOGÍA

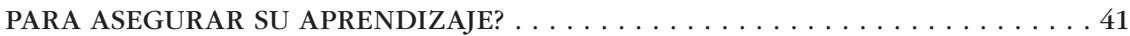
Edilma Naranjo Vélez

RETO DE ENSEÑAR A INVESTIGAR EN

LA FORMACIÓN BIBLIOTECOLÓGICA . . . . . . . . . . . . . . . . . . . . . . . . 59 Ruth Helena Vallejo Sierra

LA EVALUACIÓN DE LA INVESTIGACIÓN BIBLIOTECOLÓGICA . . . . . . . . . . . . . 75 Jorge Gómez Briseño

CONSIDERACIONES SOBRE LA EDUCACIÓN BIBLIOTECOLÓGICA EN EL SIGLO XXI . . . . . . . . . . . . . . . . . . . 105

Blanca Estela Sánchez Luna

COMPETENCIAS PARA LA ENSEÑANZA-APRENDIZAJE DE LA BIBLIOTECOLOGÍA Y LA CIENCIA DE LA INFORMACIÓN EN LA SOCIEDAD DIGITAL . . . . . . . . . . . . . . . . . . . . . . . . . . . . 119 Johann Pirela Morillo 


\section{Presentación}

n esta obra se persigue como objetivo fundamental, compren-
der las sutilezas que subyacen en la enseñanza y el aprendizaje
del conjunto de habilidades requeridas para la labor de investigación. Existe interés de analizar y proponer estrategias didácticas, a partir de la experiencia docente, con el fin de formar a los futuros investigadores, sobre la base de las tradiciones de pensamiento y enfoques académicos que se promueven activamente.

La principal inquietud es la formación de cuadros de investigación desde una fuente inagotable que se representa en el intelecto y el entusiasmo de los jóvenes matriculados en las escuelas de bibliotecología de nuestros países. A través de estrategias creativas e innovadoras, se trata de motivarlos y fomentar en ellos la voluntad de inquirir. Lo cual ofrecerá una bocanada de aire fresco a las instituciones que llevan a cabo investigaciones en materia de información, bibliotecas y su estrecho vínculo con la sociedad.

Se ha buscado con insistencia encauzar el torrente de dudas que los alumnos expresan ante los planteamientos teóricos al interior de las aulas; así como las aplicaciones de sus conocimientos en la solución de problemas en la práctica profesional. Será por medio del estímulo al pensamiento crítico y a la asimilación de contenidos que se 
erradicarán las nocivas prácticas escolares espontáneas y desarticuladas. Y justamente, los capítulos concatenan el esfuerzo de nuestros autores, su experiencia en las aulas y el progresivo acercamiento con los alumnos por medio de estrategias dinámicas.

Bajo este orden de ideas, Rojas expone la aplicación del modelo de aprendizaje basado en problemas y organizado en proyectos, en la licenciatura de Bibliotecología pedagógica de la Universidad Nacional de Costa Rica. Su trabajo apuesta por el establecimiento de entornos de aprendizaje que permita a los estudiantes ejercer autonomía a lo largo de la realización de un proyecto. Por medio de casos de éxito, la autora demuestra el acercamiento por parte de los jóvenes a la dinámica que siguen los investigadores cuando indagan en soluciones, proponiendo que los estudiantes sean capaces de identificar una problemática, definir objetivos, enmarcar la situación dentro de un contexto, encontrar los recursos de toda índole para ofrecer una solución y, por último, conseguir el grado académico de licenciatura; además ayuda a ejemplificar la manera en la que el docente diversifica sus funciones en cuanto asesor y mediador de proyectos académicos emprendidos por los alumnos; y también para apreciar las relaciones que existen entre las asignaturas al interior del plan de estudios.

Es posible apreciar en este primer comentario que una de las dimensiones de la investigación se nutre de la capacidad de percibir y delimitar el contexto dentro del cual se derivan problemáticas y se formulan posteriores soluciones. Otro elemento integrante son las competencias, a las que Martínez Rider presta una particular atención. A través de sus reflexiones, se justifica la segmentación en grupos de alumnos quienes tienen un alto, mediano o bajo desarrollo de competencias de investigación. También ha retomado las actitudes deseables de los estudiantes como el interés científico, la apertura y pluralidad de ideas, la tolerancia a otras formas de pensar, el respeto a posturas diferentes a la propia, el compromiso, la paciencia, la perseverancia y la ética en el manejo de fuentes y reconocimiento a los autores.

A esta discusión, Naranjo contribuye al reflexionar sobre una propuesta didáctica que posicione a la labor de investigación como un área de estudio, de gran importancia como la organización documental, y 
más allá del papel tradicional que la ciñe a la recolección e interpretación de datos a partir de metodología previamente estructurada. Esta área al interior de nuestra disciplina adquiriría un enfoque transdisciplinario porque el postulado es tan complejo de abordar, si se considera que para aprender a investigar es necesario primero investigar sobre ello. La autora también reconoce el gran potencial que ha sido explotado en la realización de proyectos como principal estrategia de enseñanza, con la diferencia de que sugiere conformar grupos de investigación entre estudiantes de licenciatura y posgrado donde cada uno asuma papeles auxiliares en tareas específicas, a modo de semilleros con relaciones horizontales de intercambio.

Vallejo se dio a la tarea de cuestionar cómo se han formado los bibliotecólogos y archivistas que hoy ejercen la docencia, en el contexto colombiano, enfocándose al desarrollo de habilidades metodológicas y didácticas para transmitir ese conocimiento a los estudiantes. Asimismo, argumenta que los planes de estudio en el área rescatan aspectos fundamentales de metodología, mas no fomentan la praxis investigativa. E incluso, como sucede en diferentes países, los estudiantes se acercan a la investigación hasta el momento de redactar el trabajo recepcional para titularse, siendo preocupante imaginar que estos egresados serán los futuros docentes y continuarán con este mismo ciclo. El capítulo detalla estrategias como asesorías, vinculación a proyectos, portafolio de investigaciones, talleres y laboratorios.

El punto donde convergen hasta el momento nuestras autoras es la identificación del modelo de aprendizaje basado en problemas (ABP) el cual orienta a los docentes para organizar sus sesiones de trabajo, especialmente diseñadas para adentrar a los estudiantes en la plena comprensión de la praxis investigativa, evitando reducir estos aprendizajes a la memorización de los pasos de la metodología científica. Asimismo, los autores coinciden en asumir la postura como docentes para azuzar a los estudiantes a fin de que rechacen categóricamente a resignarse con la repetición rutinaria de los pasos metodológicos, optando a ser dubitativos e inquisidores. En consecuencia, los docentes necesitan comprender a cabalidad las actividades y productos que realizan a través de la enseñanza y la investigación. 
Con respecto a lo anterior, Gómez Briseño señala la falta apremiante de evaluar desde el punto de vista cualitativo a la investigación bibliotecológica, puesto que propone que se establezca un modelo de indicadores que entrelace los criterios cuantitativos y cualitativos. Será de interés observar el debate que se suscite al interior de los claustros de profesores en cada una de las escuelas de bibliotecología, en el entendido de que todos están involucrados en la gestión de su respectiva a institución de educación superior y deberían observar el panorama integral donde no se pierdan de vista cuestiones referentes a los insumos, los resultados, el uso y el impacto de los productos de investigación.

Este asunto de la evaluación bajo criterios cualitativos forma parte de un conjunto de temáticas coyunturales las cuales se han explorado recientemente. Otros discernimientos con carácter contemporáneo se encuentran a lo largo de las aportaciones de Sánchez Luna, quien analizó las tendencias que permean a los programas curriculares de nuestra disciplina, teniendo en cuenta la incidencia que cada tópico alcanzará en la actualidad; al igual que el trabajo de Pirela, por medio del cual se han examinado seis competencias docentes en la sociedad digital. Nuestro último autor afincó su interés en el proceso de formación continua de los docentes de las escuelas de bibliotecología, como el complemento ideal a su ardua labor de enseñanza en las aulas.

No cabe duda que cada sujeto inmerso en el proceso de enseñanza y aprendizaje porta consigo un conjunto de aspiraciones, inquietudes, competencias y responsabilidades que afectan a la formación de profesionales, siendo evidente la urgencia de suscitar conciencia entre los docentes. Con este libro colectivo se someten diversos enfoques a discusión. 


\title{
Aprendizaje basado en problemas y organizado en proyectos: la experiencia de la licenciatura en Bibliotecología Pedagógica de la Universidad Nacional, Costa Rica
}

\author{
Nidia Rojas Morales \\ Escuela de Bibliotecología, Documentación \\ e Información, UNA, Costa Rica
}

\section{Resumen}

Este trabajo está basado en el estudio de caso sobre el uso del modelo de aprendizaje basado en problemas y organizado en proyectos (Project based Learning - PBL) en la Licenciatura de Bibliotecología Pedagógica de la Universidad Nacional, Costa Rica, como estrategia pedagógica para facilitar entornos de aprendizaje con la autonomía conveniente para que el estudiantado pudiera interactuar de forma cooperativa, en equipos de trabajo, lograr objetivos similares, proponer soluciones a las problemáticas vividas en sus contextos laborales y simultáneamente, para prepararlos en el trabajo final de graduación. Se presentan los resultados de la experiencia con un enfoque esencialmente cualitativo, con base en las precepciones del estudiantado y el personal docente a cargo de la licenciatura y en las fuentes documentales concernientes al diseño del plan de estudio y a los procesos de implementación y ejecución. Es posible concluir que el PBL fomentó el aprendizaje de competencias muy significativas, ya que el desarrollo del programa proporcionó un contexto de vida real en el que el estudiantado pudo vincular la teoría con la práctica. 


\title{
Project based Learning: experience in the pedagogical librarianship degree at the National University, Costa Rica \\ Nidia Rojas-Morales
}

\begin{abstract}
This paper is based on a case study about the use of the PBL model (Project Based Learning) organized in projects for the Licenciate Degree on Pedagogical Librarianship at the National University in Costa Rica. The model was used as a pedagogical strategy to facilitate autonomous learning environments for students to interact cooperatively in teams, achieve goals, propose ideas to the problems experienced at work and simultaneously this model could help them out for their final graduation thesis. Results are presented within a pure qualitative approach based on the students' and the e professors' point of views and on the document resources related to the course plan design and to the implementation and practice processes. It can be concluded that PBL encouraged very significant skill learning for the program was developed in a real life context in which students could link theory and practice.
\end{abstract}

\section{INTRODUCCIÓN}

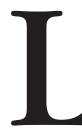

a educación superior debe propiciar la formación de profesionales que, además de una sólida educación, desarrollen competencias que les permitan convertirse en verdaderos transformadores de las realidades a las que se enfrentan, por eso es necesario examinar el modelo educativo para determinar si facilita esta formación.

La formación en la bibliotecología en particular, se ha caracterizado por propiciar un dominio satisfactorio del componente técnico, pero se han evidenciado debilidades en la capacidad de resolver problemas o necesidades a través de la investigación. Consecuentemente, 
la tradición investigativa en bibliotecología ha presentado particularidades tales como: el poco desarrollo o aplicación de habilidades investigativas sometiendo los trabajos a simples descripciones; o el uso en el sentido estricto del método científico proveniente de la corriente positivista, al asumir la existencia de un método único, con una misma lógica de validación. Morales (2005) afirma que muchos autores sostienen la idea de que para dar validez a las investigaciones bibliotecológicas es necesario el uso del método científico desde la visión positivista. Es por lo tanto una realidad que la corriente de pensamiento tradicional en las ciencias exactas ha incidido en las ciencias sociales, entre las que se encuentra la bibliotecología.

Afortunadamente, se ha producido un intenso debate sobre la idoneidad de esta posición epistemológica para observar la realidad humana y social, ya que las ciencias humanas y sociales aspiran a comprender o interpretar los fenómenos específicamente humanos; por esta razón se cuestiona el uso único del método cuantitativo para observar los fenómenos sociales y en particular los fenómenos informacionales. Es así como, con la influencia de nuevos paradigmas, como el socio cognitivismo se adopta una nueva posición con orientación cualitativa que incorpora al individuo dentro de una figura histórica y sociocultural e integra lo individual e interno con lo contextual y externo.

Como lo expone Hernández (2007), de acuerdo con este paradigma, el conocimiento es el resultado de la acción del sujeto con el medio, es una estructura creada culturalmente y un producto de la actividad humana más relacionado con la práctica social que con la mente del individuo. Estas nuevas posiciones son producto de los descubrimientos de cómo la persona construye el conocimiento y queda manifiesta la necesidad de una visión holística en la formación académica, particularmente la formación de la teoría, la técnica y la metodología bibliotecológica.

Se necesita, por tanto una nueva estrategia pedagógica como alternativa para que los bibliotecólogos desarrollen las competencias para solucionar creativamente los problemas de la sociedad. El aprendizaje basado en problemas y organizado en proyectos, comúnmente conocido como el PBL (por sus siglas en inglés), se presenta entre las alternativas más destacadas en el nivel nacional e internacional 


\section{La investigación bibliotecológica: problemas para...}

para propiciar una formación holística al estudiantado universitario. Por eso la Escuela de Bibliotecología de la Universidad Nacional, Costa Rica ante la necesidad de una estrategia didáctica especial para impartir la licenciatura en Bibliotecología Pedagógica opta por incursionar en este modelo de aprendizaje.

El propósito de la aplicación del modelo PBL en esta licenciatura es centrarse en la reflexión y experimentación de procesos de enseñanza-aprendizaje orientados a proyectos, a través de los cuales se pretende facilitar entornos de aprendizaje con la autonomía conveniente para que el estudiantado pueda interactuar de forma cooperativa, en equipos de trabajo, con los objetos de aprendizaje y explorar y proponer soluciones a las problemáticas vividas en sus contextos laborales.

Por lo tanto, en este documento se comparte la experiencia de la aplicación del modelo PBL en los cursos de la licenciatura y en el trabajo final de graduación en modalidad de seminario.

Esta experiencia se describe mediante un enfoque cualitativo basado en consulta de fuentes documentales tales como el plan de estudios, los programas e informes de curso, la documentación preparada por la Dirección de la Escuela para presentar la propuesta pedagógica y los informes de los proyectos. También se tomó en cuenta las vivencias relatadas por el personal docente y por el estudiantado durante su ejecución y las acciones y conocimientos demostrados en las sesiones de defensa de trabajos finales de graduación.

\section{APRENDIZAJE BASADO EN PROBLEMAS Y ORGANIZADO EN PROYECTOS}

Una de las razones a las que se le atañe el desinterés y aburrimiento por la educación, según lo expresa Gallegos (1999), es la poca relación que tienen los contenidos con la experiencia real de las personas y sus motivaciones. Es por eso que desde la posición holística se promueve una educación acorde con la naturaleza del ser.

Es importante aclarar que el tema de la visión holística y su aplicación en la educación han sido ampliamente tratados por innumerables especialistas principalmente del área de la educación y se dispone de abundantes fuentes bibliográficas. No obstante, se considera 
propicio al menos ofrecer una alusión al significado, como es la de Gallegos (1999:7) quien expone que la visión holística "es el supuesto de totalidad, que percibe que en el universo todo está conectado con lo demás, es una red viva de relaciones constituida por totalidades/parte, todo está interconectado formando sistemas y subsistemas; el ser humano es uno con este universo, su conciencia es la conciencia del universo." En el mismo sentido, Abarca (2012: 63) expresa que "[...] la visión holística se sustenta en la certidumbre de que todo está interconectado, de que estamos unidos a las demás personas y las formas no humanas que nos rodean en la compleja red de vida." Es así como, cuando los especialistas hablan de educación holística se refieren a un modelo integrado para educar al ser humano como un todo, que forma parte de un sistema.

Para implementar un modelo integrado es obligatoria la renovación de los métodos de enseñanza-aprendizaje en que el énfasis se centre en la actividad que los estudiantes desarrollan para construir el conocimiento.

El aprendizaje basado en problemas y organizado en proyectos (PBL), que, de acuerdo con Lorente, Doblas y Zaldumbide (2011: 1) "es una metodología proactiva basada en la autonomía con que los alumnos enfocan tanto el diseño del proyecto de aprendizaje, como el significado atribuido al mismo, todo ello en un entorno cooperativo de trabajo en equipo [...]", se convierte en una de las posibilidades para renovar los métodos didácticos universitarios.

Tarazona (2005: 50) señala tres proposiciones como los fundamentos teóricos más importantes del PBL, que han sido destacados por otros autores como Albanese (2000), Norman (1992) y Schmidt (1983): La primera es, el aprendizaje dentro de un contexto "que parte de la premisa de que cuando se aprende dentro de un contexto en el cual posteriormente se va a utilizar el conocimiento, se facilitan el aprendizaje y la habilidad para el uso de la información." La segunda se refiere a la teoría del procesamiento de la información que "muestra cómo el conocimiento se adquiere en un proceso que se inicia con la activación del conocimiento previo, y termina con la construcción del conocimiento propio a través de un proceso de incorporación del 


\section{La investigación bibliotecológica: problemas para...}

entendimiento y elaboración del conocimiento." La última es el aprendizaje en colaboración "que define y exige la fijación de metas grupales, la retroalimentación entre los participantes en el aprendizaje, y las fuentes y tareas compartidas por los miembros de un grupo, que deben producir una mejor capacidad de solucionar problemas que el aprendizaje individual competitivo."

De estas premisas teóricas se derivan principios de aprendizaje. A continuación se plantea una síntesis sustentada en Font (2004), Kolmos (2004) y Tarazona (2005):

1. Es un aprendizaje basado en la formulación de una problemática que será el punto de partida de los procesos de aprendizaje cuyo contenido se relaciona con el contexto para facilitar la motivación y la comprensión. Lo que se pretende es que el estudiante construya su conocimiento sobre la base de un problema de la vida real, que implica primero identificar el problema, reconocer lo que se debe aprender para resolverlo y encontrar la información y otros recursos necesarios para resolverlo.

2. El estudiantado toma como punto de partida sus propias experiencias o intereses. El hecho de vincular las problemáticas al mundo de la experiencia de los individuos incrementa la motivación, ya que esto se relaciona con una opinión que el estudiante se ha formado anteriormente. Es decir que el problema debe tener dos características esenciales: la familiaridad y la contextualidad. El estudiante en algún momento ha observado o experimentado el fenómeno y por ende conoce el contexto en el que ocurre. Este entorno permite un aprendizaje significativo y por lo tanto una fuerte estimulación para resolver la cuestión.

3. El estudiante es el centro del proceso, su aprendizaje es continuo y evolutivo, forma parte de un grupo social con características definidas, y aprende con el trabajo en grupo. Es capaz de analizar, aplicar y transferir el conocimiento desde el campo aprendido a nuevos campos o afines a su materia.

4. Los procesos de aprendizaje son dirigidos por el estudiantado. El propósito prioritario no es la adquisición de conocimiento sobre la especialidad de cada curso, sino su desarrollo integral a través de la solución del problema. Lo que se espera es que cada estudiante 
logre una comprensión global del problema mediante la identificación de los objetivos de aprendizaje, el compromiso, el deseo de conocer más, el desarrollo del pensamiento crítico, la creatividad, la toma de decisiones y el trabajo interdisciplinario, entre otros.

5. Al docente le corresponde la confrontación de ideas en el seno de los grupos, fomentando el trabajo en equipo, el aprendizaje colaborativo, el desarrollo de habilidades interpersonales y capacidades intelectuales. Guía el trabajo para extraer conclusiones, sintetizar ideas, construir conocimiento e identificar nuevos propósitos de aprendizaje.

Sobre estos principios, es necesario dejar claro que no se dispone de un modelo concreto para todos los casos, disciplinas o países, ya que serán distintos porque deben de adaptarse a las políticas de estudio, al contexto y a la cultura de la región o país.

\section{LA EXPERIENCIA DE APLICACIÓN DEL PBL}

La puesta en práctica del PBL surgió de la necesidad de aplicar una estrategia didáctica que se adecuara al contexto y a las particularidades en las que se ofrecería la Licenciatura en Bibliotecología Pedagógica. Este programa fue diseñado para un grupo de estudiantes de comunidades rurales aledañas al cantón de Pérez Zeledón ubicado al sur de Costa Rica, a 150 kilómetros de la capital, quienes requerían una formación especializada en bibliotecas escolares.

La Universidad Nacional en el campus de este cantón, denominado Sede Brunca, facilitaría los recursos logísticos para la ejecución del programa. No obstante los recursos laborales y el personal docente debían proporcionarse desde la sede central de Heredia, lo que implicaba un alto costo ya que se necesitaba presupuesto para el traslado, hospedaje y alimentación.

Así mismo, el programa debía garantizar que este grupo de estudiantes lograría la meta de obtener su grado de licenciatura tan pronto concluyeran su plan de estudio. Se requería entonces, que elaboraran simultáneamente su trabajo de graduación. Indudablemente este era el reto más importante de superar, por dos razones primordiales: 


\section{La investigación bibliotecológica: problemas para...}

por la ubicación geográfica sería muy costoso y complejo dar seguimiento a sus investigaciones después de concluir el plan de estudio y además, ellos debían disponer de su título de licenciatura para optar por los puestos de trabajo que el Ministerio de Educación estaba asignando en ese momento.

Es así como, la Dirección de la Escuela de Bibliotecología en conjunto con la Vicerrectoría Académica y las autoridades de la Sede Brunca acordaron ofrecer esta licenciatura de forma bimodal. El método bimodal trasciende el enfoque pedagógico universitario tradicional ya que combina sesiones presenciales y virtuales. Al adherir la virtualidad como un elemento para aprender y combinarlo con sesiones presenciales, facilitó los procesos operativos y administrativos de la vida académica y la interacción continua entre los estudiantes y los docentes. Por otra parte, ofreció soluciones a problemas comunes del estudiantado, especialmente a todos aquellos que trabajaban, tenían familia o atendían otras actividades más allá del estudio, ya que solventó de alguna forma, los problemas de tiempo para asistir a clases, distancia geográfica entre su lugar de residencia y la sede, dificultades con el transporte.

Para la implementación de esta modalidad se dispuso del Programa Institucional UNA Virtual. Esta instancia es la responsable de promover y facilitar la formación del personal académico y el estudiantado en la incorporación de nuevas tecnologías en la educación para innovar en las formas en que se produce el aprendizaje, el trabajo pedagógico y las relaciones educando-educador.

Dado a las virtudes que representaba el trabajo bajo esta modalidad, se optó por invitar a participar en este programa de licenciatura a un grupo de estudiantes del área metropolitana que también necesitaban obtener ese grado académico.

La estrategia de logística fue la siguiente: al mes se ofrecerían dos sesiones virtuales y dos sesiones presenciales alternadas. Las sesiones presenciales también turnarían el campus universitario, una sería en el campus de la Sede Brunca en Pérez Zeledón y otra en el Campus de la Sede Central en Heredia. Esto requería que una vez al mes se trasladaran a la Sede Brunca todos docentes y los estudiantes de la zona metropolitana para recibir las clase con grupo de dicha sede. Por su 
parte este grupo se trasladaría una vez al mes a la Sede Central. Para ello se disponía del servicio de transporte de la Universidad.

Esta práctica también permitió que la mayor inversión en recursos laborales solo se hiciera una vez al mes. Así, con ambas estrategias: las clases virtuales y las clases presenciales alternando la sede, se resolvió en buena medida la carencia de recursos laborales.

La otra situación que se debía solventar, que indiscutiblemente fue la más trascendente, era lograr que el estudiantado recibiera su grado de licenciatura en un tiempo pertinente. Por lo que fue necesario encontrar una estrategia de aprendizaje que permitiera la obtención de resultados de calidad y apropiados para un trabajo final de graduación. Es así como se opta por aplicar el método PBL.

Los cursos de la licenciatura y la modalidad de graduación:

De acuerdo con lo descrito en el rediseño del plan de estudio de la Licenciatura en Bibliotecología Pedagógica (2012), seguidamente se indican los nombres de los cursos que componen este programa y su respectiva descripción:

- Investigación y propuestas educativas: en este curso los estudiantes deben investigar y elaborar propuestas que sustenten y fortalezcan los procesos de enseñanza y aprendizaje, desde la labor de un bibliotecólogo educativo. Los estudiantes deben aprehender la importancia de la investigación, la evaluación educativa, lo mismo que la sistematización de experiencias, como formas efectivas de abordaje a la búsqueda de soluciones a los problemas del trabajo diario.

- Gestión de centros de recursos para el aprendizaje: introduce al estudiante en la gestión de Centros de Recursos de Aprendizaje (CRA) de forma que pueda integrar efectivamente los recursos de información, comunicación y tecnológicos al currículo escolar, mediante la articulación de los objetivos de aprendizaje, los contenidos curriculares y las estrategias de mediación para el trabajo cooperativo con estudiantes, docentes, administradores educativos e informáticos y padres de familia. Se pretende que el 


\section{La investigación bibliotecológica: problemas para...}

estudiante identifique necesidades de información de la comunidad educativa, proponga, gestione y ejecute acciones adecuadas a esas necesidades y genere recursos acordes a ese contexto.

- Servicios especializados para bibliotecas educativas: se discuten los objetivos, las funciones, los servicios y productos de la biblioteca educativa como mediadora en la investigación académica, aplicada a los diferentes niveles del sistema educativo y a las condiciones de las diversas zonas del país, sean urbanas o rurales. Con ello se pretende promover la lectura y el gusto por la literatura, así como el auto aprendizaje. La práctica consiste en la planificación de talleres dirigidos a grupos determinados según sus necesidades e intereses informativos.

- Sistemas colaborativos para educación: enfatiza el desarrollo de alianzas, de consorcios, de sistemas y de grupos documentales escolares utilizando los recursos de la institución educativa para el desarrollo de servicios y productos que involucren la participación de la comunidad local, nacional e internacional. Se estudian modelos para diseño y administración de estas alianzas y redes con sus respectivos componentes y los procesos que se utilizan para la comunicación y proyección de las Bibliotecas y Centros de Conocimiento Escolar en línea a través del Internet. Los estudiantes dispondrán de un aula virtual para realizar prácticas con los sistemas compartidos y desarrollarán un proyecto que involucre el uso de estas herramientas.

- Seminario de competencias documentales educativas: ofrece desde la perspectiva constructivista que centra la pedagogía en que los futuros bibliotecólogos elaboren su propia comprensión, a través de la investigación y el pensamiento activo. Utilizando la alfabetización informativa para capacitar al estudiantado en el aprendizaje autónomo. La práctica consiste en la elaboración de instrumentos de formación para el desarrollo de destrezas y competencias que les permitan instrumentalizar actividades pedagógicas para desarrollarlas en las bibliotecas. El curso prepara profesionales con competencias tanto en su función docente como en su función de proveedor de servicios de información. 
- Gestión de proyectos de información y documentación educativa: consiste en una experiencia de aprendizaje de investigación aplicada. Permite aplicar la investigación de campo para identificar, analizar y proponer soluciones para resolver problemas locales. Además, el estudiante realiza los procesos de planificación, diseño, control, ejecución, finalización y evaluación de proyectos para la creación, desarrollo y el mejoramiento continuo de los servicios, productos y procesos que se desarrollan en bibliotecas escolares. Se estudian metodologías de elaboración, administración, control y evaluación de proyectos. Los estudiantes desarrollan un trabajo práctico para la aplicación de la metodología seleccionada.

- Propiedad intelectual: estudia, analiza y aplica correctamente la legislación y los convenios de propiedad intelectual en las unidades de información documental. El laboratorio implica la búsqueda de material documental complementario en la red para analizarlo en clase, comentarios de experiencias laborales y análisis de casos judiciales que permitan ejemplificar las diferentes tipificaciones de la ley.

- Investigación I e Investigación II: ofrece una descripción de los posibles paradigmas de investigación en educación; resalta la importancia de la misma y facilita al estudiante la diferenciación de los modelos para que pueda identificar el más adecuado a su interés. El aspecto práctico del curso se logra por medio de la elaboración, por parte de los estudiantes, de un proyecto de investigación sobre una realidad educativa concreta, en el que se debe aplicar el método formal de investigación y cuyo resultado será el trabajo final de graduación.

El trabajo final de graduación se propone en la modalidad de seminario, que según la normativa para trabajos finales de graduación de la Universidad Nacional (2013: 2) "el seminario de graduación tiene como propósito investigar una problemática general, mediante abordajes particulares y diferentes perspectivas teóricas y metodológicas. Para ello el seminario se organizará en diversos grupos de trabajo, integrados por no más de cuatro estudiantes con responsabilidades 


\section{La investigación bibliotecológica: problemas para...}

individuales. Cada uno de estos grupos elaborará un anteproyecto que aborda un aspecto concreto de la problemática general del seminario. Puede surgir también de la iniciativa de un académico para investigar una problemática específica, para lo cual organiza uno o más grupos de estudiantes, que deberán cumplir con los requerimientos antes señalados".

\section{Los participantes}

Los participantes en la experiencia fueron los estudiantes que obtuvieron el Bachillerato en Bibliotecología Pedagógica en la Sede Brunca y el grupo graduado en la Sede Central. Se inscribieron 40 estudiantes. La licenciatura se llevó a cabo durante tres ciclos lectivos (tres semestres) con nueve cursos distribuidos en tres por cada ciclo.

Inicialmente se formaron 10 grupos de 4 estudiantes. Todos los estudiantes trabajaban en una biblioteca escolar o habían vivido una experiencia muy cercana a situación problemática que se presentaba en estas instancias. Cada grupo de Pérez Zeledón abordaría la problemática en los centros educativos de esa zona y cada grupo de los estudiantes de Heredia en el área metropolitana. Posteriormente, por variadas situaciones personales se retiraron 3 estudiantes y 2 estudiantes no concluyeron satisfactoriamente todos los cursos del plan de estudio, por lo que al final la licenciatura quedó conformada por 35 participantes distribuidos en 9 grupos.

El personal académico estuvo constituido por: Ana Beatriz Azofeifa, Jorge Alberto Ballestero, Freddy Oviedo, Mauren Hidalgo, Lovannia Garmendia, Francisco Zúñiga, Víctor Barrantes y Lucrecia Barboza.

\section{Identificación del problema y formulación de objetivos}

La Dirección propuso al personal docente que trabajara con los estudiantes un problema que se ha presentado en la mayoría de las bibliotecas escolares públicas y que se manifestó en los resultados del diagnóstico sobre las bibliotecas escolares de Costa Rica realizado por el Ministerio de Educación Pública en 2012. En este estudio se evidenció que un su mayor parte las bibliotecas no integraban de 
forma efectiva sus recursos al currículo escolar, ni existía una articulación con los objetivos de aprendizaje, los contenidos curriculares y las estrategias de mediación. Tampoco se visibilizaba un trabajo cooperativo con estudiantes, docentes, administradores educativos, informáticos y padres de familia.

A partir de este problema general, cada grupo de estudiantes debía identificar el problema en una institución educativa específica determinando las razones por la que se daba la situación, para proponer acciones que solventarían el problema o la necesidad.

Se propuso que las acciones estuvieran estrechamente asociadas a los contenidos de las materias del plan de estudio, de manera que en cada curso se elaborara un proyecto como una de las acciones propuestas para contribuir en la resolución del problema y se avance simultáneamente en el trabajo de graduación para obtener su grado de licenciatura en tanto finalicen su plan de estudio.

Para orientar el trabajo se planteó un objetivo general como punto de partida para que los estudiantes formularan el propio. El objetivo se enunció así: proponer estrategias para la integración de la biblioteca al currículo escolar, mediante el diseño de servicios y productos de información, herramientas tecnológicas y proyectos, congruentes con los objetivos de aprendizaje.

Consecuentemente, los objetivos específicos debían asociarse al general, tomando en cuenta los contenidos de cada materia, teniendo como principal propósito que resultado fuera una acción o un proyecto para contribuir en la resolución del problema, como ya se indicó.

Es así como para el curso Investigación y propuestas educativas se planteó como propósito central describir del contexto educativo en el que la biblioteca se desempeña, para la identificación de los problemas y desafíos que enfrenta. En el curso Gestión de centros de recursos para el aprendizaje se propuso analizar las estrategias de gestión de la biblioteca para evidenciar su relación con los objetivos de aprendizaje, los contenidos y la mediación pedagógica. En el curso Servicios especializados para bibliotecas escolares, el objetivo primordial fue diseñar servicios de información acordes al contexto y objetivos de aprendizaje de la escuela de manera que contribuyan activamente en 


\section{La investigación bibliotecológica: problemas para...}

el proceso educativo. Para el curso Sistemas colaborativos para bibliotecas escolares el propósito fue proponer sistemas que permitan el trabajo colaborativo, el uso de los recursos de información, la comunicación y la simplificación de los procesos cotidianos en la biblioteca. En el Seminario de competencias documentales se propuso diseñar módulos de alfabetización informacional para contribuir en el desarrollo de competencias documentales en la comunidad educativa de la escuela. Por último, en el curso Gestión de proyectos de información se solicitó proponer un marco metodológico para la formulación de proyectos de información y para su gestión, que le facilite a la escuela el acceso a recursos externos.

Los cursos de Investigación I y II se usaron para orientar metodológicamente cada trabajo de grupo y el curso optativo Propiedad intelectual complementó toda la investigación.

Se pretendía que el producto obtenido de cada curso se convirtiera en una estrategia para contribuir en la integración de la biblioteca al currículo escolar.

\section{El estado del conocimiento y la fundamentación teórica}

Se propone que en cada materia se realice una revisión de estudios afines al tema central y haga un análisis de la teoría existente referente al tema. Esto con el propósito que el desarrollo de estos contenidos también forme parte del estado del conocimiento y de la fundamentación teórica del estudio.

De acuerdo al orden de los cursos antes descrito, en el primero se hace una revisión de estudios que han abordado problemas del sistema educativo nacional y se discute y analiza la base teórica de los procesos educativos, los procesos de aprendizaje como objetos de investigación, los actores sociales en el proceso de aprendizaje y los métodos de investigación de problemas educativos.

En la segunda materia se revisan los estudios relacionados con la creación y gestión de bibliotecas escolares y centros de recursos para el aprendizaje (CRA). Se estudia el concepto de CRA, el papel del CRA en la gestión educativa, las necesidades de información de la comunidad educativa y la planeación estratégica del CRA. 
El tercer curso revisa los estudios relacionados con el diseño de servicios para centros de recursos para el aprendizaje y básicamente examina el concepto de servicio, la filosofía del mercadeo en el diseño de servicios de información y la relación del servicio de información con el currículo escolar.

La revisión de estudios relacionados con propuestas de uso de sistemas colaborativos en bibliotecas escolares o CRA, es lo que se realiza en cuarto curso, en el que además se estudian el fundamento teórico del trabajo colaborativo, las características del trabajo colaborativo, los modelos para el trabajo colaborativo y las herramientas de trabajo colaborativo.

En el quinto curso se exploran los estudios relacionados con propuestas de alfabetización informacional en centros educativos u otras instituciones y se estudian los conceptos de cultura informacional, alfabetización informacional, competencias informacionales, normas de ALFIN y programas de alfabetización informacional.

Por último se hace una revisión de estudios o experiencias relacionados con la formulación de proyectos sociales en bibliotecas escolares u otras y se analiza el concepto de proyecto de información, proyecto social, formulación de proyectos sociales, fases del proyecto y gestión de proyectos. Esto corresponde a los contenidos del sexto curso.

\section{Los métodos de aprendizaje}

Esta licenciatura disponía de una oferta académica interdisciplinaria para formar un profesional que, desde las bibliotecas, respondiera a las necesidades educativas de la comunidad, incluyendo a estudiantes, personal de los centros educativos, padres y madres de familia. En esta combinación de disciplinas asumieron un papel fundamental la bibliotecología y la educación.

Para esto se realizaron sesiones de trabajo conjunto entre el personal docente con el fin de lograr una adecuada coordinación horizontal y vertical en los cursos. Se brindaron procesos de inducción para el profesorado, para asegurar la comprensión general del plan de estudios y la integralidad que debía lograrse para alcanzar la meta de elaborar el trabajo final de graduación con los proyectos de cada curso. 


\section{La investigación bibliotecológica: problemas para...}

Se utilizó el método de aprendizaje bi-modal, en el que se conjugó el desarrollo de actividades en forma presencial y virtual por medio del aula virtual institucional, en donde los estudiantes interactuaron con los docentes y sus compañeros, prolongando de forma sincrónica o asincrónica la experiencia de aprendizaje. En este sentido, el estudiantado y sus profesores, asumieron roles distintos, protagónicos, de trabajo cooperativo, dinámicos, activos y participativos.

La metodología en la bimodalidad, implicó una lógica distinta de aprendizaje y la re-estructuración de los contenidos de los cursos, ya que el aprendizaje dejó de ser lineal. La construcción de conocimiento se dio en forma cooperativa, de manera que existió permanentemente un intercambio de ideas, documentos, vínculos de internet, fuentes documentales, experiencias previas y soluciones a los problemas. Con las sesiones presenciales se mantuvo el acompañamiento al estudiante, el vínculo directo entre profesor y estudiante y el calor humano generado en la interacción.

El estudiantado ejerció el papel protagónico en el proceso pedagógico, el personal académico fue el guía, mentor y mediador, permitiendo de este modo el cumplimiento del principio del PBL de que los procesos de aprendizaje estuvieran dirigidos por los estudiantes. Ellos aportaron a su propio proceso formativo investigaciones que tenían como finalidad emplear los conocimientos, potenciar habilidades y actitudes, analizar situaciones concretas y diseñar alternativas de solución, lo que implicó el aprendizaje de un saber, saber hacer y saber ser. En otras palabras, al estudiantado se le guió para pensar, discutir, crear, trabajar en equipos, esclarecer puntos de vista, compartir y resolver problemas reales en los contextos educativos en los que se desenvolvían.

\section{Casos específicos y resultados}

Partiendo del marco general del problema, cada grupo seleccionó una institución escolar y realizó un pre diagnóstico para determinar si se presentaba el mismo escenario en su biblioteca. 
Al confirmar que dicha biblioteca no se integraba al currículo escolar, se identificaba un problema de la vida real para que el estudiantado lo tomara como punto de partida de los procesos de aprendizaje y construyera su conocimiento, cumpliéndose así otro principio del PBL.

Los casos de estudio fueron las bibliotecas de los siguientes centros educativos: En Pérez Zeledón, las escuelas 12 de marzo de 1948, Pedro Pérez Zeledón, Liceo Las Mercedes con orientación tecnológica, Hernán Rodríguez Ruiz y Sinaí; en Heredia, las escuelas La Aurora, Manuel Camacho Hernández, La Trinidad y Elisa Soto Jiménez.

En todos los casos el grupo a cargo se identificada plenamente con el problema y su contexto. Algunos trabajaban en la institución cuyo caso se investigaba o sufrían la misma situación es sus propios centros de trabajo. Así que el principio del PBL de tomar como punto de partida las propias experiencias o intereses del estudiantado, es decir que el problema cumpliera con las características de familiaridad y contextualidad hizo significativo el aprendizaje y provocó un gran interés en buscar una solución.

El trabajo final de graduación inició simultáneamente con el desarrollo del plan de estudio. El resultado fue la propuesta de cuatro proyectos para las bibliotecas en estudio, que una vez implementados, ofrecerían una significativa contribución en su integración al currículo escolar. Las propuestas incluyeron justificación, beneficios, objetivos y diseño; con algunas particularidades entre los grupos.

Con base en las memorias de los trabajos finales de graduación se resumen los contenidos de los proyectos creados en cada curso:

- Los cursos Investigación y propuestas educativas y Gestión de centros de recursos para el aprendizaje, elaboraron un diagnóstico de su caso en estudio, es decir del centro educativo en que identificaron el problema. Este diagnóstico tuvo como propósito conocer la situación actual con respecto al contexto educativo y a la gestión de la biblioteca escolar. Se analizaron diferentes aspectos en cuanto a la política educativa nacional que atañe directamente a las labores bibliotecológicas, la inserción de la biblioteca dentro del plan institucional, posición epistemológica educativa con la cual 


\section{La investigación bibliotecológica: problemas para...}

se orientan las labores bibliotecológicas, papel de los actores educativos con respecto a la biblioteca, integración de la biblioteca al currículo educativo, lineamientos establecidos en la biblioteca, recursos y servicios de información y procesos de evaluación.

- En el curso Servicios especializados para bibliotecas escolares se propuso un servicio de fomento a la lectura con su descripción metodológica, es decir, con módulos, horarios, calendarios, tiempos de duración, espacios, mobiliario, recursos, actividades y uso de fuentes documentales. Dentro de la promoción de la lectura se invita a leer, se estimula a la lectura promocionando los materiales de diversas formas. Y dentro de la animación, se realiza un proceso se comparte y comenta la lectura, se hacen preguntas, juegos o actividades de enriquecimiento.

- En el curso Sistemas colaborativos para bibliotecas escolares se creó un sistema virtual para fomentar la lectura y el trabajo colaborativo con la herramienta Jimdo, en el que se diseñó un club virtual de lectores que el estudiantado puede acceder desde diferentes lugares y sin importar el tiempo y el espacio. El club le permite a la biblioteca comunicarse con el estudiantado a través de medios digitales y motivarlos a la lectura mediante la tecnología como una herramienta de aprendizaje divertida y fácil. Cabe destacar, que esta herramienta sería utilizada también como medio para reforzar los conocimientos en las diferentes áreas temáticas.

- En el curso Seminario de competencias documentales se crean módulos de aprendizaje que apuntan a iniciar en la población estudiantil el desarrollo de habilidades necesarias para la localizar, evaluar y usar de la información. Es un aprendizaje que va más allá del entorno formal del aula, tratando de conseguir que el estudiantado pueda utilizar la información de manera efectiva. La propuesta presenta su fundamentación pedagógica, el modelo ALFIN, los métodos y los contenidos de aprendizaje.

- En el curso Gestión de proyectos de información se plantea una propuesta aplicando las fases de la formulación de proyectos con el propósito de crear un documento de proyecto con los elementos necesarios para la negociación con organismos financieros, para obtener recursos para su ejecución. Incluye la identificación 
del proyecto, el estudio de mercado, el estudio técnico, la evaluación financiera y la evaluación social.

La mayoría de las horas dedicadas a cada curso fueron trabajadas independientemente, lo que le permitió al estudiantado convertirse en los sujetos activos y creativos en el proyecto. Las clases presenciales se utilizaron básicamente para aclarar aspectos teóricos con dinámicas y exposiciones de especialistas y para orientar las actividades de trabajo en grupo. En las sesiones virtuales, por medio de foros y chat se ampliaban y discutían los contenidos y se revisaban y corregían las tareas y avances de los proyectos.

Durante el proceso los estudiantes recibieron retroalimentación de ellos mismos, de sus compañeros y de sus docentes. Esta retroalimentación ayudó al estudiantado a comprender cómo lograr un resultado final con las exigencias requeridas.

La actividad de campo se inició con la búsqueda de información necesaria para la realización del proyecto, a través de la que se pretendía complementar y profundizar en los saberes previos y en los problemas a solventar. Seguidamente ejecutaron cada proyecto conforme avanzaron los cursos del plan de estudio. En cada curso se evaluó el proceso y el producto final.

El trabajo final de graduación y su defensa:

Al concluir con los cursos del plan de estudio, como ya se ha descrito, el estudiantado disponía de cuatro proyectos para proponerlos como alternativas para propiciar la integración de la biblioteca al currículo de los centros educativos en estudio.

Con la guía de la profesora a cargo de la orientación metodológica, los grupos unieron cada componente elaborado individualmente en los cursos, de forma que se lograra una integración y se visibilizara la progresión entre todas las partes. Así, el estudiantado reconstruyó con esos insumos todos los componentes exigidos en la formalidad de presentación de un trabajo final de graduación.

De acuerdo con la modalidad de seminario de graduación, los principales componentes del informe fueron: el planteamiento del 


\section{La investigación bibliotecológica: problemas para...}

problema y la justificación de la necesidad de resolverlo, las experiencias o antecedentes en el abordaje del objeto de estudio, los objetivos generales y específicos del proyecto, los referentes teóricos del objeto de estudio, los métodos de investigación aplicados, los resultados del diagnóstico situacional, las propuestas de acción para contribuir en resolución del problema, las conclusiones y recomendaciones y el respaldo bibliográfico.

Una vez lograda la integración del informe, cada grupo se preparó para las defensas públicas. Las fechas se programaron para el cuarto semestre, es decir el ciclo inmediato a la conclusión de los cursos, como se había previsto al inicio de la licenciatura.

El tribunal examinador estuvo constituido por el Decano de la Facultad, la Directora de la Escuela de Bibliotecología, la profesora tutora y los dos lectores de ambas especialidades: bibliotecología y educación. A este grupo se unió como especialista la persona que ocupaba la dirección del centro educativo o un representante, quien siendo uno de los sujetos afectados y vinculados al problema podía con mucha propiedad valorar la pertinencia de las propuestas.

En la mayoría de los integrantes de los grupos se reflejó una importante diferencia con otros estudiantes que se han formado con la metodología tradicional. Ellos demostraron la construcción de un conocimiento integral, mostraron creatividad, conciencia del carácter social, enfoque reflexivo y sobre todo una profunda identificación con el problema estudiado.

\section{Conclusiones}

De los resultados y experiencias presentados anteriormente, se puede concluir que una práctica pedagógica con el PBL, es una alternativa que produce resultados acordes con lo que actualmente se plantea que debe ser la formación, ya que evidentemente los estudiantes mostraron una mejoría significativa en la adquisición de conocimiento.

El PBL fomentó el desarrollo de competencias investigativas, ya que el programa proporcionó un contexto de vida real en el que el estudiantado pudo vincular la teoría con la práctica. Ellos fueron 
capaces de relacionar su trabajo académico con las situaciones en sus lugares de trabajo y proponer acciones para resolver los problemas que enfrentaban.

La experiencia realizada permitió la integración de materias, es decir que las asignaturas no se impartieron como especialidades aisladas, sino que se unieron para aplicarlas en la solución de un problema que era de naturaleza interdisciplinar.

Desde el papel del personal docente, el PBL facilitó un crecimiento del marco institucional ya que se pusieron en práctica otras perspectivas en la enseñanza-aprendizaje al eliminar las divisiones entre materias y áreas de conocimiento para incursionar en la dimensión colectiva y cooperativa de la enseñanza. Esto implicó un fortalecimiento de las competencias de los docentes.

Las dificultades surgidas al inicio del programa fueron debidas principalmente a la falta de familiaridad del estudiantado y del personal docente en el uso del aula virtual y a la falta de costumbre del estudiantado al trabajo independiente, ya que estaban habituados a trabajos más estructurados, dirigidos por el docente y con menos responsabilidad.

A partir de esta experiencia, se considera que es necesario un proceso de renovación en los planes de estudio, para proponer diseños curriculares que permitan emplear este tipo de métodos.

\section{BiBLIOGRAFÍA}

Abarca, F. (2012). "Nuevas visiones para tiempos nuevos: hacia aprendizajes holistas como derecho de la humanidad." En: Revista Latinoamericana de Derechos Humanos, 23(2): 61-85

Catalán, C., Lacuesta, R. y Hernández, A. (2005). Cambio de modelos basados en la enseñanza a modelos basados en el aprendizaje. Una experiencia práctica En: Actas del Simposio Nacional de Docencia en la Informática, 
SINDI2005 (AENUI), p.61-67 Disponible en: http://bioinfo.uib.es/ joemiro/aenui/ProcSindi/P2005/1286.pdf (Consultado 27/05/15)

Costa Rica. Ministerio de Educación Pública. Departamento de Bibliotecas Escolares (2012). Primer censo y diagnóstico se bibliotecas escolares y CRA. San José, Costa Rica: UNED.

Font, A. (2004) "Líneas maestras de aprendizaje por problemas." En: Revista Interuniversitaria de Formación del Profesorado, 18(1): 79-95 Disponible en: http://www.redalyc.org/pdf/274/27418106.pdf (Consultado 27/05/15)

Gallegos, R. (1997). Una sola conciencia. Enfoque bolístico sobre el futuro de la bumanidad. México: Editorial Pax.

___ (1999). Educación holística. Pedagogía del amor universal. México: Editorial Pax.

Kolmos, A (2004) "Estrategias para desarrollar currículos basados en la formulación de problemas y organizados en base a proyectos." En Educar 33:77-76 Disponible en: http://educar.uab.cat/article/view/262/239 (Consultado 27/05/15)

Lacuesta, R. y Catalán, C. (2004). “Aprendizaje basado en problemas: una experiencia interdisciplinar en Ingeniería Técnica en Informática de Gestión.” En $X$ Jornadas de enseñanza universitaria de la informática. Universidad de Zaragoza, España. Disponible en: http://www. dccia.ua.es/jenui2004/actas/ponencias/ponencia35.pdf (Consultado 27/05/15) 
Lorente, I; Doblas P. y Zaldumbide, I. (2011). "La competencia en comunicación en el aprendizaje orientado a proyectos (PBL)." Programa de Innovación Educativa (PIE 09/11) de la Universidad del País VascoEuskal Herriko Unibertsitatea. Girona, España. Disponible en http://dugi-doc.udg.edu/bitstream/handle/10256/3716/296.pdf?sequence $=1$

(Consultado $09 / 06 / 15)$

Morales, V. (2005) Metodología en la bibliotecología. Buenos Aires: Alfagrama.

Morin, E. (2003). Método V. La humanidad de la humanidad. La identidad humana. Madrid, España: Cátedra Teorema.

Tarazona, J. L. (2005). "Reflexiones acerca del aprendizaje basado en problemas (ABP). Una alternativa en la educación médica." En Revista Colombiana en Ostreticia y Ginecologia, 56(2):147-154 Disponible en: http://www. scielo.org.co/pdf/rcog/v56n2/v56n2a06 (Consultado 27/05/15)

Universidad Nacional, Costa Rica (2013). "Modalidades de graduación. Acuerdo de CONSACA-244-2013.” En: La Gaceta 14. Heredia, Costa Rica.

. Escuela de Bibliotecología, Documentación e Información y División de Educología (2012). Rediseño de la Licenciatura en Bibliotecología Pedagógica. Heredia, Costa Rica: UNA. 


\begin{abstract}
ANEXO
Proyectos de los estudiantes Participantes

Angulo, K., Arias, J.D., De La O., J., Sánchez, K. (2014). Propuesta para la integración de la biblioteca al currículo escolar de la Escuela Manuel Camacho Hernández, Heredia, Costa Rica. Memoria del Trabajo final de graduación para optar por el grado de licenciatura. Heredia, C.R.: Universidad Nacional. Escuela de Bibliotecología, Documentación e Información.
\end{abstract}

Arroyo, K., Esquivel, A., González, E., Granados, L.D. (2014). Propuesta para la integración de la biblioteca escolar al currículo educativo de la Escuela 12 de Marzo de 1948, circuito 01, Dirección Regional de Educación Pérez Zeledón, San José, Costa Rica. Memoria del Trabajo final de graduación para optar por el grado de licenciatura. Heredia, C.R.: Universidad Nacional. Escuela de Bibliotecología, Documentación e Información.

Barquero, L., Mena, S., Mora, S., Núñez, M. (2014). Propuesta para la integración efectiva entre la biblioteca y la comunidad educativa con respecto a la aplicabilidad del currículo en la Escuela Pedro Pérez Zeledón, Costa Rica. Memoria del Trabajo final de graduación para optar por el grado de licenciatura. Heredia, C.R.: Universidad Nacional. Escuela de Bibliotecología, Documentación e Información.

Caballero, W., Cervantes, M., Méndez, J., Valverde, C. (2014). Propuesta para la integración efectiva de la Biblioteca del Liceo Las Mercedes con Orientación Tecnológica, circuito 06, Región Educativa Pérez Zeledón, Costa Rica, al currículo escolar. Memoria del Trabajo final de graduación para optar por el grado de licenciatura. Heredia, C.R.: Universidad Nacional. Escuela de Bibliotecología, Documentación e Información. 
Calderón, E., Flores, M., Quirós, L., Solís, L. (2014). Propuesta para la integración efectiva del Centro de Recursos para el Aprendizaje de la Escuela Sinaí, Pérez Zeledón, Costa Rica, al currículo educativo. Memoria del Trabajo final de graduación para optar por el grado de licenciatura. Heredia, C.R.: Universidad Nacional. Escuela de Bibliotecología, Documentación e Información.

Cambronero, D., Fonseca, J., Zamora, K., Zúñiga, D. (2014). La integración efectiva entre la Escuela La Aurora, Heredia, Costa Rica, y su biblioteca. Memoria del Trabajo final de graduación para optar por el grado de licenciatura. Heredia, C.R.: Universidad Nacional. Escuela de Bibliotecología, Documentación e Información.

Castrillo, R., Méndez, M. (2015). Integración de la biblioteca de la Escuela La Trinidad al currículo escolar y a la comunidad educativa. Memoria del Trabajo final de graduación para optar por el grado de licenciatura. Heredia, C.R.: Universidad Nacional. Escuela de Bibliotecología, Documentación e Información.

Conejo, J., González, J., Miranda, F., Segura, G. (2014). Integración de la biblioteca de la Escuela Elisa Soto Jiménez, Heredia, Costa Rica, al currículo escolar y a la comunidad educativa. Memoria del Trabajo final de graduación para optar por el grado de licenciatura. Heredia, C.R.: Universidad Nacional. Escuela de Bibliotecología, Documentación e Información.

Fonseca, J., Sibaja, M., Sibaja, X. (2014). La biblioteca escolar de la institución Hernán Rodríguez Ruíz del distrito Daniel Flores de Pérez Zeledón y su integración efectiva al currículo y a la comunidad educativa. Memoria del Trabajo final de graduación para optar por el grado de licenciatura. Heredia, C.R.: Universidad Nacional. Escuela de Bibliotecología, Documentación e Información. 


\title{
El aprendizaje de la metodología de investigación en Ciencias de la Información
}

\author{
Rosa MARÍA MARTínez RideR \\ Universidad Autónoma de \\ San Luis Potosí, México
}

\section{Resumen}

La enseñanza de la metodología de la investigación, es una actividad que va más allá de la aplicación de métodos y técnicas. Involucra adoptar una posicion epistemológica para fundamentar el uso de un paradigma de investigación; la parte del objeto de estudio que fortalecerá la disciplina en cuestión; y el impacto que tendrá en la sociedad. Así mismo, la consideración del uso de diversas estrategias didácticas complementarias que fortalezcan lo aprendido y un modelo de evaluación, que implica el acompañamiento de los estudiantes en la concreción de su proyecto final.

\section{Learning in research methodology in Information Sciences Rosa María Martínez-Rider}

\begin{abstract}
Teaching about research methodology, is an activity that goes beyond the application of methods and techniques. Position involves adopting a epistemological basis for the use of a research paradigm; the part of the object of study that will strengthen the discipline in question; and the impact it will have on society.
\end{abstract}


Also, the consideration of the use of various teaching strategies that strengthen complementary lessons learned and a model of evaluation, which involves the accompaniment of the students in the realization of his final draft.

\section{INTRODUCCIÓN}

T a didáctica no es solo una herramienta de carácter instrumental, pues involucra una posición ante la política educativa, los recursos de las instituciones y la evaluación.

La investigación es un proceso de aprendizaje que implica aspectos curriculares, pedagógicos y didácticos.

Requiere el desarrollo de competencias específicas en un proceso transparente de evaluación formativa y el uso de rúbricas, para transparentar la formación y afianzarla.

\section{LA INVESTIGACIÓN EN LOS PROGRAMAS EDUCATIVOS DE CIENCIAS DE LA INFORMACIÓN}

Las metodologías de investigación dentro del curriculum del pregrado son fundamentales para la formación de los estudiantes porque involucran aspectos que se concretan en una aportación teórica o aplicada a las disciplinas, en este caso, a las correspondientes en Ciencias de la Información, además de que fortalecen sus conocimientos, habilidades y valores respecto de la realidad social.

Estos se refieren a la construcción del concepto de ciencia en los alumnos, la diferenciación de las características de la investigación, el desarrollo de una metodología cuantitativa o cualitativa que implica el discernimiento de los fundamentos epistemológicos, la comprensión de los objetos de estudio, las contribuciones de la interdisciplinariedad, así como la aportación de los resultados y los usos sociales que tendrán.

La ciencia ha recorrido un largo camino, Gutiérrez señala que su concepto "ha tenido una serie de variaciones que responden a los momentos históricos en que se contempla" (1992, p. 93) desde las 
contribuciones de los griegos o la separación entre ciencias sociales y duras, hasta los cuestionamientos hacia el positivismo o los problemas éticos en la generación de la tecnología, como la creación de armas inteligentes y el espionaje cibernético.

Las disciplinas del saber se han clasificado desde varias apreciaciones: por su naturaleza, su objeto, su especialidad, su método, o su complejidad y la ciencia institucionalizada es un concepto hegemónico que se liga con la racionalidad, la experiencia sensible y los métodos dirigidos a la explicación de los hechos.

Con respecto a ello, se señala que aún cuando la ciencia se caracteriza por "una gran contingencia llena de dependencias contextuales e intencionales y un gran poder estructurante y configurador" (Gutiérrez 1992, p. 170) paralelamente "se aprecian inquietantes estancamientos" (Liz 2009, p. 169) él la estudia como institución, imagen científica y cultura científica.

La Declaración sobre la ciencia y el uso del saber científico publicada por la UNESCO, destaca que está al servicio del conocimiento, de la paz, el desarrollo y debe "garantizar la libre circulación de la información sobre todas las utilizaciones y consecuencias posibles de los nuevos descubrimientos y tecnologías, a fin de que las cuestiones éticas se puedan debatir de modo apropiado" (2015, p. 5) donde la Bibliotecología, la Archivología y la Documentación representan un factor para la organización, la difusión y el libre acceso a la información, entre otros temas, que apoyarán la postura y resultados de los trabajos de investigación.

Esta actividad es una fuente de trabajo para los egresados en las instituciones donde se realiza, por ejemplo, los colegios, los centros, los institutos y la que se hace en las universidades como parte de las funciones académicas, tanto educativa como disciplinar.

Sin embargo, aunque los estudiantes se desempeñen en el campo profesionalizante y no el de investigación, adquieren competencias para la vida, de las cuales, Díaz refiere que "las definiciones recientes no distan mucho de los nuevos conceptos y de las nuevas experiencias de trabajo, vida y educación que hoy se expresan complementariamente bajo la forma de educación para la vida, educación para el 
trabajo, educación para el hacer" (2006, p. 48) y en este caso, desarrollan capacidades para elaborar programas, gestionar proyectos, presentar propuestas en las instituciones donde laboran, y experiencias de trabajo en los foros para tal efecto.

La investigación en Ciencias de Información ofrece una gran variedad de temas para las investigaciones originales, utilizar enfoques novedosos o para aplicar una metodología adecuadamente.

\section{LOS PLANES DE ESTUDIO Y LA INVESTIGACIÓN}

El curriculum debe reflejar las características del modelo educativo, pedagógico y didáctico con relación a la disciplina y por ende, con las asignaturas de investigación.

El plan de estudios es una parte medular del currículo, es una guía intencionada, normalizada, legitimada e instrumentada, en la que se planifica, se diseñan objetivos o competencias, contenidos, experiencias de aprendizaje y evaluaciones y en el que subyace un tipo de ideología, de conocimiento y de realidad.

El programa educativo debe ofrecer laboratorios, biblioteca y los recursos que faciliten la actividad de los alumnos para crear productos de calidad, aunque las investigaciones no sean tan profundas.

El docente debe contar con estas habilidades para impartir las materias de investigación y publicar los resultados de sus trabajos, tanto en el campo educativo como en el de su área disciplinar.

Es recomendable que los estudiantes inserten sus proyectos en las líneas de generación y aplicación del conocimiento de los profesores, particularmente aquellos que pretenden matricularse en los programas de posgrado, los de investigadores jóvenes o los de investigadores talento, para contribuir a la construcción de conocimientos y la solucion de problemas en esta región de conocimientos.

Asimismo, dirigir a los alumnos dentro de la enseñanza, con temas tales, como el llenado del curriculum vitae único, la gestión de la identidad como investigador, proporcionar las bases y requistos para la integración de proyectos que se someterán a evaluación para la 
obtención de recursos, cumplir puntualmente con las actividades de investigación y mantener una productividad de calidad.

Con respecto a los contenidos, las competencias deseables en el estudiante, que pondrán en práctica son las siguientes:

1. Diseñar proyectos innovadores o alternativos de investigación teórica o práctica utilizando la metodología cuantitativa o cualitativa. (Competencia científica y metodológica).

2. Sistematizar las investigaciones para construir conocimientos en Ciencias de la Información Documental. (Competencia científica y metodológica).

3. Difundir los resultados de la investigación. (Competencia social).

4. Establecer acuerdos y convenios de investigación. (Competencia social).

Este último podrá llevarse a cabo, como ejercicio de la asignatura entre los propios compañeros de clase, o con los profesores que manejan los temas de interés del estudiante, presentado propuestas de trabajo colaborativo.

Para fortalecer la adquisición de las competencias, los conocimientos propuestos se refieren a los asuntos listados a continuación:

1. Epistemología y teorías de las Ciencias de la Información Documental y de cada una de las disciplinas que conforman esta región.

2. Los Paradigmas de investigación.

3. Los Objetos de estudio de las disciplinas de las Ciencias de la Información.

4. Las Teorías que se construyen en cada disciplina.

5. Las Metodología cuantitativa y cualitativa de investigación.

6. La Estructura del documento final.

Con respecto a las habilidades se espera que los alumnos ejerciten:

1. El pensamiento crítico.

2. La disciplina como hábito de constancia.

3. El correcto uso de la ortografía y la redacción. 


\section{La investigación bibliotecológica: problemas para...}

4. El discernimiento en la selección de temas de investigación significativos.

5. La planificación, organización y sistematización del plan de trabajo para llevar a cabo la investigación.

6. El manejo acertado de los elementos de investigación.

7. El manejo de las fuentes pertinentes, precisas y oportunas de la información impresa, audiovisual y digital que apoyen el fundamento y las propuestas de la investigación.

8. La creatividad.

9. El trabajo en equipo.

10.La toma de decisiones.

11. La resolución de problemas.

En relación con las actitudes y valores, el estudiante debe tener:

1. Interés.

2. Apertura y pluralidad de pensamiento.

3. Tolerancia hacia conocimientos o paradigmas diferentes.

4. Respeto a posturas distintas.

5. Compromiso para realizar los proyectos en tiempo y forma.

6. Ética en el manejo de datos, fuentes y crédito a los autores.

7. Paciencia y perseverancia.

8. Continuidad.

Con respecto a los paradigmas, hay diversos puntos de vista que los estudiantes deben conocer para fijar su postura. Por ejemplo, hay quienes defienden que es obsoleto referirse al Paradigma Positivista, al monismo metodológico y a su característica de cuantitividad.

Otra postura, que es la de quien escribe esto, es que si hay diferencias sustanciales que le dan rasgo a cada uno de los paradigmas de investigación y que definen cada modelo (en términos kuhnianos) como tal, uno para explicar, otro para interpretar y uno más para comprender. Cada paradigma tuvo su genesis y propósito en un contexto particular, tiene su fundamento, criterios y valores.

Por ejemplo, la investigación positivista es fragmentada y la investigación crítica es histórica y multidimensional. No obstante, las 
metodologías se pueden combinar sin caer en eclecticismos, deben fundamentarse en todos los casos.

Otra posición se refiere a elegir entre las propuestas de objeto de estudio que existen para la fundamentación epistemológica, donde no hay acuerdos o incluso ni siquiera la consideración de que existen.

\section{LA DIDÁCTICA. SABERES, ESTRATEGIAS, EVALUACIÓN Y PROBLEMAS}

Ríos establece que la didáctica desde la enseñanza de la ciencia se "apoya en dos instrumentos cognoscitivos de valor universal: el círculo de la comprensión y el cambio conceptual” (2008, p. 199) El estudiante se forma "en el razonamiento, la validación del conocimiento, la experimentación, el planteamiento claro de problemas desde el contexto disciplinario, y que es capaz también de argumentar y fundamentar las soluciones que propone a partir de marcos explicativos y disciplinarios válidos" (Ríos 2008, p. 199) lo que favorece una mente analítica, crítica, propositiva, así como la autonomía, la responsabilidad en las decisiones y el fortalecimiento de la ética.

Lo primero, es identificar las características del grupo y los estilos de aprendizaje de los estudiantes, esto proporcionará elementos al docente para identificar sus intereses, atender una tutoría o asesoría académica que resuelva sus inquietudes y que además mantenga su interés.

Al respecto, Hernández y otros, expresan "La intención es alcanzar la tarea de forma significativa y apropiada (a partir de una motivación intrínseca)" (2005, p. 15) y promover "Una enseñanza que se construye sobre lo que el alumno ya sabe" (Hernández y otros. 2005, p. 15) No obstante, hay que considerar que el constructivismo no es homogéneo ni tiene un concepto único, este varía de acuerdo a la posición epistemológica, educativa, pedagógica y didáctica que se asuma.

Es un concepto dinámico porque ha transitado por diferentes experiencias, considerando el papel activo del sujeto, así como la metodología y la técnica utilizada. Así mismo, los constructivismos prueban su mejoría desde el aspecto integracionista.

Las estrategias didácticas sobre el aprendizaje basado en problemas, los estudios de caso, el aprendizaje basado en la investigación 
y el aprendizaje por proyectos, coadyuvan en una mayor facilidad de apropiación de las tareas de investigación, pues se fomenta el pensamiento crítico, la responsabilidad, las decisiones compartidas, la comunicación y la colaboración, de la cual Barkley y otros (2007, p. 17) sostienen que:

1. Promueven la interdependencia positiva

2. Favorecen la interacción promotora.

3. Fomentan la responsabilidad individual y de grupo.

4. Impulsan el desarrollo de las competencias del trabajo en equipo.

5. Fundan la valoración del grupo.

No obstante, las autoras advierten que se deben considerar los distintos ritmos de trabajo, así como los diversos grados de velocidad; que no todos los miembros del grupo trabajan equitativamente; y que se pierde tiempo en conversaciones que no tienen que ver con la tarea del grupo.

Tales estrategias brindan al alumno, el análisis profundo de los problemas, sus causas, sus efectos, sus alternativas de solución compartidas y enriquecidas, lo que promueve un alumno activo.

Asociado a los saberes, Diaz Villa y otros (2006, p. 46) los dividen en tres aspectos, el saber qué, el saber cómo y el poder hacer, haciendo hincapié en los aprendizajes previos que debe tener el estudiante, como el manejo de las matemáticas, la estadística, la lógica, la bibliografía y las tecnologías de informacion y comunicación, es decir, una serie de competencias básicas y genéricas que complementarán el desarrollo de las competencias específicas de la investigación en la profesión.

El saber qué implica contar con los conocimientos, el saber cómo con las habilidades y destrezas, en tanto que el poder hacer demuestra las aptitudes de investigación. (Cuadro 1)

Esto distancia un aprendizaje memoristico y repetitivo, de una experiencia de aprendizaje situacional. 
Cuadro 1.

Los saberes en el proceso de investigación

\begin{tabular}{|c|c|c|}
\hline Saber qué & Saber cómo & Poder hacer \\
\hline $\begin{array}{l}\text { Identificar el problema de } \\
\text { la investigación. }\end{array}$ & $\begin{array}{l}\text { Analizar el origen y } \\
\text { situación actual. }\end{array}$ & Plantear el problema. \\
\hline Fundamentar el proyecto. & $\begin{array}{l}\text { Distinguir las caracterís- } \\
\text { ticas epistemológicas y } \\
\text { teóricas del problema de } \\
\text { investigación. }\end{array}$ & $\begin{array}{l}\text { Posicionarse con funda- } \\
\text { mentos y argumentos. }\end{array}$ \\
\hline $\begin{array}{l}\text { Elegir los métodos y las } \\
\text { técnicas. }\end{array}$ & $\begin{array}{l}\text { Diferenciar los diversos } \\
\text { métodos y técnicas de in- } \\
\text { vestigación. }\end{array}$ & $\begin{array}{l}\text { Aplicar los métodos y téc- } \\
\text { nicas adecuados al } \\
\text { proyecto. }\end{array}$ \\
\hline $\begin{array}{l}\text { Elaborar el protocolo de } \\
\text { investigación. }\end{array}$ & $\begin{array}{l}\text { Identificar cada uno de los } \\
\text { componentes del protoco- } \\
\text { lo de investigación y sus } \\
\text { funciones. }\end{array}$ & $\begin{array}{l}\text { Ubicar correctamente los } \\
\text { elementos del protocolo de } \\
\text { investigación. }\end{array}$ \\
\hline $\begin{array}{l}\text { Buscar, encontrar y organi- } \\
\text { zar la información. }\end{array}$ & $\begin{array}{l}\text { Manejar las fuentes de in- } \\
\text { formación. }\end{array}$ & $\begin{array}{l}\text { Organizar la información } \\
\text { elegida. }\end{array}$ \\
\hline Aplicar el proyecto. & $\begin{array}{l}\text { Desarrollar el proyecto de } \\
\text { investigación. }\end{array}$ & $\begin{array}{l}\text { Elaborar un primer } \\
\text { borrador. }\end{array}$ \\
\hline Socializar los resultados. & $\begin{array}{l}\text { Elaborar una presentación } \\
\text { ejecutiva. }\end{array}$ & $\begin{array}{l}\text { Presentar formalmente } \\
\text { el objetivo, justificación, } \\
\text { metodología, resultados y } \\
\text { conclusiones. }\end{array}$ \\
\hline
\end{tabular}

Fuente: Elaboración propia

En el cuadro anterior se desglosan brevemente y de modo muy general, las tres formas de los saberes que se aplican en la investigación y en este proceso, se presentan problemas para el desarrollo de las competencias de investigación, por esto, el uso de rúbricas y la valoracion formativa, transparentan y hacen consciente en el alumno sus logros y dificultades de aprendizaje.

Coll (1992, p. 92) indica que hay tres momentos en la evaluación (Cuadro 2), la diagnóstica, formativa y sumativa. 
Cuadro 2.

Fases de la evaluación del aprendizaje

\begin{tabular}{|c|c|c|c|}
\hline & Evaluación inicial & Evaluación formativa & Evaluación sumativa \\
\hline ¿Qué es evaluar? & $\begin{array}{l}\text { Los esquemas de } \\
\text { conocimiento per- } \\
\text { tinentes para el } \\
\text { nuevo material o } \\
\text { situación de apren- } \\
\text { dizaje. }\end{array}$ & $\begin{array}{l}\text { Los progresos, difi- } \\
\text { cultades, bloqueos, } \\
\text { etc., que jalonan el } \\
\text { proceso de aprendi- } \\
\text { zaje. }\end{array}$ & $\begin{array}{l}\text { Los tipos y grados de } \\
\text { aprendizaje que es- } \\
\text { tipulan los objetivos } \\
\text { (terminales, de nivel } \\
\text { o didácticos) a pro- } \\
\text { pósito de los conte- } \\
\text { nidos seleccionados. }\end{array}$ \\
\hline ¿Cuándo evaluar? & $\begin{array}{l}\text { Al comienzo de } \\
\text { una nueva fase de } \\
\text { aprendizaje. }\end{array}$ & $\begin{array}{l}\text { Durante el proceso } \\
\text { de aprendizaje. }\end{array}$ & $\begin{array}{l}\text { Al término de una } \\
\text { fase de aprendizaje. }\end{array}$ \\
\hline ¿Cómo evaluar? & $\begin{array}{l}\text { Consulta e inter- } \\
\text { pretación de la } \\
\text { historia escolar del } \\
\text { alumno. Registro } \\
\text { e interpretación } \\
\text { de las respuestas } \\
\text { y comportamiento } \\
\text { de los alumnos an- } \\
\text { te preguntas y si- } \\
\text { tuaciones relativas } \\
\text { al nuevo material } \\
\text { de aprendizaje. }\end{array}$ & $\begin{array}{l}\text { Observación siste- } \\
\text { mática y pautada del } \\
\text { proceso de aprendi- } \\
\text { zaje. Registro de las } \\
\text { observaciones en ho- } \\
\text { jas de seguimiento. } \\
\text { Interpretación de las } \\
\text { observaciones. }\end{array}$ & $\begin{array}{l}\text { Observación, regis- } \\
\text { tro e interpretación } \\
\text { de las respuestas y } \\
\text { comportamiento de } \\
\text { los alumnos a las } \\
\text { preguntas y situa- } \\
\text { ciones que exigen } \\
\text { la utilización de los } \\
\text { contenidos aprendi- } \\
\text { dos. }\end{array}$ \\
\hline
\end{tabular}

Fuente: Coll, C. (1992) Psicología y curriculum. México: Paídos, p. 92

La valoracion diagnóstica y la sumativa, son complementarias a la formativa, que es aquella donde se resuelven las dudas y se afianzan los aprendizajes, por lo cual, se precisa puntualmente en cada una de las etapas de la investigación.

La rúbrica establece qué y cómo se evaluará el proceso de investigación. Es una herramienta que específica lo que se tomará en cuenta y determina la valoración en términos de esfuerzo.

A continuación, se presenta una rúbrica sobre las competencias enunciadas anteriormente (Cuadro 3), en tres niveles de desempeño aprobatorio, para hacer la calificación simple y transparente. 
Cuadro 3.

Rubrica sobre las competencias en investigación

\begin{tabular}{|c|c|c|c|}
\hline Competencia & Avanzado & Intermedio & Básico \\
\hline $\begin{array}{l}\text { Capacidad para } \\
\text { adoptar una postu- } \\
\text { ra epistemológica, } \\
\text { axiológica y ética } \\
\text { en el ejercicio pro- } \\
\text { fesional. }\end{array}$ & $\begin{array}{l}\text { Argumenta la posi- } \\
\text { ción sobre un para- } \\
\text { digmade investiga- } \\
\text { ción y un objeto de } \\
\text { estudio. }\end{array}$ & $\begin{array}{l}\text { Fija una posición } \\
\text { sobre el paradigma, } \\
\text { pero no sobre el } \\
\text { objeto de estudio; } \\
\text { o fija una posición } \\
\text { sobre el objeto de } \\
\text { estudio, pero no } \\
\text { sobre el paradigma. }\end{array}$ & $\begin{array}{l}\text { Esboza algunos ele- } \\
\text { mentos, pero no } \\
\text { adopta una posi- } \\
\text { ción sobre un para- } \\
\text { digma de investiga- } \\
\text { ción ni un objeto de } \\
\text { estudio. }\end{array}$ \\
\hline $\begin{array}{l}\text { Aplicar proyectos } \\
\text { innovadores o al- } \\
\text { ternativos de inves- } \\
\text { tigación teórica o } \\
\text { práctica, utilizan- } \\
\text { do la metodología } \\
\text { cuantitativa o cua- } \\
\text { litativa que solucio- } \\
\text { nen problemas en } \\
\text { Ciencias de la Infor- } \\
\text { mación. }\end{array}$ & $\begin{array}{l}\text { Fundamenta el pro- } \\
\text { yecto de investiga- } \\
\text { ción en todas sus } \\
\text { etapas y obtiene } \\
\text { resultados. }\end{array}$ & $\begin{array}{l}\text { No cimienta el pro- } \\
\text { yecto de investiga- } \\
\text { ción, pero obtiene } \\
\text { entre } 70 \% \text { y } 80 \% \text { de } \\
\text { los resultados. }\end{array}$ & $\begin{array}{l}\text { No proporciona las } \\
\text { bases del proyecto } \\
\text { de investigación y } \\
\text { obtiene } 60 \% \text { de los } \\
\text { resultados. }\end{array}$ \\
\hline $\begin{array}{l}\text { Difundir los resulta- } \\
\text { dos de las investiga- } \\
\text { ciones. }\end{array}$ & $\begin{array}{l}\text { Publica los resulta- } \\
\text { dos de su investiga- } \\
\text { ción. Presenta po- } \\
\text { nencias en eventos } \\
\text { académicos. }\end{array}$ & $\begin{array}{l}\text { No publica los } \\
\text { resultados de su } \\
\text { investigación. Pre- } \\
\text { senta ponencias en } \\
\text { eventos académi- } \\
\text { cos. }\end{array}$ & $\begin{array}{l}\text { No publica los re- } \\
\text { sultados de su in- } \\
\text { vestigación. No } \\
\text { presenta ponencias } \\
\text { en eventos acadé- } \\
\text { micos. Cuenta con } \\
\text { un borrador de es- } \\
\text { bozo. }\end{array}$ \\
\hline $\begin{array}{l}\text { Establecer conve- } \\
\text { nios y acuerdos de } \\
\text { investigación. }\end{array}$ & $\begin{array}{l}\text { Presenta propues- } \\
\text { tas integrales para } \\
\text { establecer conve- } \\
\text { nios y acuerdos de } \\
\text { investigación via- } \\
\text { bles. }\end{array}$ & $\begin{array}{l}\text { Presenta propues- } \\
\text { tas integrales para } \\
\text { establecer conve- } \\
\text { nios y acuerdos de } \\
\text { investigación, regu- } \\
\text { larmente viables. }\end{array}$ & $\begin{array}{l}\text { Presenta propues- } \\
\text { tas para establecer } \\
\text { convenios y acuer- } \\
\text { dos de investiga- } \\
\text { ción con algunas } \\
\text { bases. }\end{array}$ \\
\hline
\end{tabular}

Fuente: Elaboración propia 


\section{La investigación bibliotecológica: problemas para...}

Se entiende que quien no cumple con el criterio básico, no aprobará la materia, pues hay poco o nulo esfuerzo.

Entre los problemas mas frecuentes, en la experiencia de quien escribe esto, la mayores dificultades de los alumnos se presentan en la delimitación del tema de investigación; la congruencia entre los objetivos y las hipótesis; la identificación de la metodología adecuada al tipo de problema que se va a resolver; revisar el estado del arte; y definir la muestra estadística. Particularmente, en la metodología cualitativa, el problema se presenta en la categorización de información y definir cual y como se usará. El compromiso, ir caminando junto con ellos para que sea un proceso de acompañamiento.

\section{CONSIDERACIONES FINALES}

La tarea de investigación es una competencia para la vida que plantea un gran número de retos, pero tambien de oportunidades.

Es tan importante como las actividades profesionalizantes en las biblioteca, archivos y otras unidades de información, porque contribuye a fundamentar y justificar las necesidades en diversas áreas laborales.

Es un proceso que amplía y cambia la perspectiva de los estudiantes sobre el campo profesional y el mundo.

Los docentes deben preparar la tarea y contar los materiales de aprendizaje. Acompañar al estudiante en el camino, a través de una evaluacion formativa y transparente, para que sea consciente de sus avances y salte los obstáculos para alcanzar la meta esperada, aprovechando los todos los recursos en su aprendizaje.

\section{BIBLIOGRAFÍA}

Barkley, Elizabeth F., K. Patricia Cross y Claire Howell Major. "Argumentos a favor del aprendizaje colaborativo." Técnicas de aprendizaje colaborativo. Madrid: Morata, 2007. pp. 17-31.

Coll, César. Psicología y curriculum. México: Paídos, 1992. 
Díaz Villa, Mario et al. "Nociología de las competencias. Referentes básicos de la noción de competencia.” Educación Superior: Horizontes y Valoraciones. Bogotá: ICFES-Universidad de San Buenaventura, 2006.

Gutiérrez Pantoja, Gabriel. Metodología de las ciencias sociales. México: Harla, 1992.

Hernández Pina, F., Martínez Clares, P., Da Fonseca Rosario, P. \& Rubio Espín, M. "Los enfoques de aprendizaje: una revisión del estado de la cuestión." En: Aprendizaje, competencias y rendimiento en educación superior. Madrid: Muralla, 2005.

Liz, Manuel. "La ciencia como institución, la imagen científica, y la cultura científica..." Argumentos de Razón Técnica, 12 (2009), 167-181.

Ríos Ortega, Jaime. Didáctica de la Bibliotecología:Teoría y principios desde la enseñanza de la ciencia. México, UNAM. Instituto de Investigaciones Bibliotecológicas y de Información, 2008.

UNESCO. Declaración sobre la ciencia y el uso del saber científico. Disponible en línea: http://www.unesco.org/ science/wcs/esp/declaracion_s.htm (Consultado el 20 de abril de 2015) 


\title{
¿Cómo enseñar a investigar en bibliotecología para asegurar su aprendizaje?
}

\author{
EdILMA NARANJO VÉLEZ \\ Escuela Interamericana de Bibliotecología, \\ UdeA, Colombia
}

\section{Resumen}

Encontrar la manera de enseñar el proceso de investigación en bibliotecología y otras ciencias afines, de manera que se pueda lograr su aprendizaje es un objetivo central en este capítulo, pues no es fácil de lograr, si se tiene presente que para aprender a investigar es necesario investigar, además de disfrutar de esta actividad y disponer de los elementos conceptuales, teóricos, metodológicos y prácticos que demanda esta acción. La reflexión acerca de la investigación en general, es el inicio del capítulo, para adentrarse en el proceso formativo en investigación en las aulas de clases con procesos validados desde los currículos y planes de estudios; no limitando la acción formativa a la educación formal, sino haciendo uso de otros espacios alternativos, puesto que la intención es crear una cultura investigativa en el mundo bibliotecológico; finalmente, se presentan algunas estrategias para llevar a cabo la enseñanza de la investigación en bibliotecología, describiendo algunas y referenciando otras. 


\title{
How to teach research in Librarianship to ensure learning Edilma Naranjo-Vélez
}

\begin{abstract}
Finding the way to teach the research process in librarianship and other related sciences, in order to achieve its learning is the main objective in this chapter, since it is not easy to achieve it, if it is considered that to learn and research is necessary to research along with enjoying this activity and having the conceptual, theoretical, methodological y practical elements required by this action. The reflection about researching, in general, is the beginning of the chapter, to get into the formative process in researching in the classrooms with processes validated from the curricula and syllabi; without limiting the formative action to the formal education, but making use of other alternative spaces, since the intention is to create a researching culture in the librarianship world. Finally, some strategies to carry out the teaching of researching in librarianship are presented by describing some and referencing others.
\end{abstract}

\section{INTRODUCCIÓN}

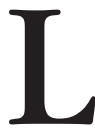

a generación de conocimiento y la aplicación de la ciencia y la tecnología en un país permiten hablar de su crecimiento y desarrollo. Por ello, se esperaría que la investigación estuviera en el quehacer de todos, que se asumiera como una actividad básica del hombre, puesto que le permite la reflexión y el conocimiento de sí mismo, de su contexto y su entorno y de las condiciones de vida, dándole la posibilidad de prepararse para afrontar los momentos y situaciones imprevistas, al igual que los retos que le plantea la vida en su ambiente profesional y personal.

De allí que se diga que la investigación es el motor en los avances científicos, tecnológicos y sociales de un país y se espera que parte del presupuesto de una nación se dedique a sostenerla y fortalecerla. 
En consonancia, en la educación superior se ha convertido en un eje de su función misional, pues ella nutre a la docencia, al entregarle sus resultados como insumo para la enseñanza, pues permite la discusión en el aula de clase a través de la conversación o de los ensayos y experimentos en los laboratorios, de manera que en esos espacios áulicos se generen preguntas, inquietudes, cuestionamientos, se hagan visibles quiénes comparten los resultados y quiénes se oponen a ellos. Esta dinámica, a su vez, genera nuevas ideas, nuevas propuestas y proyectos de investigación; esto es, el aula de clase, el laboratorio son los espacios en los que se espera que surjan nuevas investigaciones, pues allí se encuentran los estudiantes inquietos, ávidos de conocimiento, deseosos de brindar su energía y juventud para los nuevos hallazgos, los nuevos productos.

Se dice entonces que la universidad debe cumplir con sus funciones misionales de docencia e investigación; con ellas se busca y pretende contribuir con la sociedad sin limitarse a la adquisición de saberes enciclopédicos, incluyendo también el saber aplicado y la creación de conceptos y teorías, ya que si bien desde los estudios universitarios es importante hacer cultura o adquirir una serie de conocimientos que capaciten a los sujetos para desempeñar funciones en la sociedad, es fundamental encontrar los datos más profundos que muestran y tiene una relación creativa con la realidad, la que debe ser comunicada, para entablar el dialogo entre la institución educativa y la sociedad.

La articulación de los procesos de docencia e investigación en la educación universitaria se asocian con el desarrollo de la ciencia y la tecnología como instrumentos dinámicos del cambio social y de la evolución de los servicios informativos en función del progreso de las comunidades. Al partir de las ideas de que para investigar es necesario disponer de la actitud del investigador, además de su acción, por lo tanto la universidad es la encargada de prepararlos, es posible afirmar que "se requieren [...] bibliotecólogos y docentes bien formados inquietos por indagar y proponer ideas que marchan a la par de las tendencias mundiales, pero [sin olvidar] la importancia de saber lo que ocurrió en el pasado y qué generó el presente que se vive." (Naranjo \& Rendón, 2004a, p. 131) 


\section{La investigación bibliotecológica: problemas para...}

Con la investigación se busca una mejor actualización del grupo de profesionales y aumentar la conciencia social acerca de la importancia que tiene la información para mejorar la calidad de vida de la sociedad. Esto se logra a través del proceso de revisión del conocimiento, el establecimiento de nuevas relaciones entre los hechos o la aplicación del conocimiento a algún problema, lo cual influye así en el desarrollo de una disciplina y la comunicada académica y científica que la lidera.

En la actualidad la bibliotecología y las disciplinas afines tienen mayor reconocimiento y posición en el ambiente académico y social, en gran parte por su labor investigativa, realizada desde las escuelas y facultades y por su papel de apoyo a los avances científicos y tecnológicos con el acceso y uso de la información bajo la premisa del uso de las tecnologías de la información y la comunicación -TIC. Estas disciplinas, con la construcción de su cuerpo teórico y sus fundamentos, indican cómo la madurez y crecimiento de la profesión dependen del desarrollo de la investigación, razón de más sustentar la importancia de la preparación en investigación del bibliotecólogo. (Naranjo \& Rendón, 2004b)

Además, las derivaciones de las investigaciones, bien sea con productos, con aplicaciones o con reflexiones y propuestas, se convierten en un aporte para la sociedad y permiten a las universidades realizar su función social que la deben caracterizar, pues, finalmente, el conocimiento ha de servir si trasciende los laboratorios y las aulas universitarias. El conocimiento adquiere valor cuando la comunidad (general o específica) se beneficia de él, lo valora y contribuye a su transformación.

\section{LA FORMACIÓN EN INVESTIGACIÓN EN BIBLIOTECOLOGÍA Y DISCIPLI- NAS AFINES}

La cientificidad de una disciplina, se logra cuando se realiza un trabajo sistemático basado en los métodos de investigación, que permiten la producción de nuevo conocimiento para sustentarla teóricamente, además de dar cuenta de su práctica, lo que brinda elementos para 
que la profesión se desarrolle con base en procesos metódicos y sistemáticos. Si bien hoy en día puede hablarse de una abundante producción científica de calidad en bibliotecología y disciplinas afines, no es factible desconocer que aún se puede realizar más investigación, en la medida en que se profundiza en el tema y se genera más teoría.

Además de que la bibliotecología tradicionalmente se ha considerado una disciplina empírica, y de caracterizarse por ser una profesión de servicio, en ella también tiene cabida la investigación, como función esencial para su desarrollo, posicionándola como una disciplina científica, lo que redunda en beneficio de la formación de profesionales. Esta última actividad, es quizá una de las más importantes que le ha merecido a la bibliotecología un reconocimiento y status social en los últimos tiempos. Por lo tanto, incorporar la investigación en los procesos de servicios, técnicos, tecnológicos y de gestión de la información facilita la generación de nuevo conocimiento alrededor de estas disciplinas, de acuerdo con las demandas del mundo contemporáneo.

Lo anterior insta a formar a los estudiantes ofreciéndoles contenidos en los cuales estén presentes los aspectos teóricos y técnicos precisos, para abordar una investigación de carácter científico, con temas en los que estén presentes los elementos metodológicos y epistemológicos, para que comprendan e interpreten los principios rectores en el quehacer científico con un sustento fundamentado, con una posición crítica y con un espíritu creativo.

El dominio de estos elementos les permitirá a los bibliotecólogos responder a las presiones creadas por los cambios a los que se ven sometidos las unidades de información y la profesión, ante la aplicación masiva de las tecnologías de la información y las necesidades de los usuarios, pero ante todo por el carácter científico que requiere nuestra profesión. (Rendón, 2003, p. 121)

Si se considerada la investigación como vía fundamental para buscarle solución a los problemas de la sociedad y como una aplicación a las fronteras del conocimiento, se deben propiciar los ambientes que permitan entenderla como la creadora de nuevos conocimientos, de nuevas técnicas y de mejores formas de observar el mundo y transformarlo. 


\section{La investigación bibliotecológica: problemas para...}

Debería ser la investigación, en la formación de bibliotecólogos, un eje transversal a la propuesta curricular, que permita el análisis y la confrontación de los cambios que día a día sufre profesión debido a los avances de las TIC y a las necesidades de los sujetos frente al proceso de transferencia de información y las tendencias de la profesión en el ámbito nacional e internacional.

Lo anterior justifica la formación de personal cualificado para realizar investigaciones que den respuesta a las tendencias disciplinares, a las inquietudes de los profesionales y a las necesidades del medio, por eso el aprendizaje del proceso de investigación, no es sencillo, aunque sí posible de lograr; este depende en gran medida del proceso de enseñanza que, liderado por el docente, debe mostrar los diferentes caminos existentes en el mundo científico, puesto que la investigación es una labor sistemática que requiere tiempo y dedicación, que exige rigor académico y disciplina.

Solo hasta los años 30 del siglo XX fue introducida en Estados Unidos la enseñanza de los métodos de investigación en las escuelas de Bibliotecología, a partir de ese momento se vio la importancia de llevar a cabo estudios sistemáticos (Delgado, 2001). Se inicia con el método científico o positivista; posteriormente tienen presencia el método cualitativo con sus diferentes enfoques, entre los cuales cabe destacar la hermenéutica, la investigación acción participación (IAP), la fenomenología, entre otras. Este desarrollo y uso ha facilitado que el estudiante de bibliotecología y disciplinas afines, tanto en el nivel de pregrado como en el posgrado, se sensibilice y comprenda el papel beneficioso de la investigación "propiciando un ambiente permeable para el cambio y facilitando la captación de futuros profesionales de la información y bibliotecología y su capacitación para el ejercicio de la investigación." (Rendón, 2002, p. 54)

En las escuelas de formación en bibliotecología y disciplinas afines se han incorporado los cursos de investigación con diferentes enfoques y profundidad, en este momento no puede concebirse un currículo sin que se tenga la presencia de la investigación como un eje central de su plan de estudios, bien sea porque los profesionales asumirán la investigación como una labor esencial en su desempeño 
laboral o porque consideren que requieren de este conocimiento para disponer de

[...] herramientas metodológicas fundamentales que les ayudarán en el futuro a planificar, gestionar y evaluar las bibliotecas y unidades de información en las que desempeñen su trabajo de una forma científica y profesional y no de manera intuitiva, basándose en la autoridad, tradición, costumbres o en la propia experiencia personal o importada (Delgado, 2001, p. 52).

La enseñanza de la investigación y sus procesos en la bibliotecología permite a los estudiantes, en su proceso de aprendizaje, formar un espíritu crítico, cuestionador y a la vez propositivo, que busca solución a los problemas y diversas situaciones que se le presentan en su quehacer profesional y personal. Es de esperar que la comprensión y dominio de los elementos propios de los diferentes métodos de investigación, sean una oportunidad para que manifieste la creatividad, el cambio y le permita liderar racional y sistemáticamente las actividades que requieran de este conocimiento; esto exige creatividad, disciplina, dedicación, inquietud permanente, indagación, estar en condición de sorprenderse y sentir la necesidad de dar solución a los problemas que surjan, a las preguntas que aún no encuentran respuesta y ante todo, el deseo de una formación permanente que le permita la búsqueda y generación de nuevo conocimiento.

La formación en investigación en bibliotecología, además de incluir la enseñanza de la técnicas de investigación, debe recalcar en los principios teóricos y epistemológicos de este qué hacer, "fomentando en el estudiante el análisis, la evaluación y el seguimiento de las situaciones" (Rendón, 2002, p. 56) en estudio. Esto lleva a que el estudiantado se pregunte por el por qué de las cosas, el para qué y el cómo hacerlas, elementos esenciales al momento de querer incrementar la actividad investigativa con pretensiones de solucionar los problemas y avanzar en el conocimiento, lo cual se logra cuando se procura conocer las causas y las leyes que los rigen. 


\section{La investigación bibliotecológica: problemas para...}

La enseñanza de la investigación bibliotecológica, no debe mirarse solo como un proceso que se lleva a cabo en el posgrado (especialización o máster, maestría y doctorado), sino que también debe incluirse en el nivel de pregrado o licenciatura, pues su aprendizaje importa tanto para la generación de conocimiento, como para el conocimiento aplicado que requiere de los procesos metodológicos y los saberes académicos aprendidos para poder resolver los problemas que surgen en la cotidianidad del ejercicio profesional. En consecuencia, la enseñanza se puede establecer por niveles, los cuales indican la variación en la complejidad de los contenidos y en los procesos. Es diferente la investigación en pregrado y en posgrado, los alcances de la misma varían, al igual que los intereses de los estudiantes.

En el caso del pregrado se puede proponer que en un plan de estudios se establezca la investigación como eje transversal en este; siendo este un enfoque que permite hablar de un currículo investigativo; aunque también es factible establecer un plan de estudios con un núcleo investigativo o con cursos que permitan al estudiante comprender el papel de la investigación en su disciplina y los pasos sistemáticos que se deben llevar a cabo, para afrontar el quehacer profesional de acuerdo con las exigencias laborales o con sus compromisos personales. Igualmente, este primer eslabón en la enseñanza de la investigación, es uno de los pasos iniciales para motivar a los profesionales a continuar formándose como investigadores en los niveles de posgrado.

La investigación debe asumirse, a su vez como área de estudio en algunos cursos, al igual que como una propuesta didáctica que sea transversal a todo el currículo, esto indica que se podría hablar de un currículo problemático que se apoya en estrategias y métodos en los cuales la pregunta y el planteamiento de problemas orientarán los procesos de enseñanza y los de aprendizaje.

Por lo tanto, justificar la presencia de la investigación en los planes de estudio de bibliotecología y disciplinas afines no es difícil, pues el perfil de egreso que se establece en algunas escuelas y facultades refleja que este conocimiento también es fundamental, más cuando se quiere contar con profesionales capaces de planear, gestionar y evaluar las unidades de información y sus servicios de una manera científica y profesional, y no de manera intuitiva o empírica. No obstante, 
es de esperar, como expresan Naranjo y Rendón "que el énfasis empiece a darse más en el proceso de investigación que en las técnicas de recolección de datos y presentación de trabajos [...]" (Naranjo \& Rendón, 2004a, p. 137).

Por ello, los currículos de las instituciones de educación superior, tienen el reto de acercarse a la investigación para develar problemas complejos desde los objetos de conocimiento, lo cual involucra un trabajo transdisciplinario, puesto que existen múltiples y variadas soluciones para cada uno de esos problemas, es decir, se requiere una interacción permanente entre las diversas disciplinas que tiene un vínculo (directo o tangencial) con la situación planteada.

En el caso de los posgrados, se tienen instituciones universitarias en las que se establece, mediante reglamento, que quienes aspiren a ser estudiantes de maestría y de doctorado deben presentarse con una propuesta de investigación respaldada por un grupo de investigación, de suerte que se garantice al estudiante el acompañamiento y la asesoría por el tiempo que duren sus estudios; además de que esta es una forma de enriquecer la relación docencia-investigación. Así mismo, esta característica se establece para garantizar el desarrollo de la investigación teórica y que los estudiantes dispongan de un espacio para desarrollar sus competencias investigativas.

\section{Alternativas PARA CREAR UNA CUlTURA INVESTIGATIVA}

Crear una cultura de la investigación, como es la tendencia universitaria, debido a las exigencias que en ciencia y tecnología demanda la sociedad, conlleva a pensar en diferentes estrategias, no limitada a la enseñanza formal, sino también dando lugar a otras alternativas, como son los semilleros de investigación, los grupos, líneas y equipos de investigación. Estas otras alternativas, dan lugar a la participación de profesores, estudiantes y egresados, deseosos de formular y presentar proyectos.

Una de las formas de enseñanza es a partir de los eventos que se organizan para divulgar los resultados de investigación y socializar los proyectos que se llevan a cabo, pueden ser eventos de profesionales o 


\section{La investigación bibliotecológica: problemas para...}

de los mismos estudiantes quienes presentan los mejores trabajos que realizaron durante el semestre a partir de una labor investigativa, esta es una forma de motivarlos e incentivarlos a continuar con esta actividad; su periodicidad puede ser anual, bianual o por cohortes (estudiantes).

Otra manera de enseñar a investigar es incluyendo en los proyectos de investigación a los estudiantes en formación, tanto del pregrado como del posgrado. Estos estudiantes, además de cumplir el papel de auxiliares, deben asumirse como sujetos activos dentro de los procesos, invitarles a ser partícipes en las discusiones alrededor del proyecto y ser escuchados con sus ideas, además de involucrarlos en los procesos de escritura.

En el pregrado, es posible que los estudiantes, realicen como trabajo de grado, una monografía en la que inicien sus conocimientos investigativos, con el acompañamiento de los profesores; esta monografía podrá ser el insumo para un proyecto de investigación de mayor envergadura.

Los estudiantes, también pueden ser auxiliares de investigación, si los recursos de la investigación incluyen la presencia de auxiliares, contratados para realizar actividades muy precisas. Como expone Rendón (2004, p. 119)

La investigación en un ambiente universitario adquiere mayor sentido cuando se involucran diferentes estamentos y se relaciona con la docencia y la extensión, lo que posibilita a la comunidad académica una mayor interrelación con el sector educativo y empresarial, al compartir experiencias, validar teorías, conocimientos y resultados mediante la publicación en revistas nacionales e internacionales, y la participación en redes y eventos académicos de su especialidad e a nivel mundial al mantener un diálogo activo con sus pares.

Otra alternativa son los semilleros de investigación, estos son espacios formativos en los que conciben, se comparten y se comunican una serie de estrategias y procesos con las personas interesadas en aprender a investigar; allí tiene cabida la reflexión crítica, el inicio y la práctica permanente del ejercicio investigativo; se reúnen para confrontar la teoría con la práctica o la realidad de esa teoría. Allí, los interesados 
encuentran el lugar para dar a conocer y compartir su creatividad y curiosidad, además de que pueden satisfacer la necesidad que sienten de resolver sus problemas e inquietudes profesionales.

La importancia del semillero radica en la motivación de sus participantes, quienes asisten en forma voluntaria para aprender a conjugar teoría, práctica, estrategias metodológicas de investigación y otra serie de conocimientos afines a estos. La cultura de la investigación se cultiva al contar con unos sujetos que manan una actitud creativa, crítica, reflexiva, evaluativa y con interés por la generación de nuevo conocimiento en la bibliotecología y la ciencia de la información.

Los semilleros se asumen como comunidades de aprendizaje de carácter interdisciplinario y multiestamentario que favorecen las relaciones entre la docencia y la investigación, además de que promueve el espíritu científico en el ámbito educativo. Dentro de los semilleros cuenta con varias alternativas de reunión: grupos de estudio; grupos lectura, discusión y redacción de documentos; semilleros de investigación de carácter interuniversitarios; también se habla de semilleros por grupos de investigación, por facultades, por centros o unidades de investigación. (Rendón, 2002)

Es de destacar que los semilleros de investigación presentan las siguientes particularidades:

- En ellos se da la formación integral.

- Cada uno de los participantes es consciente y protagonista de su avance en el aprendizaje.

- Las experiencias de los participantes en otros lugares académicos o investigativos, se convierten en el insumo de preguntas problemas que se plantean.

- Se pretende que las preguntas y problemas que allí se plantean, se conviertan en proyectos de investigación.

- Es una dinámica extracurricular en la que libremente se seleccionan los temas, las preguntas y las estrategias y dinámicas metodológicas que puede tener o no conexión directa con las actividades curriculares.

- Las relaciones que se establecen son horizontales, dialógicas y de persuasión. 


\section{La investigación bibliotecológica: problemas para...}

- Los problemas y proyectos planteados buscan contribuir al mejoramiento de las regiones y el país, en procura de colaborar en la construcción de una ciudadanía crítica, reflexiva y propositiva.

Estos elementos dan la oportunidad de exponer cómo la enseñanza de la investigación en la bibliotecología y disciplinas afines ha diversificado sus contenidos y sus objetivos, al igual que sus estrategias didácticas y los procesos de evaluación, pues tiene mayores herramientas, como se verá a continuación.

\section{Algunas estrategias didácticas}

Una estrategia didáctica se enfoca a partir del método; es decir, la estrategia es una propuesta relacionada con la enseñanza que busca el logro de metas y resultados que se convierte en un proceso complejo, planeado y coordinado, el cual requiere de la reflexión permanente, puesto que para su diseño y aplicación se debe plantear un fin, además de que precisa de un fundamento teórico, de los objetivos y los contenidos a desarrollar. La estrategia se organiza por fases y estas a su vez por segmentos, que regularmente siguen una secuencia; el contexto y los sujetos partícipes se deben tener en cuenta al momento de organizar la estrategia didáctica, al igual que los medios a utilizar. Para determinar el logro es necesario realizar la evaluación tanto del proceso de enseñanza como del aprendizaje de los estudiantes (Naranjo, 2014)

Estas estrategias se diseñan con el fin de materializar el proceso de enseñanza, el cual por su complejidad, puede presentar una serie de problemas al momento de llevarlo al aula de clase; así mismo, las estrategias facilitan el aprendizaje. En la enseñanza de la investigación en bibliotecología y disciplinas afines también están presentes los problemas, algunos de los cuales emanan de la cantidad de líneas y áreas que se establecen en los currículos (tanto de pregrado como de posgrado), producto de la posmodernidad y con ella los avances tecnológicos, entonces se requiere de un profesor que, además de tener un conocimiento acerca de los procesos metodológicos de la enseñanza, 
también los posea en relación con la investigación, que esté a la vanguardia de los cambios y tendencias temáticas. Este profesor no tiene que ser experto en cada una de ellas, seguramente lo será en una o, incluso otras más, pero no en todas. Esto quiere decir que el docente debe cumplir con dos características: tener conocimiento acerca de los procesos de enseñanza y aprendizaje que incluye las estrategias didácticas, y conocedor de la temática investigativa: tipos, enfoques, métodos, técnicas, instrumentos y teoría de la investigación, así como de las áreas, teorías y epistemología de la bibliotecología.

Puesto que, de acuerdo con lo expuesto en párrafos anteriores, en relación con la exigencia actual de la sociedad con los resultados de las investigaciones, el estudiante universitario desde que inicia hasta que finaliza su plan de estudios se debe relacionar con actividades de investigación como una estrategia pedagógica. Se habla así de la formulación de problemas, el uso de técnicas de investigación como la observación o el registro sistematizado de situaciones o fenómenos, que buscan que el estudiante asuma el aprendizaje y la creatividad. Igualmente, que inicie con tipos básicos de conocimiento, tales como la estructura teórica, los modelos, principios y reglas del área; los productos, instrumentos, servicios, materiales y procedimientos que permiten materializar el conocimiento; y los métodos de trabajo y el desarrollo de habilidades necesarias para el desempeño profesional.

La enseñanza de la investigación, además de incluir la distinción de los tipos de investigación, los enfoques, los métodos, las técnicas, los instrumentos y las interpretaciones, también abarca la reflexión, el análisis, la comprensión, la interpretación y la síntesis de los resultados obtenidos y de los documentos que dan soporte al trabajo. Es decir, se debe enseñar la cartografía mental, pero también a preguntarse constantemente, a comparar las lecturas de acuerdo con el problema, las preguntas y los objetivos planteados y se debe enseñar a triangular la información acopiada en fuentes impresas y empíricas.

La enseñanza de la investigación en bibliotecología y disciplinas afines encuentra algunos problemas que se van superando, en la medida en que la función de investigador se torna más exigente y se presenta el trabajo interdisciplinario y transdiciplinario. Los aspectos técnicos, 


\section{La investigación bibliotecológica: problemas para...}

tecnológicos y procedimentales en el quehacer investigativo, marcaron por mucho tiempo la pauta en los procesos de enseñanza, de allí la poca trascendencia de los resultados que obtenían; además de que se daba una limitación con los métodos de investigación, pues, básicamente, se trabajaba con el método científico como enfoque, limitándose, en muchas ocasiones, a las técnicas de carácter cuantitativo, como la encuesta. No obstante, la situación ha cambiado, y ya se puede hablar de investigaciones realizadas con métodos cualitativos con enfoques fenomenológicos, hermenéuticos, la acción participación, la etnometodología entre otros, alternativas que involucran a los sujetos como parte directa de la investigación y en la que ellos son conscientes de su propio papel en el resultado de la investigación sin olvidarse del enfoque positivista, por supuesto. Así, se "[...] busca contribuir a la formación de representaciones del conocimiento, desarrollar habilidades mentales, crear jerarquías conceptuales y diseñar estrategias creativas y de pensamiento." (Naranjo \& Rendón, 2004a, p. 136)

Se observa cómo, cuando el currículo asume la investigación como un eje transversal, durante cada una de las asignaturas se hace el seguimiento de su propio objeto de estudio, valiéndose de diferentes métodos. A modo de ejemplo se presenta el ABP (Aprendizaje Basado en Problemas) que une la investigación con la docencia. De este modo la enseñanza y el proceso investigativo se convierten en un incentivo para el estudiante. Esto permite que las actividades y los procesos de enseñanza y de aprendizaje de la investigación se profundicen en la medida en que los estudiantes aumentan su nivel formativo. Otros métodos que se contemplan son: el ensayo teórico, el estudio de caso, la elaboración de portafolio (más como una técnica) y la elaboración de trabajos de grado.

En la creación de la cultura investigativa y en la búsqueda de estrategias didácticas que permitan acercar al estudiante a su aprendizaje como investigador, en cada curso se debe propiciar la acción de investigar comprensivamente, además, debe abrirse el espacio en las clases para presentarse informes orales y escritos de tal forma que se promueva la comunicación y se generen las comunidades de aprendizaje. Es fundamental brindar asesoría personal a cada estudiante y hacer seguimiento a sus trabajos de clase. 
A la par, se deben generar espacios alternativos para discutir y aprender de los estudiantes mediante la confrontación y divulgación en público de sus trabajos académicos, sean estos anteproyectos de investigación, ensayos, estados del arte, estudios de caso, experiencias laborales o trabajos de grado. Esto permitirá despertar el interés de los aspirantes a continuar su formación a través de un programa de postgrado.

[Se...] confronta la realidad y la práctica con la teoría bibliotecológica y demás disciplinas afines; además de estimular, crear y solidar una cultura de investigación... y de formar líderes y profesionales críticos con actitudes y aptitudes para el trabajo investigativo; y por ende ayudar a la conformación de grupo de investigación que lideren la generación y transfieran el conocimiento en el área. (Naranjo \& Rendón, 2004a, p. 136).

La enseñanza de la investigación, además de incluir la distinción de los tipos de investigación, los enfoques, los métodos, las técnicas, los instrumentos y las interpretaciones, también abarca la reflexión, el análisis, la comprensión, la interpretación y la síntesis de los resultados obtenidos y de los documentos que dan soporte al trabajo. Es decir, se debe enseñar la cartografía mental, pero también a preguntarse constantemente, a comparar las lecturas de acuerdo con el problema, las preguntas y los objetivos planteados.

\section{CONSIDERACIONES FINALES}

Este trabajo, que apenas se inicia, no puede afirmarse que sea perfecto; por el contrario, es necesario aceptar los retos que establecen la disciplina y los organismos nacionales e internacionales con miras al mejoramiento permanente de esta labor en la que se hurga, se husmea, se busca la claridad, para generar conocimiento y crecimiento económico, cultural, educativo y político y social.

Tanto los cursos regulares de investigación, como la transversalidad de la investigación en el currículo, como los semilleros de 


\section{La investigación bibliotecológica: problemas para...}

investigación y la participación directa en proyectos y grupos de investigación son espacios formativos dinámicos, que facilitan el crecimiento individual y grupal, en los que se da un crecimiento individual y grupal que facilita a los sujetos aprender a aprender, aprender a investigar y aprender investigando. Allí se conjugan los intereses académicos con los personales y profesionales, los cuales impulsan la formulación de preguntas, la creación de propuestas y proyectos, ideas innovadoras, creación de comunidades y redes académicas e investigativas; además de que amplía los horizontes hacia el ejercicio de la profesión, además de permitir asumir una posición crítica, reflexiva y ética ante cualquier situación en la vida personal o profesional en forma individual o colectiva.

Los semilleros de investigación son espacios alternativos en la formación de investigadores responsables, éticos, críticos y autónomos; la enseñanza favorece el aprendizaje individual y colectivo al propiciar la lectura, discusión y generación de documentos significativos; esto es, se da la transformación tanto de los documentos como de los sujetos, esto últimos como personas sentipensantes, donde se preparan para llegar con mayor seguridad y compromiso a los equipos de investigación.

La actitud hacia la investigación se caracteriza por una curiosidad permanente que exige disciplina, dedicación, interés por aprender e innovar, capacidad para interactuar con el manejo y administración de información; más compromiso con la búsqueda de soluciones a los problemas que afectan la región y, sobre todo, una buena formación. Por lo tanto es indispensable que las instituciones educativas orienten la formación de investigadores para el trabajo científico en bibliotecología y disciplinas afines, no solo a partir de los cursos regulares sobre métodos y técnicas de investigación o investigaciones independientes llevadas por los profesores y estudiantes, sino también fortaleciendo las habilidades, actitudes e intereses personales, teniendo en cuenta que el investigador se forma participando en el proceso mismo de la investigación.

El bibliotecólogo debe reconocer permanentemente el valor que tiene la investigación para desarrollar la profesión no solo adoptando actitudes positivas hacia ella, sino también identificando áreas 
prioritarias y dedicando tiempo para su estudio y su práctica, de tal manera que esto le permita tener una clara conciencia de su función social y educativa, obtener bases sólidas para responder a las tendencias y necesidades de su entorno, atender con mayor eficacia el objeto de su actividad, y generar nuevo conocimiento a partir de su experiencia personal.

\section{BiBLIOGRAFÍA}

Delgado, E. (2001). “Por qué enseñar métodos de investigación en las facultades de biblioteconomía y documentación?" En: Anales de Documentación, 4; pp. 51-71. En línea. URL: http://revistas.um.es/analesdoc/article/ view/2391 Consulta: 2015-05-28

Escalona, L. (2004). "Aproximaciones a la investigación bibliotecológica en los programas de licenciatura." En: Coloquio de Investigación Bibliotecológica y de la Información (21-2003-México, D. F.). La investigación bibliotecológica en la era de la información: memoria del XXI Coloquio de Investigación Bibliotecológica y de la Información. México: UNAM, Centro Universitario de Investigaciones Bibliotecológicas; pp. 128-129.

Naranjo, E. (2014). Didáctica de los sistemas de información documental: transformación de la información en conocimiento. México: UNAM, Instituto de Investigaciones Bibliotecológicas y de la Información. En línea. URL: http://132.248.242.6/ publica/conmutarl. php?arch=1\&idx=286 
Naranjo, E. \& Rendón, N. (2004a). "Docencia e investigación: congruencia en la Escuela Interamericana de Bibliotecología." En: Coloquio de Investigación Bibliotecológica y de la Información (21-2003-México, D. F.). La investigación bibliotecológica en la era de la información: memoria del XXI Coloquio de Investigación Bibliotecológica y de la Información. México: UNAM, Centro Universitario de Investigaciones Bibliotecológicas; pp. 130-141.

. (2004b). "La investigación bibliotecológica y las comunidades científicas en un contexto colombiano." En: Coloquio de Investigación Bibliotecológica y de la Información (21-2003-México, D. F.). La investigación bibliotecológica en la era de la información: memoria del XXI Coloquio de Investigación Bibliotecológica y de la Información. México: UNAM, Centro Universitario de Investigaciones Bibliotecológicas; pp. 77-91.

Rendón, N. (2002). La cultura de la investigación en bibliotecología: los semilleros de investigación como una alternativa de formación en el pregrado. En: Revista Interamericana de Bibliotecología, 25 (2); pp. 53-71.

___ (2003). "Fomento y apoyo a la investigación desde el Centro de Investigaciones en Ciencia de la Información -CICINF- de la Escuela Interamericana de Bibliotecología." En: Coloquio de Investigación Bibliotecológica y de la Información: prsente y futuro (20: 2002: México, D.F.). México: UNAM, Centro Universitario de Investigaciones Bibliotecológicas; pp. 116-128.

. (2004). "El quehacer del Centro de Investigaciones en Ciencia de la Información -CICINF- de la Escuela Interamericana de Bibliotecología: más allá de la gestión de la investigación.” En: Revista Interamericana de Bibliotecología, 27 (1); pp. 119-133. 


\title{
El reto de enseñar a investigar en la formación bibliotecológica
}

\author{
Ruth Helena Vallejo Sierra \\ Consultora independiente, Colombia
}

\section{Resumen}

La investigación formativa es un desafío que deben asumir las escuelas de Bibliotecología y Archivística hoy; la necesidad de producir conocimiento y metodologías propias es urgente para lograr su consolidación como ciencia; esto requiere una visión global desde la cultura investigativa hasta las didácticas en el aula de clase, pasando por una mirada a la praxis investigativa en los currículos. Todo esto implica llevar a cabo una pedagogía de la investigación que incluya una variedad de técnicas que permitan que la enseñanza de la investigación supere los conocimientos básicos de los cursos de metodología y se refleje en una apropiación del trabajo científico por parte de los estudiantes, llevar acabo procesos sólidos de formación de docentes y estudiantes que logren poner en discusión muchos de los referentes teóricos e instrumentos que se han estado aplicando y dar una nueva dimensión a la investigación para que permee todas los campos de formación profesional. 


\title{
Challenge of teaching about research in \\ LIS professional training Ruth-Helena Vallejo-Sierra
}

\begin{abstract}
Education research is a challenge that the schools of Librarianship and Archives must assume today; the need to produce knowledge and specific methodologies is urgent, which would allow to achieve its consolidation as a science; this requires a global vision from the research culture to the teaching in the classroom, through a look at the research praxis in the curricula. In order to reach this, It is necessary to train in research which includes a variety of techniques that exceed the basic knowledge of methodology courses and it is reflected in the appropriation of scientific work by the students; to carry out solid training processes for teachers and students to bring into question many of the theoretical referents and instruments that have been applied and give a new dimension to research with the purpose of permeate all fields of professional training
\end{abstract}

\section{INTRODUCCIÓN}

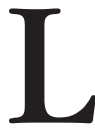

a investigación formativa es un tema complejo de abordar, pues tal como lo describe Parra (2009), esta trasciende su función puramente docente, para convertirse en una estrategia pedagógica de mayor alcance: lograr una formación universitaria basada en el trabajo científico de los estudiantes.

Así mismo, la circulación de conocimiento hoy genera otras formas de pensar, producir y de divulgación; Christensen y Eyring (2011), plantean que hacer ciencia en la sociedad contemporánea implica sumarse a otros circuitos de formación y de participación, incluir nuevas formas de integración, de comunicación, de publicación y de apropiación social del conocimiento que están presionando al propio sistema universitario para su renovación y adecuación a los nuevos ámbitos sociales de producción del saber. 
Todo esto implica reconocer la diversidad de actores, la cultura académica, el currículo y la pedagogía de la misma de la investigación; pero por otra parte, pensarla para una profesión sin mucha tradición, ni métodos propios como la bibliotecología; por ello, a partir de estos enunciados se considera un reto enseñar a investigar en la formación bibliotecológica. Siendo así, en el transcurso del documento se irá abordando desde las políticas institucionales hasta llegar al aula de clase a través de una mirada práctica que permita vislumbrar claramente que el proceso es posible, pero involucra a toda la comunidad académica.

\section{Cultura aCAdémica investigativa}

La visión institucional de sus capacidades investigativas, es el punto de partida para nutrir cualquier propuesta de formación, pues nos permite apreciar cual es la valoración que la universidad hace del tema. Es decir, esta se encuentra en una opción de universidad profesionalizante, está en transición de convertirse en una universidad que hace investigación, o finalmente es una universidad que aprende por que investiga y está dispuesta a aportar a la sociedad en que está inmersa.

Esto necesariamente debe estar asociado a unas preguntas de base... ¿Qué es investigar?, cómo la disciplina se concibe y cuáles son sus métodos propios. Frente a la primera, puede resultar ilustrativa la definición que hace Rico (1996, p. 3):

Investigar es cuestionar y cuestionarse, plantearse interrogantes sustanciales en procesos de ensayo y de error; es la búsqueda del sentido, la articulación de las ideas, el desarrollo de las argumentaciones. También la investigación implica revisar la historia, el pensamiento y los caminos recorridos por otros y otras, relacionarse con las fuentes de información, conocerlas, conquistarlas, perderles el miedo. Investigar es en síntesis, lograr la sistematización de la experiencia, develar misterios y proyectar sueños. Es colonizar una parcela pequeña o grande, sembrar, cultivar, cosechar y distribuir sus frutos, para que luego vengan otros a mejorar, optimizar y superar nuestra faena. 


\section{La investigación bibliotecológica: problemas para...}

Y en la segunda, para el caso de la disciplina Bibliotecológica, la preocupación que Rendón y Martínez (2004) describen de la bibliotecología como ciencia, planteando como posibles razones: la no existencia de un acuerdo unánime sobre su objeto de estudio, la falta de investigación sobre la concepción de ciencia desde la comunidad bibliotecológica, la limitación dentro de los métodos propios de las ciencias duras y la interdisciplinariedad, que reduce la bibliotecología a un enfoque empírico y evidencia el poco trabajo en paradigmas alternativos y la necesidad de una sistematicidad teórica.

Esto implica, que el reto de investigar en Bibliotecología, empieza por entender el qué y para que se va a hacer. Para luego si aplicar las directrices vigentes en cada país, por ejemplo en el caso colombiano, desde la Ley 30 de 1992 de Educación Superior, se le otorga a la universidad la función de generar nuevo conocimiento, a través de la investigación de alto nivel, que debe verse reflejada en los programas de Maestría y Doctorado; y por otra parte la investigación formativa que se espera en los programas de pregrado. Por otro lado, el Consejo Nacional de Acreditación, resalta la cultura investigativa, como variable esencial en el logro de la calidad.

Este panorama conceptual e institucional, nos lleva a dos escenarios complejos: formar en investigación y realizar investigación propiamente dicha; al respecto, Restrepo (2002, p. 106) aclara:

En la sociedad del conocimiento la calidad de la educación superior está íntimamente asociada con la práctica de la investigación, práctica que se manifiesta de dos maneras: enseñar a investigar y hacer investigación. La primera hace alusión al ejercicio de la docencia investigativa, esto es, a utilizar la investigación en la docencia, tanto para darle pertinencia científica a ésta, como para familiarizar a los estudiantes con la lógica de la investigación e iniciarlos en su práctica, es decir para adelantar formación investigativa. La segunda hace alusión a la producción o generación sistemática de conocimiento y a su aplicación para resolver problemas del contexto.

Así, pensar en investigación disciplinar e investigación formativa asociados a la Bibliotecología y Archivística, nos llevan a considera la 
producción científica en el área y al lugar que ha ocupado la investigación en los currículos, y especialmente al recurso humano que se encargará de desarrollar los procesos:

- ¿Cómo se han formado los bibliotecólogos y archivistas que hoy son docentes?

- ¿Qué nivel de formación profesional tienen?

- ¿Tienen formación metodológica y didáctica en este tema?

- ¿Cuentan con producción de conocimiento en el área?

Hasta épocas recientes, el tema de investigación empezó a verse reflejado en los currículos de Bibliotecología y Archivística, aunque en la mayoría de los casos se enfocaba a la enseñanza de la metodología de la investigación, es decir pensada como un espacio académico independiente que en muchos casos hacia parte de la malla complementaria. En este contexto, se formaron la mayor parte de los docentes que hoy son responsables de producir conocimiento, llevar la investigación al aula y formar en investigación.

En este sentido, los posgrados en Colombia siempre han tenido un enfoque profesionalizante, reflejado especialmente en especializaciones (postgrados de un año), y solo en la última década surgen las primeras maestrías, pero adicionalmente no existen doctorados en el área; esto por supuesto implica que un profesor no tiene una amplia oferta para formarse, y que los programas académicos cuenten con muy pocos o ningún profesor en esta categoría y que por supuesto sus competencias investigativas están por desarrollarse.

Esta ausencia de experiencia investigativa, está asociada a que tampoco adquiere conocimiento sobre pedagogía y didáctica de la enseñanza, esto aplica tanto para la instrucción de sus materias técnicas o si debe impartir espacios académicos de la línea investigativa; de igual manera, puede asumir la investigación como responsabilidad de los profesores de esa área, sin cuestionarse que este es un tema transversal en el currículo.

Todas estas problemáticas asociadas a los resultados de sus investigaciones, directamente inciden en la creación de conocimiento en Bibliotecología y Archivística para resolver las problemáticas de su 


\section{La investigación bibliotecológica: problemas para...}

realidad y por otra parte limita la aplicación de sus conocimientos en el aula de clase para superar la lógica de dictar clases.

Estas reflexiones que se han venido presentando, se han enfocado a revisar el hacer de la investigación y el rol que juega el docente-bibliotecólogo, dejando entrever el papel protagónico que asume en este proceso y dónde es claro que debe empezar por su propia formación y su desempeño, para enfrentar el desafío de hacer y enseñar a investigar.

\section{EL ENFOQUE DE LA INVESTIGACIÓN EN EL CURRÍCULO}

El enfoque de operacionalización con que se ha plasmado la investigación en las universidades, está dada por líneas y grupos, e indica que los programas deben apostar por la generación de conocimiento resultado de la investigación formativa y profesional; y con ello, impactar la calidad de la docencia, contribuir al avance científico y supone la complejidad de crear hábitos investigativos, y familiarizar a los estudiantes con la lógica de la investigación científica, para lograr obtener un título profesional.

Todo este entramado, indica que los programas organicen la administración de su investigación y que se vean obligados a trazarse objetivos entorno a ello:

- Construir una cultura investigativa en el programa, tanto a nivel científico-profesional y formativo, para incentivar la calidad académica y la innovación.

- Generar las condiciones académicas para implementar la política investigativa en los programas de acuerdo con los lineamientos de la Universidad.

- Fomentar la investigación interinstitucional para resolver las problemáticas de la disciplina.

- Hacer parte de redes de investigación temática desde varias expectativas disciplinarias e interdisciplinarias y desde diversas modalidades de investigación. 
- Incentivar el desarrollo de habilidades y competencias investigativas en los estudiantes que permitan conformar semilleros de investigación.

- Desarrollar procesos que incentiven y formen a los docentes tanto en sus competencias propias de investigación como en la enseñanza de la misma.

A partir de esta cultura investigativa, los programas de Bibliotecología y Archivística deben repensar sus modelos de enseñanza de la investigación y a algunos a dar inició a la investigación propiamente dicha y donde se conciba la investigación como un eje transversal del currículo, adicionalmente convendrá incluir espacios académicos sobre el tema y la investigación deberá abrirse un espacio en las modalidades de grado; esto hará que se entienda que la formación en investigación es mucho más que enseñar metodología de la investigación y que además no es solo una responsabilidad de los espacios académicos de la praxis investigativa.

Esto involucra que se deban implementar: la praxis investigativa en la malla curricular, se conformen los semilleros de investigación y se conciba la investigación-innovación vinculando a los estudiantes a este tipo de proyectos.

En este sentido, es muy complejo determinar cuándo es el momento adecuado y a través de que estrategias se va a lograr el objetivo planteado. En el primer caso, generalmente los estudiantes se acercan al tema en los últimos semestres porque deben iniciar sus trabajos de grado, como requisito para graduarse; o puede ocurrir que sea una cuestión que se aborda desde los primeros semestres y si el tema hizo parte de una línea de praxis investigativa o de todos los espacios académicos.

En la primera parte, la inclusión del eje de investigación en el plan de estudios se debe expresar bajo la estrategia didáctica que se aprende a investigar investigando y se debe implementar bajo espacios académicos teórico-prácticos, con el propósito de desarrollar aptitudes investigativas en el manejo de metodologías, técnicas e instrumentos para generar conocimiento, a partir de la identificación de problemáticas del campo que hayan logrado descubrir a través de la malla curricular y que se convierten en las preguntas de investigación que 


\section{La investigación bibliotecológica: problemas para...}

el estudiante a través de los espacios académicos deberá aprender a plantear dentro de una estructura metodológica y la aplicación de estos a un proyecto de investigación específica.

Esto implica una visión diferente, es decir en todos los espacios académicos deben plantearse interrogantes, los estudiantes deben verse conducidos a preguntarse y a argumentar. Esta capacidad irá abriendo el camino para que los espacios propios de la investigación, vayan aportado a la construcción de la propuesta de modalidad de grado.

Todo esto conlleva, a que como mínimo el estudiante se relacione con los fundamentos de la investigación: para comprender los conceptos básicos y entiendan, e interpreten las teorías científicas y los paradigmas de investigación; así como los elementos que fundamentan la construcción de conocimiento y adquiera los conocimientos para diseñar y formular una propuesta de investigación.

Posteriormente, surgen las modalidades de grado, mecanismo a través del cual el estudiante puede obtener su título profesional, con el objetivo de consolidar las diferentes competencias desarrolladas a los largo del programa: planteamiento de un problema de investigación o problema a resolver, fundamentación teórica con un enfoque metodológico y una propuesta de resolución a un problema.

Adicionalmente, en el engranaje de la investigación se deben privilegiar espacios extracurriculares con asesorías y tutorías y redes de investigación de estudiantes sobre problemáticas específicas planteadas desde la línea de investigación o producto de la profundización de los proyectos resultantes de su praxis investigativa que puede llevar a la creación de los semilleros. Así, a través de las competencias adquiridas, se vinculan estudiantes con el acompañamiento docente a las investigaciones que llevan a cabo los profesores investigadores y que favorecen propuestas de grado como: la monografía, la investigación-innovación y/o la producción académica.

\section{INVESTIGACIÓN FORMATIVA}

La investigación formativa, debe entenderse desde la necesidad de enseñar el proceso científico y la preparación para la práctica 
investigativa; es en esta perspectiva que lo plantea el Consejo Nacional de Acreditación (1998), cuando considera que la investigación formativa es formar en y para la investigación, con la intención de familiarizar con la investigación, con su naturaleza como búsqueda, con sus fases y funcionamiento.

Para Parra (2009), la investigación formativa, considerada como una estrategia pedagógica para el desarrollo del currículo, integra tres elementos: técnicas didácticas, estilo docente y finalidad específica de formación.

En el primer caso, la investigación formativa aporta elementos didácticos fundamentales para desarrollar un aprendizaje autónomo y significativo. La contextualización de los problemas de investigación, la selección de las metodologías apropiadas para el objeto de estudio, la construcción de un discurso coherente de los hallazgos, son algunas muestras de este tipo de aprendizaje.

Esto hace pensar en las múltiples posibilidades didácticas que esto plantea, algunos autores como Restrepo (2004), mencionan la enseñanza problemica y el aprendizaje basado en la solución de problemas (ABP); además de otras formas de implementación de la investigación formativa:

- Trabajo de grado: es una tarea urgente de abordar en las instituciones, comprender y exigir la profundidad y alcance del trabajo investigativo de acuerdo con el nivel de formación, entiendo que este es un espacio donde se debe realizar un ejercicio académico que permita al estudiante adquirir competencias básicas en investigación, de acuerdo con la enseñanza que ha recibido, y que dado su nivel de pregrado, se espera una comprensión del proceso y de su importancia. Pero también es indispensable, tomar en cuenta la función trascendental que cumple tanto el asesor en el área disciplinar como metodológica, en el sentido de la retroalimentación permanente; ya que la lectura cuidadosa permite hacer un acompañamiento real al estudiante, toda vez que si el docente no lee, no revisa y no conoce realmente la propuesta que plantea el estudiante, puede surgir una desmotivación y no lograr que comprendan las características del trabajo científico. 


\section{La investigación bibliotecológica: problemas para...}

- Ensayo teórico: planteado con todas las características argumentativas y empleado en diversos espacios académicos, puede servir de base para adquirir las competencias necesarias para la construcción de marcos teóricos, o análisis descriptivos y conclusiones que facilita que el estudiante de bibliotecología y archivística vaya haciendo disertaciones sobre su quehacer profesional.

- Vinculación de estudiantes a proyectos de investigación de los docentes: esto implica que los docentes lleven investigaciones con todo el rigor científico, que permitan la participación de los estudiantes en el proceso; sin embargo es necesario tener cuidado en la organización del tiempo y las actividades de manera que no se afecten los resultados esperados de uno y otro.

- Portafolio Investigativo: los estudiantes pueden ir construyendo poco a poco su trabajo investigativo, avanzando con su plan de estudios, de manera que vayan haciendo entrega parciales de la definición del problema, el planteamiento metodológico (tal vez uno de los temas más complejos y difíciles de definir por parte de los estudiantes), la recolección de información etc.

- Preseminario investigativo o talleres que respondan a las necesidad básicas que tienen los estudiantes, entre ellos: cómo formular problemas en el campo de la bibliotecología y la archivística, que se amplíen a temas más allá de lo técnico; cómo y cuándo resulta conveniente utilizar métodos cualitativos o cuantitativos; cómo analizar datos productos de estos métodos con criterio y rigor entre otros.

- Club de revistas: aunque esta técnica prepara al estudiante para ser riguroso en la revisión de literatura o documentación de un tema de investigación, se esperaría que los bibliotecólogos con su experticia no tuvieran que realizarlo, sin embargo dada la importancia del tema no sobra fortalecerla.

- Investigación formativa asociada a la proyección social: el trabajo con comunidades es una experiencia muy enriquecedora para la formación de cualquier profesional; para el bibliotecólogo es una oportunidad de diagnosticar las necesidades de información, de conocer el estado de las bibliotecas públicas o comunitarias etc. 
- Laboratorio de investigación: a partir del planteamiento de los problemas que surgen en las bibliotecas y los archivos, es posible ir planteando respuestas a partir del método científico.

- Los ejercicios de diseño de anteproyectos de investigación, sobre temas puntuales de una asignatura: el éxito de la técnica radica en la habilidad para formular problemas teóricos o prácticos de la bibliotecología y archivística y que esto haga parte de una proyecto generalizado del programa académico.

La segunda estrategia es el estilo docente, haciendo referencia al papel que desempeñará el docente como acompañante responsable del proceso y el rol que jugará el estudiante: receptor del conocimiento que expone su docente o protagonista del mismo, al buscar sus propias preguntas, problemas y respuestas.

El profesor debe buscar las herramientas y métodos que motiven al estudiante a indagar a preguntarse, a cuestionar lo que aprende y lo que practica; esto puede no resultar muy fácil toda vez que la investigación generalmente es vista como un espacio académico, o en el caso de los trabajos de grado como un impedimento para lograr el objetivo de finalizar su etapa académica; llevando incluso a que su tiempo de graduación supere los tiempos previstos de la universidad, y desafortunadamente tanto la formación investigativa, como la modalidad de grado se convierten en un contrariedad para el futuro profesional, pues como lo afirma Vallejo (2014), los estudiantes lo consideran un aspecto del proceso universitario que no han influido en el desarrollo de la identidad profesional como bibliotecólogo, ni es una experiencia significativa en el proceso de adquirirla.

Estas percepciones de los estudiantes, pueden estar asociadas al alcance que se le otorga en las universidades a este proceso formativo, es decir la exigencia que empieza a hacer de trabajos de grado, no como un inicio al proceso de investigación, sino con la exigencia de competencias investigativas de alto nivel a estudiantes de pregrado. Pero también a que los docentes no han logrado incentivar a los estudiantes, para que esto sea visto como una habilidad y destreza indispensable para su desempeño profesional. 


\section{La investigación bibliotecológica: problemas para...}

Esto enfrenta al docente a la necesidad de ser innovadores, de estar preparados para el desafío, de buscar nuevas maneras de entender el proceso investigativo, como la única forma de lograr que los estudiantes realmente logren el objetivo de la praxis investigativa.

Izquierdo (2010), hace una propuesta sobre las actividades de aprendizaje que debe llevar el docente en la formación investigativa:

- Actividades de inicio: para sensibilización y motivación sobre el tema de la investigación.

- Actividades de desarrollo: familiarización con los aspectos clave del trabajo científico (planteamiento de problemas, definición de objetivos, formulación y fundamentación de hipótesis, construcción de marcos teóricos, recogida de datos, análisis e interpretación de resultados, formulación de conclusiones, etc.).

- Actividades de síntesis: desarrollo de la competencia dialógica y argumentativa así como de estrategias de meta-aprendizaje.

- Actividades de reflexión sobre los aprendizajes adquiridos: logros y retos.

Por supuesto no son las únicas, el problema del papel de docente en la enseñanza de la investigación ha sido objeto de investigación desde muchas áreas del conocimiento, incluso desde la bibliotecología y la archivística misma.

Ahora bien, frente al objetivo de la formación investigativa, resulta innegable la necesidad de que los estudiantes de bibliotecología y archivística logren una formación universitaria basada en el trabajo científico:

- El estudiante podrá tener una visión más amplia de los problemas y sus posibles soluciones.

- El espíritu investigativo lo llevará a que indague y se realice preguntas más allá de lo que aprende en un aula.

- Lo hará entender que la investigación es transversal a toda la formación teórica, y que es la manera de encontrar nuevas respuestas, nuevas formas de hacer las cosas. 
- A comprender que si no se logra motivarlos a la investigación en todo su proceso formativo, no es posible lograr la formación integral del estudiante de bibliotecología y archivística.

A tener claridad de que la investigación contribuye a crear espíritu crítico de los estudiantes y a desarrollar procesos sistemáticamente.

\section{REFLEXIÓN FINAL}

Enseñar a investigar en la profesión bibliotecológica, es un gran reto para todos, porque más allá de un trabajo docente para un espacio académico determinado, es una estrategia pedagógica que trasciende todo el proceso de enseñanza aprendizaje.

Por otra parte, no es posible determinar que hay un solo modelo o método que garantice el éxito de la investigación formativa, es una mezcla de motivación, de compromiso, de didácticas adecuadas, de apuestas de los docentes y los estudiantes; de compromisos asumidos desde los programas mismos.

\section{BIBLIOGRAFÍA}

Consejo Nacional de Acreditación (1998). La evaluación externa en el contexto de la acreditación en Colombia. Santafé de Bogotá: Corcas.

Christensen, C. M., \& Eyring, H. (2011). The Innovative University: Changing the DNA of Higher Education from the Inside Out. USA: Jossey-Bass Higher and Adult Education Series. 
Izquierdo Alonso, M.; Izquierdo Alonso, A.M. (2010). "Enseñar a investigar: una propuesta didáctica colaborativa desde la investigación-acción." Documentación de las Ciencias de la Información. (33), 107-123. Recuperado de http://www.eduonline.ua.es/jornadas2009/ comunicaciones/6c3.pdf

Parra, Ciro. (2009). "Apuntes sobre la investigación formativa." Educación y Educadores, 7. Recuperado el 24 de febrero de 2015, http://educacionyeducadores.unisabana.edu.co/index.php/eye/article/view/549/642

Rendón Rojas, M.A. y Martínez Rider, R.M. (2004). "Algunas propuestas latinoamericanas de objetos de estudio para la investigación bibliotecológica." Revista Interamericana de Bibliotecología, 27, 1.

Restrepo, B. (2004). Hacia el maestro investigador: cambio de modelo en la formación de formadores. Recuperado el 20 de febrero de 2015, de http://redepja.ajusco. upn. $\mathrm{mx} / \mathrm{docs} /$ RedKipus/Conferencias/bernardorestrepo. pdf

___ (2009). "Investigación de aula, formas y actores." Revista Educación y Pedagogía, 21 (53), 103-112.

Restrepo, F. (2002). Conceptos y aplicaciones de la investigación formativa, y criterios para evaluar la investigación científica en sentido estricto.Bogotá: CNA. 
Rico de Alonso, Ana (1996). "Investigación en la universidad colombiana: contexto y estrategias." Nómadas, (5). Recuperado el 10 de febrero de 2015, de http://www. redalyc.org/pdf/1051/105118998016.pdf

Vallejo Sierra, Ruth Helena (2014). La Bibliotecología como profesión en Colombia. (Tesis para optar al título de doctora en documentación). Universidad de Salamanca, España. 


\title{
La evaluación de la investigación bibliotecológica
}

\author{
JORGE GÓMEZ BRISEÑO \\ Dirección General de \\ Bibliotecas, UNAM
}

\section{Resumen}

El propósito del presente trabajo es tratar sobre la calidad de la investigación y las metodologías que se han empleado para su evaluación, encontrándose que el enfoque se ha centrado en el uso de indicadores bibliométricos. Así mismo, se trata el por qué hoy en día, es importante aplicar una metodología distinta a la cuantitativa, para lo cual se describen dos esquemas de indicadores que se orientan a la evaluación cualitativa, con lo cual, se pueden realizar evaluaciones formativas.

\section{The research assessment in Library and Information Science Jorge Gomez-Briseño}

\section{Abstract}

The purpose of this paper is to discuss the quality of research and methodologies that have been used for their evaluation, finding that the approach has focused on the use of bibliometric indicators. Likewise , this is why today it is important to apply a different methodology to the quantitative, for which two schemes of indicators that focus on the qualitative assessment are described, which formative assessments can be performed. 


\section{La investigación bibliotecológica: problemas para...}

\section{INTRODUCCIÓN}

$\mathbf{R}$ evisando la literatura, se encontró que son pocos los estudios que tratan sobre la evaluación de la investigación bibliotecosi se ha tratado ampliamente es sobre la medición de la calidad de la investigación aplicando indicadores bibliométricos, es decir, el método cuantitativo.

Sin embargo, la revisión de la calidad de la investigación bibliotecológica aplicando un sistema de indicadores para su evaluación, diferentes a los que se plantean en el esquema bibliométrico está tomando otras dimensiones, pero además mayor relevancia, principalmente por los recortes presupuestales que se están dando en la educación en todos los niveles.

Dichos recortes presupuestales están obligando a las instituciones universitarias a usar de manera más eficiente el presupuesto que se les asigna, para lo cual están sometiendo los procesos académicos a evaluación, y hoy en día, las actividades de la investigación no son la excepción, motivo por el cual se pretende evaluar su calidad a través de la revisión por pares evaluadores, para lo cual requieren de apoyarse en modelos de indicadores cualitativos y cuantitativos.

Lo anterior se debe a que, además de conocer la calidad de la investigación, la evaluación permitirá a las instituciones universitarias contar con información sobre los costos que se invierten en ella, promocionar su excelencia (Bertocchi, Gambardella, Jappelli y Nappi 2015, p. 451) al mismo tiempo que conocer su pertinencia en la sociedad.

A lo anterior, se puede agregar que al igual que los procesos de la enseñanza superior bibliotecológica son sometidos a la evaluación por pares externos para conocer su nivel de calidad, también es importante evaluar la calidad de la investigación bibliotecológica aplicando indicadores cualitativos y cuantitativos (Peña 2011, p. 277) con el propósito de que se permita conocer el estado de calidad en el que ésta se encuentra, así como su pertinencia y el impacto que tiene en el desarrollo económico, político y social de un país, y por supuesto, en el desarrollo de la disciplina bibliotecológica (Obaseky, Ibrahim y Momoh 2010, p. 1-3). 
Por lo anterior, hoy en día, se requiere contar con un modelo de sistema de indicadores para evaluar la investigación bibliotecológica que consideren no solo a la parte cuantitativa, también es importante evaluar el aspecto cualitativo, para que se refleje de manera objetiva la calidad de cada uno de los componentes que conforman al desarrollo de la investigación, a saber: los insumos (recursos humanos y materiales); el proceso de la investigación (aspectos de contenido), y los resultados (pertinencia de la investigación bibliotecológica).

En este sentido, el objetivo del presente trabajo es analizar lo referente a la evaluación de la calidad de la investigación bibliotecológica, así como a revisar si existen modelos de indicadores cualitativos para su evaluación.

\section{LA CALIDAD DE LA INVESTIGACIÓN CIENTÍFICA}

Antes de tratar sobre la evaluación de la investigación bibliotecológica, se considera oportuno mencionar de manera breve lo que implica la calidad de la investigación. En este sentido, es interesante manifestar que diversos autores señalan que el concepto de calidad se aplica a distintos ámbitos de nuestra vida social, pero hoy lo asociamos con más frecuencia a todo aquello que tiene que ver con bienes o servicios de uso común y que regularmente adquirimos a través del comercio y los servicios o de la interacción entre gobernantes y gobernados.

Por su parte, Westerheijden (1999, p. 446) señala que la calidad es una evidencia compartida de la educación superior, al mismo tiempo que para él, es un concepto esencialmente subjetivo por lo que la medición de la calidad no puede existir. Sin embargo, establece que es posible medir la calidad aplicando un esquema de indicadores, es decir, el autor, aun cuando considera a la calidad como algo subjetivo, acepta que los indicadores son instrumentos que pueden aplicarse a una realidad para conocer variables teóricas desconocidas, es decir, el estado en que ésta se encuentra y que puede ser en un alto nivel o en un bajo nivel de calidad. 


\section{La investigación bibliotecológica: problemas para...}

En el caso de la calidad de la investigación bibliotecológica, Clyde (2006, p. 181) menciona que ésta puede ser factible siempre y cuando se demuestre a través de la evidencia basada en la práctica.

Lo anterior puede entenderse en el sentido de que el autor está de acuerdo en que si existen evidencias de la calidad de la investigación basadas en la práctica, se puede hablar de calidad y en caso de que ésta no se demuestre con dichas evidencias resulta difícil entender esto último.

En este sentido, coincido con el autor, ya que para hablar de la calidad de la investigación bibliotecológica, se requiere contar con evidencias claras de que el producto intelectual de los investigadores cumple con los siguientes puntos:

a. Que los artículos sean originales

b. Que los artículos no sean fraudulentos

c. Que los artículos sean publicados en revistas reconocidas en los ámbitos nacional e internacional (Clayde 2006, p. 186)

Si bien Clyde lo menciona, también opino que hay otros elementos que pueden ser considerados para determinar si los productos de los investigadores son de calidad y que más adelante se analizará sobre ello.

Por otra parte, es interesante mencionar lo que Clyde se pregunta con relación a lo siguiente "¿A qué se le puede llamar calidad? ¿Cuándo encontramos la calidad? ¿cómo puede medirse?” (2006, p. 186).

A dichas preguntas, Clyde (2006, p. 186) encontró cuatro respuestas que se acercan a lo que se puede considerar como calidad de la investigación, las cuales son:

1. La calidad como un bien último:

En este caso, Clyde menciona los argumentos de Platón sobre la calidad, quien la consideraba como una belleza absoluta y un bien absoluto. En este caso, se observa que Clyde no está de acuerdo con lo absoluto porque este término puede verse con suspicacia, incluso, ni en la disciplina bibliotecológica puede ser aceptado como tal. En este sentido, estoy de acuerdo con el autor con respecto a que el término absoluto no puede ser aceptado como tal, debido a que un 
producto de un investigador puede ser de calidad para unos usuarios, mientras que para otros no, por lo que entonces no se puede hablar de una calidad absoluta, sin embargo, si puede hablarse, por ejemplo, de una mejoría de un bien o de una investigación.

2. La calidad como un valor relativo:

Analizando lo que el autor menciona con relación al valor relativo de la calidad, desde mi perspectiva, considero que se refiere específicamente al análisis de citas, pues establece que la evaluación se puede realizar a partir de que se localizan las obras de los autores citados en ponencias o en libros, por lo que, el promedio de valor que se les asigne, puede ser alto o incluso bajo, debido a que no se evalúa un artículo como un todo, es decir, solo una parte al tomarse en cuenta solo la cita bibliográfica.

3. La calidad como un constructo social o cultural:

Con relación a este punto, Clyde señala que la calidad puede tener diferentes significados en diferentes contextos, culturas y países, y por tanto, para diferentes poblaciones.

En este caso, coincido con el autor, ya que en efecto, cuando el concepto de calidad se usa en contextos específicos y especializados, como es el caso de la industria, el comercio o las organizaciones que prestan servicios, etc., el término adquiere un significado más técnico, y obviamente se refiere a la producción de bienes y servicios que tienen especificaciones para su elaboración, entonces, el término se aplica para hablar de las características de algún producto o servicio, lo que permite realizar comparaciones entre productos similares (Vázquez 2004, p. 53-66), es decir, se puede medir su calidad para elegir el que más beneficios le aporte al usuario. En otras palabras, la investigación se puede desarrollar en contextos educativos, culturales, industriales, comerciales, ambientales, entre otros, por lo tanto, se hablará de diferentes significados de la calidad de la investigación.

4. La calidad basada sobre la evaluación referenciada en criterios:

De acuerdo con Clyde, la calidad de la investigación se puede determinar con base en la aplicación de criterios establecidos, aspecto con lo cual coincido, ya que en efecto, el aplicar un sistema de indicadores en el cual se contemplan diversas variables al evaluar 


\section{La investigación bibliotecológica: problemas para...}

un objeto determinado, en este caso la investigación bibliotecológica, se obtiene información objetiva y confiable, lo que permite establecer mejores juicios para determinar su nivel de calidad, cuando se observa que se cubren los requisitos establecidos en un instrumento de evaluación.

Otro concepto que coincide con lo anterior se refiere a que si bien, no existe una definición universal sobre qué es la calidad, si se pueden establecer algunos enfoques (Silva 2006, p. 19) entre los cuales se encuentra el sistémico, dentro del cual se toma en cuenta al sistema en su conjunto, es decir, se ubica en un entorno más amplio y algunos de sus elementos pueden ser transformados en insumos y necesidades que se pueden mejorar y satisfacer de acuerdo con la evaluación realizada a dichos insumos (Silva 2006, p. 19).

Con base en lo anterior, se puede mencionar que resulta interesante observar cómo los estudiosos establecen diferentes puntos de vista sobre la calidad, misma que también puede ser aplicada a la calidad de la investigación, dentro de la cual se incluye a la investigación bibliotecológica. En este sentido y de acuerdo con Silva (2006, p. 19), dicha calidad se puede enmarcar dentro del enfoque sistémico, para lo cual se deben considerar las dimensiones particulares de ésta, las cuales son: La primera dimensión se refiere a la relevancia, dentro de la cual se tiene que observar en qué medida, en este caso la investigación bibliotecológica cumple con las expectativas de los diversos sectores de la sociedad.

La segunda de las dimensiones es la eficacia, es decir, todo proyecto o programa de investigación debe cumplir en tiempo, lugar, cantidad y calidad sus metas y objetivos. En este sentido, se puede mencionar que todo proyecto de investigación bibliotecológica que forme parte de un programa, debe ser finalizado en tiempo y forma para que la institución educativa en la que se llevan a cabo dichos procesos cumpla con sus objetivos y alcance sus metas.

La tercera dimensión es la relacionada con la eficiencia, misma que se refiere a la relación obtenida entre los resultados de la investigación y los recursos dedicados a la misma. En otras palabras, si los resultados de un programa de investigación se cumplen optimizando 
la generación de los productos intelectuales de los investigadores, además de ponerlos a disposición de la sociedad en el menor tiempo posible, así como los recursos económicos y materiales invertidos los objetivos y las metas de la institución educativa o de investigación se cumplirán de manera eficiente.

Otra dimensión es la que puede aplicarse a la equidad. En este caso y aun cuando Silva (2006, p. 19) orienta esta dimensión a la calidad de los programas educativos, desde un punto de vista particular se considera que no es limitativa a éstos, es decir, esta dimensión también es aplicable al libre acceso a los productos intelectuales producidos por los investigadores, en otras palabras, todo individuo que desee revisar cualquier recurso documental producto de la investigación bibliotecológica se le debe proveer el acceso a dichos recursos sin importar raza, nacionalidad, clase social y personas con capacidades diferentes.

Por su parte, Westerheijden señala que la calidad de la investigación va más allá de su relevancia y se enfoca en otro concepto que implica a la calidad social. Para el autor, este concepto significa la investigación orientada a la innovación, es decir, desarrollar temas que contribuyen a su relevancia social y la define como "la extensión en la cual se espera que la investigación contribuya al desarrollo social, por tanto, debe ser un conocimiento social de alto impacto, además de que considera que sus metas deben ser importantes para la sociedad en su conjunto, o bien, para un sector social específico" (1999, p. 449-450).

Por otro lado, con el propósito de conocer algunos aspectos que permitan identificar los indicadores de la calidad de la investigación, Westerheijden (1999, p. 450) establece cinco puntos que los proyectos y programas de investigación deben cumplir para reflejar la calidad social, estos son:

1. Expectativas razonables de relevancia: Visión de las expectativas que pueden esperarse de la investigación, de acuerdo con el avance social.

2. Alcance y urgencia de las demandas sociales: Políticas gubernamentales sobre las tendencias de la ciencia para [fortalecer] las disciplinas para las cuales, la demanda social es evidente [y estimular 


\section{La investigación bibliotecológica: problemas para...}

aquellas en las que se tiene que realizar un trabajo más sólido de investigación].

3. Interacción y comunicación: Interacción entre investigadores disciplinarios e interdisciplinarios, con actividades y metas claras para los proyectos de investigación con los cuales, los actores [investigadores] transferirán conocimiento nuevo, así como innovaciones a la sociedad.

4. Uso e impacto de los resultados de la investigación: Amplitud de su relevancia en los grados académicos superiores [postgrado], para generar nuevo conocimiento.

5. Métodos con mecanismos para su aplicación: En algunas áreas del conocimiento, el alcance de las políticas de la investigación deben estimular el desarrollo de métodos específicos y claros para mejorar las probabilidades de aplicación, por ejemplo: diseño de métodos y transparencia de los métodos de investigación para los usuarios.

Analizando lo que Westerheijden establece sobre la definición de la calidad de la investigación y los puntos que plantea en términos de su relevancia social, considero que en efecto, el autor tiene razón al señalar que, si la investigación impacta en la generación de nuevos conocimientos y en los diversos sectores sociales, tales como en el desarrollo económico, en la industria, en el tecnológico, en el educativo, en las políticas públicas y en la sociedad, entonces se puede hablar de su calidad, pero si una investigación no tiene repercusión en los ámbitos mencionados, simplemente se puede visualizar como un documento publicado, pero no como una investigación de alto impacto.

De acuerdo con lo anterior, se logra observar que hay autores que aún no están plenamente de acuerdo con el concepto de la calidad de la investigación, sin embargo, lo aceptan con una visión pragmática en donde según, la calidad es definida en función de una serie de indicadores y criterios que reflejan la opinión de los "distintos grupos de interés dentro y fuera de la universidad, [y] el tomar en cuenta estos criterios puede [ayudar] a obtener una solución práctica de un problema filosófico complejo" (Muro y otros 2003, p. 2-3) que permitirá conocer su estado real. 
Con base en lo anterior, en el siguiente apartado se tratara sobre la evaluación de la investigación bibliotecológica.

\section{LA EVALUACIÓN DE LA INVESTIGACIÓN BIBLIOTECOLÓGICA}

Revisando la literatura no se logró encontrar una definición concreta sobre la evaluación de la investigación bibliotecológica, incluso, algunos estudiosos mencionan que son pocos los acuerdos a los que se ha llegado sobre lo que significa la calidad de la investigación y como puede ser medible. No obstante lo anterior, cabe mencionar que existe una gran cantidad de información sobre la evaluación de la investigación desde la perspectiva cuantitativa a través de la bibliometría y poco sobre la evaluación cualitativa.

Aun con lo anterior y de acuerdo con Shafique y Mahmood (2010, p. 3), Powell (2006, p. [102]) y Huang (2011, p. 1), mientras que algunos autores mencionan que la evaluación de la investigación se puede visualizar como un proceso metodológico y es llevado a cabo en contextos políticos y organizacionales, para lo cual se requiere un equipo de trabajo con habilidades para aplicar criterios (Clyde 2006, p. 181) que permitan obtener de manera sistematizada información y evidencias confiables para determinar su calidad social, otros la visualizan como una técnica, y otros más establecen que la investigación es una actividad que emplea métodos y criterios para propósitos de evaluación (Powell 2006, p. [103]), que ayudarán a identificar sus fortalezas y debilidades y se estará en posibilidades de mejorarla.

Por su parte, McMeeking, Basile y Cobb citando a Weiss (1998), mencionan que la evaluación de la investigación se está "incrementando no solo para dar respuesta a la pregunta ¿qué es un programa de trabajo?, también [se pretende que dé respuesta a otras preguntas, tales como] ¿qué se hace en ese trabajo? ¿Por qué es exitoso o no es exitoso? ¿De qué manera se puede hacer mejor?” (2012, p. 509).

Analizando lo anterior, se observa que es interesante lo que mencionan los autores, ya que ciertamente para llevar a cabo un proceso de evaluación, antes es importante tener claro cuál es el propósito de evaluar, que objeto se evaluará y por qué hay que hacerlo. 


\section{La investigación bibliotecológica: problemas para...}

En este contexto y de acuerdo con Abramo y D’Angelo (2014, p. 1131) y Wu (2015, p. 52), se puede mencionar que el objeto que se evalúa en las actividades de la investigación son los siguientes elementos que se dividen en cuatro categorías, a saber:

1. Insumos. Se refiere a los recursos humanos (investigadores), así como a los recursos tangibles, por ejemplo, los instrumentos científicos empleados, los recursos materiales, el uso de la biblioteca, los laboratorios, entre otros, y los recursos intangibles que se refieren al conocimiento acumulado (literatura existente sobre una área del conocimiento disciplinario), a los recursos económicos que se destinan a las actividades de la investigación y a las redes sociales, que se puede interpretar como a la creación de redes de investigadores.

2. Resultados. En este caso, los resultados de la investigación se pueden entender como la generación de nuevos conocimientos que se plasman en las publicaciones impresas o electrónicas (libros y artículos), en patentes, en trabajos que se presentan en eventos académicos, en bases de datos. Incluso, en este caso, se puede hablar de la productividad por investigador y si realmente sus publicaciones tienen un mérito académico y social, es decir, contribuyen a la enseñanza de la disciplina, así como al desarrollo económico y social.

3. Uso de la investigación. Esta categoría se orienta al factor de impacto, en otras palabras, el análisis de citas, por lo que específicamente se refiere al uso de indicadores cuantitativos.

4. Impacto de la investigación. Si bien los autores lo enfocan a la evaluación a través de la revisión por pares, desde un punto de vista particular se considera que la visión debería orientarse hacia la pertinencia de la investigación en los ámbitos educativos, económicos, tecnológicos y sociales, es decir, observar si cumple con la calidad social.

Por su parte, Powell (2006, p. [103]) menciona que existen diversos factores por los que se debe evaluar un objeto y si bien los enfoca de manera general a la evaluación de las organizaciones, sus operaciones y recursos, se considera que se pueden aplicar a la evaluación de 
la investigación bibliotecológica, por lo que, con el propósito de identificar dichos elementos, a continuación se describen:

1. Ofrecer una rendición de cuentas claras sobre el financiamiento y distribución del presupuesto asignado para el desarrollo de los programas de investigación.

2. Mostrar a través del programa de investigación, el objeto sobre el que se investiga.

3. Realizar análisis sobre el impacto académico y social que tiene el programa de investigación.

4. Incrementar la eficiencia y eficacia del programa de investigación.

5. Que sirva como argumento a los directores de los programas de investigación para tomar buenas decisiones que apoyen a la mejora del programa de investigación, y;

6. Que la evaluación de la investigación sirva como una herramienta de apoyo para fortalecer el estatus académico y social de la investigación bibliotecológica.

Con base en lo anterior, se puede mencionar que la evaluación de la investigación bibliotecológica, debe reflejar qué los programas de investigación tienen metas y objetivos claros, existe un objeto claro sobre el cual se debe investigar, pero además, reflejar que dicha investigación es pertinente académica y socialmente.

En otras palabras, la evaluación tiene que reflejarse en el avance de la disciplina bibliotecológica, ya que es a través de las actividades de la investigación como se logran construir nuevos conocimientos, además de proveer los fundamentos teóricos (Shafique y Mahmood 2010 , p. 3) disciplinarios, y esto a su vez, debe impactar en la mejora de las unidades de información (denominadas: bibliotecas, centros de información, museos, galerías, archivos, entre otras), así como en los servicios bibliotecarios y de información que ofrecen, y por supuesto, como lo menciona Westerheijden, se desea que impacte en el desarrollo de los diferentes ámbitos sociales, es decir, en la industria, ya que son las empresas las que se benefician por la generación de nuevos conocimientos e innovaciones tecnológicas que se ponen a su disposición en las unidades de información; en la enseñanza, ya que los 


\section{La investigación bibliotecológica: problemas para...}

estudiantes y los profesores son consumidores directos en las aulas de los productos de investigación; en las políticas públicas, ya que son las unidades de información las que ponen a disposición de los tomadores de decisiones, políticos, funcionarios públicos, organismos no lucrativos y lucrativos un gran cúmulo de información para apoyarlos en la solución de problemas complejos.

Como ya se mencionó, debido a que la evaluación de la investigación se lleva a cabo en contextos determinados (Westerheijden 1999, p. 445-447), en los cuales se deben tomar ciertas decisiones, además de servir como una herramienta de apoyo a los administradores de los programas de investigación para una mejor administración y distribución de los recursos financieros que se asignan a la investigación, también puede tener influencia en el reconocimiento académico que se le debe otorgar a los investigadores por sus méritos en esta actividad.

Asimismo, un ejemplo de que la evaluación de la investigación logra ser un argumento sólido para que el financiamiento de esta actividad sea bien administrado y distribuido es en el Reino Unido. Otro ejemplo que se puede mencionar es de los Países Bajos, en donde la calidad de la investigación es evaluada desde 1993, con el propósito de mejorar la investigación que se realiza en las instituciones de educación superior y el proceso de evaluación es coordinado por la Dutch Association of Universities (VSNU) empleando para ello un equipo de evaluadores que se apoya en cuatro indicadores de evaluación (Westerheijden 1999, p. 448).

A lo anterior, se debe agregar que Bertocchi, Gambardella, Jappelli, Nappi y Peracchi (2015, p. 451) señalan que la evaluación de la investigación académica está tomando nuevas tendencias en Europa para promover, además del financiamiento a la investigación por parte de los organismos que la apoyan con la disposición de presupuesto, al incremento de la excelencia y el desempeño académico en términos de costos, tiempo de inversión para la investigación y los recursos empleados.

Por otra parte, es interesante observar que algunos estudiosos en la materia establecen que la evaluación no debe verse como parte de una verdad, es decir, la investigación no puede ser evaluada y visualizada como una parte del todo, más bien tiene que reflejarse como un todo y aun cuando para unos autores la calidad no puede ser medible 
porque es un concepto subjetivo, finalmente se acepta que la evaluación de la investigación es un proceso que debe llevarse a cabo para conocer el estatus de las innovaciones que se van generando en la investigación.

En este contexto, a continuación se tratará sobre las metodologías de evaluación de la investigación existentes.

\section{MÉTodos de EVAluación de la INVESTIGACIÓN}

De acuerdo con Huang (2011, p. 3), existen diferentes métodos de evaluación y es importante tener clara su diferenciación, ya que dependiendo de su orientación y que puede ser la evaluación universitaria, la evaluación académica o de la investigación, se aplicarán diferentes sistemas de indicadores, tal y como se muestra en la Gráfica 1.

\section{Gráfica 1.}

Tipos de evaluación

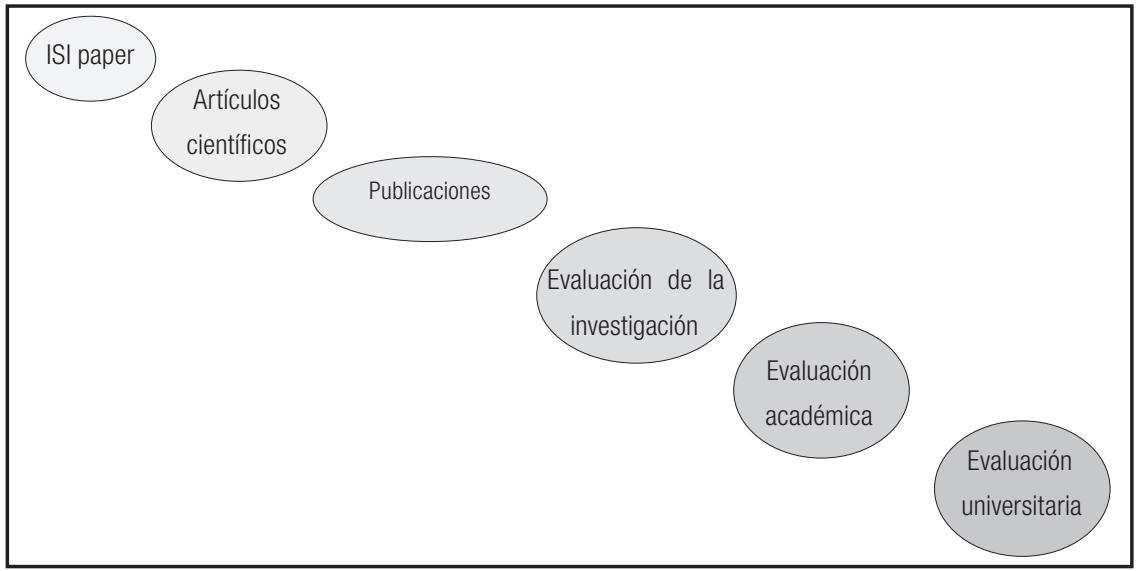

Fuente: Huang, M. (2011) "Comparison of the three major academic rankings for world universities: from a research evaluation perspective" [en línea] Journal of Library and Information Studies [9:1], p. 3 (Consultado el 22 de febrero de 2015). 


\section{La investigación bibliotecológica: problemas para...}

Según el autor, la evaluación universitaria es un proceso amplio e incluye no solo a la investigación, también a los programas educativos, es decir, cubre los procesos administrativos y los procesos de enseñanza. En concreto, en este caso se puede entender como la evaluación de la calidad educativa de un programa de estudios.

En relación con la evaluación académica Mu-Hsuang (2011, p. 2), señala que cubre el aseguramiento de las actividades académicas y sus logros, así como los resultados de las inversiones en la investigación, entre otros aspectos.

Analizando lo anterior, no resulta clara la diferencia entre la evaluación universitaria y la académica, ya que en ésta, se habla de las inversiones en la investigación, aspecto que también puede ser cubierto en la primera.

Sin embargo, si se puede establecer con claridad la evaluación de la investigación, ya que como se mencionó, se enfoca a la evaluación de los productos generados por los investigadores para conocer cuál es su impacto en la enseñanza, en el desarrollo económico, en la industria, en el desarrollo social, incluso en el avance disciplinario.

En este sentido, algunos estudiosos, tales como Mu-Hsuang (2011, p. 3), Bertocchi, Gambardella, Jappelli, Nappi y Peracchi (2015, p. 451, 461), así como Jiménez-Contreras, Robinson-García y CabezasClavijo (2011, p. 506), señalan que para la evaluación de la investigación se aplican dos metodologías; una es a través de la aplicación de indicadores bibliométricos y la otra es mediante la revisión por pares.

Es de mencionarse que, los dos métodos se usan para evaluar la calidad de la investigación y el que se ha aplicado con mayor amplitud es el esquema bibliométrico, sin embargo, diversos autores, tales como Bertocchi, Gambardella, Jappelli, Nappi y Peracchi (2015, p. 453), Bordons y Zulueta (1999, p. 790, 793-797), Camps (2008, p. 76-79) y Wu (2015, p. 53, 75-77), señalan que si bien, la bibliometría se utiliza para evaluar la investigación y según resulta ser un método confiable, también tiene sus limitaciones al emplear únicamente indicadores cuantitativos, tales como:

1. Indicador de actividad científica: Con dicho indicador se mide el número de publicaciones que producen los investigadores de un 
centro, de un instituto de investigación o de un programa de investigación. Dicho indicador se aplica para conocer la producción científica de una disciplina del conocimiento en una determinada institución y de un país en particular.

Cabe señalar que, con la aplicación del indicador de actividad científica no se pueden realizar comparaciones sobre la investigación bibliotecológica entre las instituciones y los países que generan productos sobre la disciplina, debido a que es probable que mientras en un país se tenga un alto porcentaje de autores que publican, en otros no, motivo por el cual solo se obtienen datos cuantitativos sobre el número y distribución de publicaciones por instituciones, sobre la productividad del investigador, en qué revistas publica, coautorías, trabajos colaborativos entre grupos de investigadores.

En concreto y como ya se mencionó, con el indicador sobre la actividad científica no se logran obtener datos cualitativos, ya que aun cuando las publicaciones son los resultados de la investigación, lo que finalmente se mide es la productividad de los autores, lo que implica que dicha medición solo está en torno al aspecto cuantitativo.

2. Indicadores de impacto. De acuerdo con Bordons y Zulueta (1999, p. 794-795), así como Camps (2008, p. 76-78), los indicadores de impacto valoran el impacto de los autores, sus trabajos o revistas, lo cual se mide a través del factor de impacto.

En este sentido, Bharathi (2011, p. 563-564), señala que el factor de impacto se encuentra ligado al número de citas de los artículos publicados en revistas que tienen un alto reconocimiento o estatus. Sin embargo, aun cuando este indicador es ampliamente aceptado para evaluar la investigación científica, existen problemas con dicho indicador.

Al respecto, Bharathi (2011, p. 563-564) y Camps (2008, p. 76), señalan que aun cuando la vida media en que aparece la citación de los artículos es de dos a cuatro años, existe la posibilidad de que durante los años mencionados las citas de algunos autores tarden en aparecer, mientras que en otros casos, ocurre que inmediatamente después de que algún autor publicó un artículo, casi de manera inmediata se localiza un alto número de citas del mismo, lo cual refleja no solo el 


\section{La investigación bibliotecológica: problemas para...}

impacto de los autores, de los artículos o de las revistas, también se manifiesta una discrepancia significativa entre los artículos que rápidamente son altamente citables y la pobreza de aquellos artículos que no lo son.

Así mismo, Clyde señala que se han realizado estudios en donde los resultados obtenidos manifiestan que "los problemas del análisis de citas reflejan que se llega a hacer un mal uso de éstas" (2006, p. 182), por lo que los autores que han realizado dichos estudios, sugieren que el "análisis de citas, se orienta más hacía la capacidad para informar, pero no a determinar los juicios de la calidad de la investigación", es decir, continua enfocándose a la obtención de datos cuantitativos, pero no cualitativos.

A los problemas detectados por los autores mencionados, se puede agregar lo que la Declaración de San Francisco de Evaluación de la Investigación señala con relación a la problemática detectada sobre el factor de impacto.

En la mencionada Declaración, se señala que el "índice de impacto de las revistas se utiliza con frecuencia como parámetro primario con el que comparar la producción científica de las personas y las instituciones [... el cual fue] creado como una herramienta para apoyar al bibliotecario a identificar revistas que comprar, [pero no para medir] la calidad científica de la investigación en un artículo. Por lo anterior, los problemas que se encontraron son:

a. La distribución de citas en revistas está muy sesgada.

b. Las propiedades del índice de impacto son específicas del campo científico considerado: es una combinación de varios tipos de artículos, muy diversos, incluyendo artículos de investigación primaria y opiniones.

c. Los índices de impacto se pueden manipular [o trastear] por la política editorial" (2014, p. [191-192]).

Por la problemática mencionada en la Declaración de San Francis$c o$, a continuación solo se proporciona la recomendación general que consiste en lo siguiente: 
No utilice métricas basadas en revistas, tales como índices de impacto de revistas, como una medida sustitutiva de la calidad de los artículos de investigación individuales, con el fin de evaluar las contribuciones de un científico, o en la contratación, promoción o, en las decisiones de financiación. (2014, p. 192-195)

Asimismo, en la Declaración de San Francisco se emiten diversas recomendaciones, no solo para los bibliotecólogos, también se dirigen a los organismos de financiamiento, a las instituciones académicas, a los editores de las revistas, a las organizaciones que proveen métricas y para los investigadores, a quienes incluso, una de las recomendaciones que se les hace es la de "cambiar las prácticas de evaluación de la investigación que se basan inadecuadamente en los índices de impacto y [que] promueva y enseñe las mejores prácticas que se centran en el valor y la influencia de los resultados específicos de la investigación" (2014, p. 192-195), de tal manera que los datos que se obtengan con la aplicación de los indicadores empleados para tal efecto, reflejen de manera confiable que no existen sesgos o información inadecuada para evaluar la investigación, en este caso la bibliotecológica.

Con relación al método de revisión por pares, Clyde (2006, p. 183184), Huang (2011, p. 3-5), Bertocchi, Gambardella, Jappelli, Nappi y Peracchi (2015, p. 452, 461), así como Wu (2015, p. 57), mencionan que pareciera ser que la mejor vía para evaluar la investigación de cualquier disciplina, incluida por supuesto la bibliotecológica, es a través de dicho método porque a partir de la revisión realizada por un par evaluador experto se puede obtener información confiable y los juicios de valor que emita ayudarán a determinar el nivel de calidad de un artículo. Lo anterior se debe a que se consideran criterios de evaluación, tales como relevancia del artículo, su originalidad e innovación, así como su visibilidad internacionalización.

Sin embargo, de acuerdo con los autores mencionados, el método de revisión por pares también tiene sus problemas, uno de los principales es que no es fácil contar con un Comité de Pares Evaluadores Expertos, que se dediquen de manera continua a la evaluación de los productos generados por los investigadores. 


\section{La investigación bibliotecológica: problemas para...}

Otro problema es que la evaluación de la investigación solo es entendida por un pequeño grupo de expertos, pero según los autores, existe la posibilidad de que en las entrevistas que realizan y revisión de productos de investigación no logren identificar que el impacto de la investigación que se da a través del análisis de citas solo genera datos cuantitativos, mientras que el interés o impacto social de un producto de investigación genera un dato cualitativo, es decir, no visualizan con claridad el aporte que una investigación hace al desarrollo económico y social.

A lo anterior se puede agregar que, exista la posibilidad de que los juicios de valor no sean emitidos de manera equitativa, ya que por ejemplo, Clyde (2006, p. 183) señala que los pares evaluadores expertos, de 12 artículos que revisan, solo aceptan tres y los otros nueve no los admiten porque son de mala calidad.

De acuerdo con lo mencionado por Clyde, se puede mencionar que el número de artículos aceptados como de buena calidad es bajo y la cantidad de artículos que consideran de mala calidad es alta. Al respecto, se puede mencionar que, o realmente los artículos evaluados son de mala calidad o, también es factible que el evaluador no haya tenido una adecuada interpretación del tema. Como quiera que sea, finalmente es otro de los problemas que se presentan en el método de revisión por pares.

Por su parte, Bertocchi, Gambardella, Jappelli, Nappi y Peracchi (2015, p. 452) mencionan que otro problema que se presenta con el método de la revisión por pares, son los conflictos de interés, debido a que se puede beneficiar a los amigos, mientras que a los investigadores que pudieran no ser del agrado del evaluador sus artículos pueden ser mal evaluados, motivo por el cual existe la posibilidad de que no sean incorporados en las revistas de investigación de reconocido prestigio en los ámbitos nacional e internacional.

Aun cuando los estudiosos en la materia han detectado los problemas mencionados, algunos de ellos, como por ejemplo Bertocchi, Gambardella, Jappelli, Nappi y Peracchi (2015, p. 463), sugieren que se mejore la metodología que se aplica a la evaluación de la investigación, para lo cual se debe emplear un sistema de indicadores cualitativos y 
cuantitativos, lo que se puede llevar a cabo a través de la correlación de los estudios bibliométricos y de la revisión por pares.

Si bien los autores mencionados establecen dicha sugerencia, también se debe recordar lo que se establece en las recomendaciones de la Declaración de San Francisco, en las cuales se menciona que para evaluar la calidad de la investigación, ya no se deben considerar el análisis de citas, por lo que a continuación se tratara sobre los modelos que se han creado para evaluar la calidad de la investigación.

Sistemas de INDICADORES PARA LA EVAluaCión DE LA CALIDAD DE LA INVESTIGACIÓN

Según Suarez (2010, p. 76), para evaluar la calidad de la investigación bibliotecológica se ha empleado el método cuantitativo y en algunos casos se han incluidos elementos cualitativos, como por ejemplo la realización de entrevistas con estudiantes y profesores, así como llevar a cabo estudios de observación, que permiten obtener datos confiables y mostrar que efectivamente los investigadores del área bibliotecológica generan productos de calidad.

Aun cuando el autor menciona que ha resultado difícil llevar a cabo el proceso de evaluación de la investigación bibliotecológica aplicando un método distinto al cuantitativo, considera que dicho proceso es importante, aspecto con el cual se coincide, ya que ello permitirá a las autoridades competentes contar con argumentos sólidos para tomar mejores decisiones con relación a la distribución del financiamiento para apoyar a la investigación bibliotecológica.

A lo anterior, debe agregarse que resulta interesante señalar que Suarez (2010, p. 76-77) manifiesta que la evaluación bibliotecológica debe realizarse aplicando el esquema de la evidencia basada en la práctica, en el cual, aun cuando se puede aplicar criterios cuantitativos y más allá de que ha sido el método ampliamente usado para dicha actividad, también es factible incorporar aquellos que son de orden cualitativo. Lo importante en este caso, es que los expertos en la evaluación de la investigación bibliotecológica identifiquen con claridad las evidencias cualitativas. 
Para lograr identificar las mencionadas evidencias cualitativas, de acuerdo con Suarez (2010, p. 77), se debe tomar en cuenta siete criterios, los cuales son:

1. Contar con una política sobre ética de la investigación.

2. Proporcionar a la investigación la importancia que requiere.

3. Analizar si la investigación tiene coherencia y claridad.

4. Observar si la investigación es desarrollada con el método adecuado y riguroso.

5. Analizar si la investigación incorpora una autorreflexión crítica.

6. Vigilar la tendencia de la investigación, y;

7. Establecer la validación de la investigación a través de su análisis, su credibilidad y confiabilidad.

Revisando los criterios establecidos por Doug Suarez, se puede observar como es de su interés que la investigación bibliotecológica se evalúe, no solo desde la perspectiva bibliométrica, ya que de acuerdo con sus razonamientos, se visualiza la pretensión de que se realice una evaluación cualitativa y no únicamente cuantitativa.

Lo anterior se refleja en cada de los criterios, los cuales contienen aspectos cualitativos que los evaluadores deben identificar en el momento de evaluar un producto de investigación, y ello a su vez, les permita estar en posibilidades de validarlos como productos de calidad.

Por otra parte, para ilustrar como los bibliotecólogos pueden llevar a cabo el proceso de evaluación de la investigación desde la perspectiva cualitativa, Suárez (2010, p. 79), citando a Russell y Gregory (2003), menciona un esquema de preguntas que pueden ser consideradas para realizar dicho proceso, las cuales son las siguientes:

Preguntas para apoyar de manera crítica la investigación cualitativa (adaptadas de Russell y Gregory, 2003)

1. ¿Los resultados son validados?

a. ¿La pregunta de la investigación es clara, adecuada y sustancial?

b. ¿El diseño de la pregunta de la investigación es apropiada? 
c. ¿El método usado para el diseño de la muestra es el apropiado para la pregunta de la investigación?

d. ¿Los datos obtenidos son administrados de manera sistemática?

e. ¿Los datos obtenidos son analizados de manera apropiada?

2. ¿Qué resultados se obtienen?

a. Los resultados son descritos de manera rigurosa?

3. ¿Cómo pueden ser aplicados los resultados a la práctica bibliotecaria?

a. ¿Qué significado y relevancia tiene la investigación para la práctica bibliotecaria?

b. ¿La investigación me ayuda a entender el contexto de la práctica bibliotecaria?

c. La investigación me ayuda a aumentar y mejorar mi conocimiento sobre la práctica bibliotecaria?

Reflexionando sobre lo anterior, se puede mencionar que Suarez está estableciendo un instrumento para la evaluación cualitativa de la investigación bibliotecológica porque de acuerdo con Powell (2006, p. 111), los componentes mencionados no reflejan elementos cuantitativos, es decir, lo que se intenta es solucionar un problema cualitativo y no una situación estrictamente sumativa.

Otro esquema que se puede considerar como instrumento para evaluar la calidad de la investigación, es el desarrollado por el Grupo de Trabajo sobre identificación de criterios de calidad en la investigación en Humanidades formado por la Fundación Española para la Ciencia y la Tecnología y la Agencia Nacional de Evaluación y Prospectiva (Criterios de calidad en la investigación en Humanidades, informe, 2007, p. 1-15).

El grupo de trabajo desarrollo los criterios de calidad en la investigación en humanidades, con el propósito de que estos se aplicaran a las disciplinas que forman parte de las humanidades.

Los criterios se encuentran organizados en tres documentos interrelacionados:

En el primer documento se establecen los criterios sobre evaluación del Curriculum Vitae del investigador, en el cual se consideran los siguientes criterios: 
A. Información general del investigador.

B. Actividad investigadora.

b1. Actividades relacionadas con la actividad investigación

b2. Resultados de la investigación

b2.1. Publicaciones

Monografías

Ediciones críticas

Ediciones de documentos y corpus documentales

Traducciones

Capítulos de libros

b2.2. Contribuciones a congresos

b2.3. Bibliografías, catálogos y bases de datos

b3. Interacción con el entorno y transferencia de conocimiento

C. Difusión y divulgación de la investigación y actividades de fomento de la cultura científica.

D. Actividad formativa.

E. Otros méritos.

En el segundo documento, se establecen los Criterios para evaluar proyectos de investigación en Humanidades y son los siguientes:

A. Valoración de los objetivos, metodología y viabilidad del proyecto. a2. Viabilidad, metodología y diseño de la investigación

a3. Plan de difusión y transferencia de conocimiento

B. Valoración del historial científico del investigador(a) principal y del equipo de investigación.

b1. Historial científico del investigador principal

b2. Historial investigador del equipo

b3. Criterios adicionales para la valoración de equipos coordinados. C. Presupuesto.

En el tercer documento se establecen los criterios para el apartado sobre: Categorización de las revistas científicas españolas de Humanidades 
En la categoría $C$, se establecen los requisitos que deben cubrir las revistas en Humanidades, por ejemplo: Antigüedad mínima de publicación, Consejo o Comité Editorial, filiación institucional de la persona que dirige la revista, entre otros aspectos.

Dentro de la categorización de las revistas, en la categoría $B$, se establece la siguiente información que deben cubrir las revistas, a saber: Declaración de periodicidad de la publicación de la revista, aportación de dos resúmenes, uno en el idioma original y otro en una lengua de amplia difusión, así como información sobre los objetivos de los artículos.

Reflexionando sobre los esquemas para la evaluación de la calidad de la investigación, se puede mencionar que aun cuando el adaptado por Suarez es breve, ya que solo incorpora tres categorías de indicadores, los cuales son: 1. ¿Los resultados son validados? 2. ¿Qué resultados se obtienen? y 3. ¿Cómo pueden ser aplicados los resultados a la práctica bibliotecaria?, se puede lograr lo que Suarez pretende, es decir, que la investigación bibliotecológica sea evaluada con una metodología distinta a la bibliometría.

Por otra parte, considerando que diversos estudiosos de la Bibliotecología opinan que ésta forma parte de las Humanidades, los expertos en el tema de evaluación de la investigación bibliotecológica pueden realizar estudios para analizar y buscar la posibilidad de desarrollar un modelo de evaluación cualitativa más completo, con base en los criterios que adapto Suarez y los criterios de calidad en la investigación en Humanidades, ya que incluso, se observa que ambos pueden ser aplicables a las diferentes disciplinas de las humanidades.

\section{Conclusiones}

Hoy en día, se continúa evaluando la investigación a través del uso de indicadores bibliométricos, por lo que no cabe la menor duda que los expertos en esta materia (Jiménez-Contreras, Robinson-García y Cabezas-Clavijo, 2011) dominan los parámetros habituales para medir la productividad científica, básicamente a partir de los aspectos más cuantitativos que cualitativos. 


\section{La investigación bibliotecológica: problemas para...}

Sin embargo, el contar con un marco de indicadores cualitativos que permita evaluar de manera uniforme y sistemática la investigación bibliotecológica ayudara a dar respuestas objetivas a las preguntas que actualmente se hacen con relación a las limitaciones que se generan al evaluar la investigación, no solo a la bibliotecológica, también la de otras disciplinas con solo la aplicación de los indicadores cuantitativos.

Asimismo, se considera que el contar con un sistema de indicadores cualitativos contribuirá a darle mayor confiabilidad y validez a la evaluación de la investigación bibliotecológica. En este sentido, se respetará lo que se establece en la Declaración de San Francisco al no continuar aplicando el indicador de "análisis de impacto de revistas como una medida sustitutiva de la calidad de los artículos de investigación" (2014, p. 2)

Con lo anterior, los pares expertos estarán en posibilidades de aplicar la evaluación formativa con el empleo de indicadores cualitativos, en donde la prioridad debe ser la evaluación de la calidad de la investigación bibliotecológica por sus méritos.

Finalmente, es de mencionarse que, evaluar la investigación bibliotecológica con un sistema de indicadores cualitativos, permitirá evaluar de manera sistemática categorías fundamentales, tales como: Curriculum del investigador, la productividad del investigador y el impacto de la investigación bibliotecológica, lo que proporcionará al proceso de evaluación mayor objetividad y credibilidad, al mismo tiempo que ello ayudará a la disciplina bibliotecológica a legitimarla y darle el reconocimiento que se merece ante la sociedad.

\section{BIBLIOGRAFÍA}

Abramo, Giovanni y Ciriaco Andre D'Angelo. "How do you define and measure research productivity?" [en línea], Scientometrics (2014): 1129-1144. (Consutado el 23 de febrero de 2015). Disponible en: http://link.springer. com/article/10.1007/s11192-014-1269-8 
Bertocchi, Graziella, Alfonso Gambardella, Tullio Jappelli, Carmela A. Nappi y Franco Peracchi. "Bibliometric evaluation vs informed peer review: evidence from Italy" [en línea], Research Policy 44 (2015): 451-466. (Consultado el 26 de febrero de 2015). Disponible en: morgana. unimore.it/bertocchi_graziella/papers/vqrweb.pdf

Bharathi, D. Gnana. "Methodology for the evaluation of scientific journals: aggregated citations of cited articles" [en línea], Scientometrics 86(3) (2011): 563-574. (Consultado el 14 de julio de 2015). Disponible en: http://www.akademiai.com/doi/abs/10.1007/s11192010-0291-8

Bordons, María y Ma. Ángeles Zulueta. "Evaluación de la actividad científica a través de los indicadores bibliométricos" [en línea], Revista Española de Cardiología 52 (1999): 790-800. (Consultado el 23 de junio de 2015). Disponible en: http://www.revespcardiol.org/es/evaluacion-actividad-cientifica-traves-indicadores/articu$10 / 190 /$

Camps, Diego. "Limitaciones de los indicadores bibliométricos en la evaluación de la actividad científica biomédica” [en línea], Colombia Médica 39(1) (2008): 74-79. (Consultado el 25 de junio de 2015). Disponible en: http://www.redalyc.org/articulo.oa?id=28339109 
Clyde, Laurel Anne. "The basis for evidence based practice: evaluating the research evidence" [en línea], New Library World 107(1224/1225) (2006): 180-192. (Fecha de consulta: 21 de mayo 2015). Disponible en: www.emeraldinsight.com/doi/pdfplus/10.1108/03074800610665194

Criterios de calidad en la investigación en Humanidades : informe [en línea] [España: Fundación Española para la Ciencia y la Tecnología : Agencia Nacional de Evaluación y Prospectiva], 2007. 15 p. (Fecha de consulta: 27 de julio de 2015). Disponible en: http://www.idi.mineco.gob.es/stfls/MICINN/Investigacion/FICHEROS/2007criterios-hh.pdf

DORA : Declaration on Research Assessment $=$ Declaración de San Francisco de Evaluación de la Investigación [en línea], College and Research Libraries 75(4) (2014): 191196. (Consultado el 15 de Julio de 2015). Disponible en: http://crln.acrl.org/content/75/4/191.full

González-Alba, B, L. Moreno, F. Morillo y M. Bordons. "Indicadores bibliométricos para el análisis de la actividad de una institución multidisciplinar: el CSIC" Revista Española de Documentación Científica 35(1) (2012): 9-38.

Huang, Mu-Hsuan, "A comparison of three major academic rankings for world universities: from a research evaluation perspective" [en línea], Journal of Library and Information Science 9 (2011): 1-25. (Consultado el 22 de febrero de 2015). Disponible en: http://jlis.lis.ntu.edu. tw/article/v9-1-1.pdf 
Jiménez-Contreras, Evaristo, Nicolás Robinson-García y Álvaro Cabezas-Clavijo. "Productividad e impacto de los investigadores españoles: umbrales de referencia por áreas científicas" = "Productivity and impact of Spanish researchers: reference thresholds within scientific areas" [en línea], Revista Española de Documentación Científica 34 (2011): 505-525. (Consultado el 26 de febrero de 2015). Disponible en: http://digibug.ugr.es/ bitstream/10481/19151/1/713-1210-1-PB_Post-print.pdf

McMeeking, Laura B., Carole Basile y R. Brian Cobb. "An organizational model to distinguish between and integrate research and evaluation activities in a theory based evaluation" [en línea], Evaluation and Program Planning 35 (2012): 508-516. (Consultado el 26 de febrero de 2015). Disponible en: http://www.ncbi.nlm. nih.gov/pubmed/22580233

Muro, Xiomara (y otros ocho), "Hacía una definición de la calidad de la investigación en la Universidad Pedagógica Experimental Libertador" [en línea], Investigación y Postgrado 1 (2003): 23 p. (Consultado el 22 de febrero de 2003). Disponible en: http://www.scielo.org.ve/scielo.php?pid=\$1316-00872003000100005\&=sci_arttext

Obaseki, Tony I., Salisuki Dasuki Ibrahim y Juliet N. Momoh. "Scientific research in Librarianship: a panacea for library development in Nigeria" [en línea], Library Philosophy and Practice (2010): 1-4. (Consultado el 22 de febrero de 2015). Disponible en: http://www.webpages.uidaho.edu/ mbolin/obaseki-ibrahim-momoh.htm 
Pérez Juste, Ramón. Evaluación de programas educativos. Madrid: La Muralla, 2006. 565 p. (Manuales de metodología de investigación educativa)

Peña Ocando, Dionnys. "Algunas razones para evaluar la investigación científica venezolana desde la bibliometría" [en línea], Revista Interamericana de Bibliotecología 34 (2011): 271-281. (Consultado el 06 de junio de 2015). Disponible en: http://www.redalyc.org/articulo. oa?id=179022762003

Powell, Ronald R., "Evaluation research: an overview" [en línea] Library Trends 55(1) (2006): 102-120. (Consultado el 11 de junio de 2015). Disponible en: http://citeseerx. ist.psu.edu/viewdoc/download?doi=10.1.1.465.800\&r ep $=$ rep1\&type $=$ pdf

Shafique, Farzana y Khalid Mahmood. "Model development as a research tool: an example of PAK-NISEA [en línea]" Library Philosophy and Practice (2010): 1-12. (Consultado el 08 de junio de 2015). Disponible en: http:// digitalcommons.unl.edu/libphilprac/427/

Silva Laya, Marisol. La Calidad educativa de las universidades tecnológicas : su relevancia, su proceso de formación y sus resultados, México, D.F.: Asociación Nacional de Universidades e Instituciones de Educación Superior, Dirección de Servicios Editoriales, 2006, p. 19 
Suarez, Doug, "Evaluating qualitative research studies for evidence based library and information" [en línea], Evidence Based Library Information Practice 5(2) (2010): 75-85. (Consultado el 17 de junio de 2015). Disponible en: http://ejournals.library.ualberta.ca/index.php/ EBLIP/article/view/7418

Westerheijden, D.F., "Innovation indicators in science and technology evaluation: comments from a higher education point of view" [en línea], Scientometrics 45(3) (1999): 445-453. (Fecha de consulta: 19 de mayo de 2015). Disponible en: http://download-v2.springer. com/static/pdf/839/art

Wu, Zhiqiang, "Average evaluation intensity: a qualityoriented indicator for the evaluation of research performance" [en línea], Library \& Information Science Research 37 (2015): 51-60. (Consultado el 17 de junio de 2015). Disponible en: http://www.sciencedirect.com/ science/article/pii/S0740818815000080 


\title{
Consideraciones sobre la educación bibliotecológica en el siglo XXI
}

\author{
Blanca Estela Sánchez Luna \\ Facultad de Filosofía \\ y Letras, UNAM
}

\section{Resumen}

El presente trabajo ofrece una serie de consideraciones entorno a lo que debe enseñarse al bibliotecólogo del siglo XXI, para lo cual se han revisado estudios en donde se analizan las tendencias de los programas curriculares en el plano internacional; se determina que las materias que incidirán en la actualidad por la introducción de los componentes tecnológicos así como la perspectiva social es la preservación digital y que la alfabetización informacional debería desarrollarse más aún, en este sentido, se reflexiona sobre la importancia de la función y rol social del bibliotecólogo y de la necesidad de que en su enseñanza se afiancen los principios y fundamentos de la propia disciplina.

\section{Library education in 21st Century: some considerations Blanca Estela Sánchez-Luna}

\section{Abstract}

This paper addresses some considerations about what should be taught to the Librarianship students of this $21^{\text {st }}$ century. To achieve this objective have been reviewed some studies of the curriculum at an international level. In this paper also is considered that the matters that 


\section{La investigación bibliotecológica: problemas para...}

nowadays will affect due to the introduction of technological components and by the social perspective is the digital preservation and for that reason, the topic about information literacy should be further developed. Also are discussed the importance and the social role of the $\mathrm{Li}$ brarian who is graduated from the Librarianship schools, without neglecting the importance that in Library Science teaching, the foundations of the discipline represents a fundamental aspect.

\section{INTRODUCCIÓN}

1 paso de la primera década y primer lustro del siglo XXI, la
comunidad que se desarrolla en el área de la Bibliotecología ha
mostrado interés por estudiar sobre los nuevos roles, habilidades y conocimientos que debe asumir y aprender el bibliotecólogo en este siglo que se ha caracterizado por ofrecer grandes cambios en el tratamiento de la información, sobre todo en ambientes electrónicos y digitales. Por lo anterior, resulta interesante mostrar en este trabajo de forma general, qué se debe enseñar al bibliotecólogo, a partir del análisis de algunos estudios realizados sobre los programas curriculares en las escuelas de bibliotecología en un plano internacional para determinar si existe alguna tendencia por enseñar materias de tecnología, y con ello, indagar si está olvidándose nuestras funciones sociales y principios esenciales dentro de nuestra disciplina, como lo ha afirmado Gorman recientemente; por otra parte, también se ofrecen algunas consideraciones sobre el enfoque de competencias, las funciones y roles del bibliotecólogo, así como determinar qué materias se están estudiando en los programas mencionados por esa necesidad de estar al día o, en todo caso, con qué enfoques se están tratando las materias ya existentes con el propósito, como ya se mencionó, de ofrecer un acercamiento sobre el panorama actual. 
CONSIDERACIONES SOBRE LA FUNCIÓN SOCIAL DEL BIBLIOTECÓLOGO EN EL SIGLO XXI

El bibliotecólogo del siglo XXI tiene un legado cultural producto de las diversas épocas históricas, por lo que socialmente debe cumplir con ciertas funciones y roles como profesionista, de aquí la importancia de que su educación esté basada en principios y fundamentos, independientemente de que existan nuevas formas, procesos y recursos para registrar, tratar, almacenar y difundir la información.

Una de las disciplinas que nos ha ofrecido sus herramientas en el campo de la Bibliotecología es la administración, misma que le ha dotado de reconocimiento social. De acuerdo con Gorman (2015), gracias a la perspectiva de la administración, las bibliotecas cuentan con tres componentes:

- Preservación del registro humano para que el conocimiento pueda compartirse y le sea garantizado a las siguientes generaciones.

- Cuidar y mantener nuestras bibliotecas y con ello obtener el reconocimiento y respeto de las comunidades a las que se sirve.

- Cuidar y promover la educación en bibliotecología con el propósito de ejercitar nuestros mejores valores y prácticas profesionales.

En relación con este último aspecto, la educación bibliotecológica siempre ha buscado renovarse de acuerdo a las distintas épocas y por consiguiente en nuestros días, muestra de ello son los estudios que han realizado Mardis (2007), Shannon $(2002,2008)$ y Tiley y Callison (citados en Yi y Turner 2014), quienes han afirmado que los bibliotecólogos de las bibliotecas escolares requieren replantearse sus roles y competencias debido a que necesitan especialistas en medios para dichas bibliotecas por lo que se planteó la necesidad de cubrir dicha demanda instruccional (Yi y Turner 2014). Así como sucede en las bibliotecas escolares, los medios y la tecnología que las hacen posible se han introducido en las prácticas cotidianas de la biblioteca en general, lo cual implica reconocer que el bibliotecólogo moderno debe en primer lugar reflexionar y analizar sus prácticas profesionales, modificar los 


\section{La investigación bibliotecológica: problemas para...}

planes curriculares de las instituciones educativas en donde se ofrece la educación bibliotecológica para entonces así promover las habilidades, competencias, conocimientos y valores necesarios.

Con respecto a las bibliotecas universitarias, Widén y KronqvistBerg, citados por Neigel (2015) analizaron las competencias del bibliotecario del futuro. Ellos sugirieron una serie de habilidades nuevas en los siguientes procesos: cambio de negociación en desarrollo de colecciones; nuevas formas de aproximarse a las conductas de búsqueda más evolucionadas por parte el usuario; y, desarrollo de sistemas de entrega de información (Neigel 2015). Cada uno de estos aspectos, sin duda vienen influidos nuevamente por lo tecnológico, en donde el desarrollo de colecciones desde luego se torna diferente cuando se han transformado los recursos de información de impresos a digitales, lo cual implica licencias de uso, considerar las características de las plataformas, aspectos de usabilidad, etc.; en el caso de las nuevas formas de búsqueda ahora el usuario tiene acceso en línea a una gran cantidad de herramientas como bases de datos, redes sociales, motores de búsqueda, por mencionar algunos, y por lo mismo su conducta informacional es más compleja. Lo anterior implica además que el bibliotecólogo participe en el desarrollo de tecnologías para la entrega de la información como son descubridores de información, gestores de recursos electrónicos, portales y otras tecnologías que emergen rápidamente en el mercado. En otras palabras, lo digital o electrónico y en sí la tecnología ha trastocado nuestros objetos de estudio así como nuestras prácticas profesionales, pero no así las funciones esenciales y principios de la Bibliotecología ni de los profesionistas que la ejercen. Por ejemplo, los soportes que contienen la información con el paso del tiempo han evolucionado de lo ideográfico a lo escrito a lo impreso a analógico y a lo digital.

Gorman (2015) señala que la humanidad hoy cuenta con una gran variedad de medios a diferencia de las sociedades prehistóricas, quienes tenían una comunicación no grabada o no registrada, más bien oral, en donde la principal característica de aquellos es su gran capacidad de extensión para llegar a diversos destinos, pero su principal inconveniente es su poca durabilidad, por lo anterior, se vuelve necesario comprender para el bibliotecólogo la preservación en el entorno digital como parte 
de su responsabilidad social, muestra de ello es que a través del tiempo en las bibliotecas se retienen los medios más antiguos por el bien de la durabilidad y de su comunicación a generaciones posteriores.

Además, como desventaja principal es que muchos de los recursos digitales no tienen varias de las características que sí ofrece lo impreso como autenticidad en relación con su contenido y fijeza por la gran volatilidad que supone la Red o la necesidad de actualización continua de los programas informáticos para su lectura, además del hardware. Sin embargo, una de las mayores ventajas de dichos recursos es que generan un vínculo de confianza con el usuario. En suma, lo que puede ser considerado como el centro de la controversia experimentada por autores y lectores en el mundo digital es la libertad de fijeza, estandarización y veracidad comprobable (Gorman 2015).

Por tanto, no se puede soslayar la importancia de las tecnologías de información y comunicación dentro de la disciplina, por lo que se vuelve indispensable comprenderlas, estudiarlas, colaborar en su desarrollo e implementación e incluso promover su uso dentro de las bibliotecas, pero también a que sea parte de los planes curriculares de las escuelas de bibliotecología para que el propio bibliotecólogo desarrolle habilidades, capacidades, conocimientos y valores sobre este tema emergente, como ya se ha señalado; sin embargo debe darse más peso al enfoque de preservación de la información en formato digital debido a que es uno de los componentes más importantes que como bibliotecólogos deben cumplir de acuerdo con Gorman (2015), quien además advierte que si el conocimiento e información registrada que posee la humanidad actualmente estuviera disponible en soportes digitales, sin duda, se estaría frente a un riesgo mayúsculo de preservación del registro humano, nunca antes visto desde la aparición de la imprenta.

Por lo anterior, el bibliotecólogo no sólo debe centrar sus procesos de enseñanza en lo tecnológico sino que a partir de los fundamentos y principios que son esenciales de la disciplina. De acuerdo con Church, Dickinson, Everhart y Howard (2012) en un estudio en donde comparan estándares de certificación de programas curriculares para formar bibliotecólogos escolares en Estados Unidos, descubrieron que todos los estándares explorados abordan el uso efectivo de la información; además, en cuatro de ellos se centran en aprendizaje, liderazgo, 


\section{La investigación bibliotecológica: problemas para...}

lectura y evaluación del estudiante; en tanto que otros cinco abordan la colaboración y la alfabetización. Los autores afirman que los bibliotecólogos de cualquier tipo de biblioteca están interesados en ofrecer acceso a la información, mediante la promoción de la lectura y la orientación al usuario para que se convierta en un agente efectivo de ideas e información. Además, los autores afirman que los programas educativos en bibliotecología, deben fortalecer la ética profesional y práctica del liderazgo. En este sentido, no parece existir la tendencia por la tecnología sino por los aspectos centrales de la Bibliotecología.

Ahora bien, como se ha mencionado la preservación del conocimiento y la información registrada ha sido una de las funciones sociales del bibliotecólogo con el propósito de que estén disponibles en un formato auténtico y fijo no sólo para las siguientes generaciones sino para un futuro indefinido; y además, otra de nuestras funciones es la de garantizar el vínculo de confianza entre la biblioteca y la sociedad, preservando y transfiriendo el conocimiento de la bibliotecología para las siguientes generaciones de profesionistas por medio de la educación bibliotecológica (Gorman 2015). Lo anterior nos lleva a reflexionar ¿Qué y cómo se debe enseñar en la educación bibliotecológica bajo este entorno en este nuevo siglo?

\section{LA EDUCACIÓN BIBLIOTECOLÓGICA Y LOS PROGRAMAS CURRICULARES EN EL ENTORNO INTERNACIONAL}

Antes de intentar responder o reflexionar sobre dicha pregunta, primero se debe comprender bien el campo laboral para tratar entonces de redefinir los roles, sin embargo como lo comenta Neigel (2015) debe reconocerse que los entornos dentro de la información son siempre cambiantes en el sentido de las necesidades de las comunidades, además hay pocos datos o discusiones sobre la reestructuración del trabajo y los roles entre las jerarquías de las bibliotecas; por otra parte, la práctica del trabajo diario tiene implicaciones en bibliotecas, en donde el cambio que se produce en el trabajo es en gran medida por la adopción tecnológica debido a que es una manera de modernizarlo. Por lo anterior, continua Neigel, existe la necesidad de examinar la 
forma en que éstos cambios modifican el trabajo por lo que se vuelve significativo indagar sobre la evolución de la práctica bibliotecológica con el propósito de no marginar la propia fuerza de trabajo por el error de desafiar prácticas excluyentes y condiciones que den acceso limitado al desarrollo profesional y personal. Conocer dichos aspectos nos ofrecería elementos esenciales para potenciar las verdaderas habilidades, conocimientos y capacidades del bibliotecólogo en lo que va del siglo XXI con el objeto de no caer en lo ya anticipado por Freer-Leszczybski (2015), quien reconoce que en la actualidad los talentos únicos y el desarrollo de fortalezas desarrolladas en los programas de Maestría en Biblioteca y Ciencias de la Información no son utilizados en su totalidad, por lo tanto si los programas se mantienen sin cambio entonces estaremos en un riesgo significativo.

Sin embargo, reconociendo el entorno cambiante que implica trabajar actualmente en el campo de la información, que no existen estudios sistemáticos sobre el impacto, principalmente de lo tecnológico en las actividades diarias en las bibliotecas y que hay un reconocimiento de que no todo lo que se está enseñando actualmente en los programas curriculares en Bibliotecología se utiliza en su totalidad, entonces regresando a la pregunta ¿Qué y cómo se debe enseñar en la educación bibliotecológica bajo este entorno en este nuevo siglo? Yi y Turner (2014) recientemente realizaron un estudio con los diferentes planes curriculares de formación de Bibliotecólogos Escolares y de los programas de maestría en Bibliotecología de los Estados Unidos, tanto certificados por la American Library Association (ALA), American Association of School Librarians (AASL) y con los programas que no están certificados. En el estudio se describen, entre otros aspectos, que los cursos más frecuentemente encontrados en los programas curriculares, correspondieron al área de Servicio a las poblaciones de usuarios, y por otra parte, los cursos del área de Informática resultaron los menos frecuentes. Además, ofrecieron una lista de los términos, extraídos de todos los programas y son los siguientes: liderazgo, web, alfabetización, metodología y plan de estudios.

Ahora bien, dentro del área más popular Servicio a las poblaciones de usuarios de todos los planes curriculares, el tema más común corresponde a Literatura para niños. Por otra parte, con los programas 


\section{La investigación bibliotecológica: problemas para...}

curriculares sólo acreditados por la AASL el área que aparece representada más fuertemente, como habría de esperarse, es la de Bibliotecas Escolares, en tanto que la más débil es el área de Sistemas de información y recuperación en comparación con los otros tipos de programas curriculares, lo cual nos muestra que el área dedicada a los aspectos de la bibliotecología en sí, como en este caso las bibliotecas escolares, tienen más peso que las áreas de la tecnología. Sin embargo otro de los descubrimientos que hacen estos autores en su artículo, considerando específicamente los programas sólo acreditados por la ALA encontraron que todas las áreas están representadas de manera uniforme con excepción de Servicio a las poblaciones de usuarios e Informática. Ahora bien, al unir los programas acreditados por ambos grupos (ALA y AASL), el resultado es otro, en donde el área relativamente más fuerte es Sistemas de información y recuperación. Con respecto a los programas no certificados parecen ser relativamente más fuertes en las áreas de Organización de la Información, Tipos de bibliotecas y proveedores de información y, particularmente en Dirección y Administración. Por lo tanto, este estudio permite afirmar en forma general que en dichos programas curriculares, existe una tendencia por los temas relacionados con la bibliotecología; en tanto que si sólo se analizaran los planes curriculares certificados por la ALA y AASL, entonces la tecnología está teniendo más representación por lo que el argumento de Gorman cobra cierto sentido, y de ahí la necesidad de que la tecnología además se estudie bajo la perspectiva de la función social de la Bibliotecología, a efecto de que se incorpore el aspecto de la preservación digital.

Siguiendo a Yi y Turner (2014) en su mismo estudio, afirman que para los bibliotecólogos escolares, o es decir, para los programas curriculares mediante los cuales ellos son formados, la alfabetización informacional no es un gran componente dentro del área de Servicio a las poblaciones de usuarios, a diferencia del plan curricular K-12 con el que se forman los profesores en Estados Unidos, lo cual advierte una necesidad de mayor incorporación de la misma en el plan curricular de las escuelas de Bibliotecología.

Además, si en los programas de educación bibliotecológica se reconoce la preponderancia del área de servicios a las poblaciones de usuarios, no se debe olvidar la importancia que juega la conducta 
ética, la responsabilidad social y la justicia social como fundamentos filosóficos importantes para la profesión bibliotecológica, incluso en las materias de tecnología, que de acuerdo con James y Reschke (2015), recientemente se ha desarrollado un curso con este enfoque llamado Sociedad e Información, dentro de un diplomado de dos años de duración, impartido en Library and Information Technology Program de MacEwan University.

Algunos de los primeros estudios sobre el mapa del plan curricular sobre las materias los realizó Beheshti en 1999 (en Yi y Turner 2014), quién analizó tanto los títulos como las descripciones de los cursos de 44 programas de Master of Library and Information Science acreditados por la ALA e identificó los 57 conceptos de más intensa cobertura. Desde ese entonces, ya se habían vislumbrado los cuatro conceptos básicos con mayor intensidad: tecnología, dirección, organización de la información y búsqueda y desarrollo de bases de datos. De acuerdo con dichos autores, el estudio de Beheshti comprobó que tanto los conceptos tradicionales de Bibliotecología y Ciencias de la Información estuvieron cubiertos, como también conceptos nuevos que habían sido incorporados dentro de los planes curriculares de Biblioteca y Ciencias de la Información, tales como desarrollo de bases de datos, métodos matemáticos, medios no impresos, interface humanocomputadora e inteligencia artificial.

Ya entrado el siglo XXI, Markey en 2004 manualmente analizó el plan curricular de 56 instituciones miembros de la Association for $\mathrm{Li}$ brary and Information Science Education (ALISE). Su estudio mostró los siguientes campos: Organización, Referencia, Fundamentos y Dirección, y un curso en Investigación o en Tecnología de la Información. Markey en su estudio identifica una nueva tendencia, aproximarse a la entrega de información centrada en el usuario (Yi y Turner, 2014).

Posteriormente, Hall en 2009, examina el plan de estudios básico de 55 programas de Bibliotecología y Ciencias de la Información acreditados por la ALA, enfocándose en los cursos básicos obligatorios, y encontró las siguientes áreas: Fundamentos, Organización, Dirección, Referencia, Métodos de Investigación y Tecnología de la Información. Su conclusión fue que el plan curricular básico había evolucionado, 


\section{La investigación bibliotecológica: problemas para...}

pero algunas áreas como alfabetización informacional y la ética de la información no están desarrollándose lo suficientemente rápido (Yi y Turner 2014).

Con lo anterior se comprueba que con los estudios de Markey (2004) y Hall (2009), prácticamente los programas curriculares han permanecido muy similares, sin embargo con la conclusión de Hall en donde la alfabetización y la ética no se han desarrollado muy rápido, coincide con las afirmaciones actuales de Yi y Turner (2014) y la de James y Reschke (2015) respectivamente, por lo que sin duda la enseñanza del bibliotecólogo del siglo XXI deberá centrarse en desarrollar dichos aspectos.

Ahora bien, ¿Cómo se debe enseñar o qué modelo de enseñanza debe adoptarse en bibliotecología? Tiene que recordarse que, en los últimos años ha existido una tendencia por estructurar los perfiles y planes curriculares a nivel internacional con base en competencias, muestra de ello es el estudio de McKinney publicado en 2006, en donde examinó 56 planes curriculares en Bibliotecología y Ciencias de la Información acreditados por la ALA y confrontados con las $8 \mathrm{com}$ petencias básicas de la misma Asociación. MaKinney reportó que el 95\% de los programas contienen cursos que se dirigen a dichas competencias, pero solamente el $15 \%$ de los planes satisfacen en sus totalidad las competencias (Yi y Turner 2014). En este sentido, habría que preguntarse ¿Qué tipo de profesionistas se quiere formar en nuestra disciplina? ¿Reflexivos, con sólidos conocimientos en nuestra área, capaces de establecer relaciones sociales? Entonces, si sólo se basa la educación en el enfoque de competencias, afirma Neigel (2015), se corre el riesgo de ignorar procesos basados en la productividad y resultados, en donde las relaciones sociales, el poder y el conocimiento juegan un rol menor. Por lo que el autor recomienda que el bibliotecólogo necesita habilitarse y aprender, pero no sólo bajo una dimensión en la que lo convierta en un buen ejecutor de labores específicas dentro de los intereses de producción de ciertos servicios y productos, sino por el contrario, el bibliotecólogo al igual que el profesionista en otras disciplinas, debe formarse con el propósito de desarrollar los aspectos intelectuales del trabajo de la información sin excederse en competencias y estandarización. 
Este argumento confirma la postura de Gorman (2015) y nos previene en no confundir la instrucción con la educación, quien argumenta que muchos profesionales y empleadores aún no han distinguido. El entrenamiento de los bibliotecarios debe ser impulsado y desarrollado en el campo laboral, en tanto que la educación, la buena educación basada en fundamentos del conocimiento y del entendimiento es responsabilidad de las universidades.

Por lo tanto, la enseñanza en el siglo XXI para el bibliotecólogo deberá buscar el cultivo de su esencia y fundamentos más que el entrenamiento en competencias procedimentales, misma que es necesaria, pero al no enfocarse bajo los fundamentos bibliotecológicos se pasa por alto el aspecto de la preservación digital como se ha señalado. Además, Gorman (2015) afirma que muchos de los cursos de educación bibliotecológica, sobre todo los acreditados como ya lo he mencionado antes, son ignorados prefiriéndose los cursos en ciencia de la información y tecnología de la información mismos que tienen poca relevancia, argumento que coincide con la apreciación de Freer-Leszczybski (2015), en el sentido de que no todos los talentos y fortalezas de dichos programas curriculares se están utilizando, como se ha mencionado antes.

\section{ConClusiones}

El bibliotecólogo del siglo XXI debe cumplir con su función social, por lo que el proceso de enseñanza debe estar dirigido a sus fundamentos y principios con el objeto de que la preservación del registro humano debe ser un aspecto que se debería atender, en concordancia con dicha función, más aún en nuestra época en donde lo digital y electrónico ha comenzado a ser un formato de gran interés.

Cabe recordar que el legado cultural e histórico completo de los registros de la humanidad, tienen su complemento en el legado documental y de información que nos toca administrar. Dicho registro humano es uno de nuestros más importantes deberes y responsabilidades. Profesionistas de otras disciplinas como profesores, investigadores, libreros, editores, museógrafos, incluso el ciudadano en 


\section{La investigación bibliotecológica: problemas para...}

general se benefician de la disponibilidad de los registros del pasado. Ahora bien, los bibliotecólogos y los archivistas son los profesionistas que ven por la preservación de dichos registros (Gorman 2015).

Aún cuando la tecnología de la información es un área importante y emergente, ésta debe ser vista como un área de apoyo. Debe introducirse en nuestros planes curriculares como se ha venido haciendo, sin embargo el enfoque social y ético nos permitirá dejar a un lado el simple aspecto operativo, por lo que es importante no perder de vista que en la universidad se educa, en el más amplio significado de la palabra, en tanto que la práctica y la experiencia operativa nos la ofrecerá el campo laboral. Ahora bien, esa práctica laboral debe ser estudiada de manera sistemática con el objeto de ir adaptando de mejor manera los planes curriculares así como los nuevos roles y las competencias del bibliotecólogo y no en la forma en como se ha hecho al menos en el plano internacional. Por otra parte, el modelo sólo basado en competencias tiende al desarrollo de lo procedimental y deja fuera el desarrollo intelectual, por lo que es necesario experimentar un modelo combinado para reestructurar perfiles, roles y programas curriculares.

A parte de las materias de tecnología, sin duda debe desarrollarse e introducirse más significativamente en los planes curriculares la materia Alfabetización informacional, por que como afirma Church, Dickinson, Everhart y Howard (2012), la necesidad de enseñar habilidades en alfabetización informacional a los usuarios en todos los tipos de biblioteca crece. Lo mismo concluyen Yi y Turner (2014): en la educación bibliotecológica del siglo XXI, ambas materias son emergentes y por tanto, de suma importancia para los estudiantes en los programas de las escuelas de bibliotecología. Aunado a lo anterior, por el mismo avance tecnológico es necesario desarrollar las materias sobre el uso ético de la información, el desarrollo de colecciones de recursos electrónicos y el desarrollo de sistemas de entrega de información centrados en el usuario.

Finalmente, no se puede olvidar que si dentro de la educación bibliotecológica, los procesos de enseñanza no implican el estudio del control bibliográfico y aspectos fundamentales para nuestra área la Bibliotecología, sino suponen conocimientos más significativos para 
desarrollar al webmaster, entonces los programa curriculares serán juzgados sobre éstos (Gorman, 2015).

\section{BIBLIOGRAFÍA}

Church, Audrey P., Gail K. Dickinson, Nancy Everhart y Jody K. Howard. "Competing Standards in the Education of School Librarians." Journal of Education for Library and Information Science 53(3) (2012): 208-217.

Freer-Leszczybski, Cathy. "Growing Tomorrow's Librarians Today." Feliciter, 61(1) (2015). Recuperado de: http://www.cla.ca/Content/NavigationMenu/Resources/Feliciter/Feliciter_Spring_2015_FINAL.pdf

Gorman, Michael (2015). "Stewardship \& Librarians." $\mathrm{Fe}$ liciter 61(1). Recuperado de http://www.cla.ca/Content/NavigationMenu/Resources/Feliciter/Feliciter_ Spring_2015_FINAL.pdf

James, Norene y Karen Reschke. "Addressing the Issues of Social Responsibility in an LIT Education." Feliciter 61(1) (2015). Recuperado de http://www.cla.ca/Content/NavigationMenu/Resources/Feliciter/Feliciter_ Spring_2015_FINAL.pdf

Neigel, Christina (2015). "Finding Voice and Agency in the Twenty-First Century." Feliciter 61(1). Recuperado de http://www.cla.ca/Content/NavigationMenu/Resources/Feliciter/Feliciter_Spring_2015_FINAL.pdf

Yi, Kwan y Ralph Turner. "The Current Landscape of the School Librarianship Curricula in USA.” Journal of Education for Library and Information Science 55(4) (2014): 303-321. 


\title{
Competencias para la enseñanza-aprendizaje de la bibliotecología y la ciencia de la información en la sociedad digital
}

\author{
Johann Pirela Morillo \\ Programa de Sistemas de Información y Documentación, \\ Universidad de La Salle, Colombia
}

\section{Resumen}

Se proponen seis competencias docentes que deben desarrollar los docentes de Bibliotecología y Ciencia de la información, como formadores de los profesionales de la información requeridos para apalancar procesos de desarrollo sostenible en el contexto de las actuales sociedades digitales. La propuesta se basa teóricamente en la propuesta de la Red para el Desarrollo y Evaluación de Competencias Académicas (REDECA) y en los planteamientos de Guzmán, Marín e Inciarte (2014), según los cuales la docencia universitaria debe transitar hacia un nuevo modelo de formación docente por competencias. La metodología consistió en comparar los criterios señalados por estos autores latinoamericanos y algunas experiencias de estrategias de aprendizaje y de evaluación por competencias utilizadas en la enseñanza-aprendizaje de la Bibliotecología y la Ciencia de la Información. Las conclusiones enfatizan en la necesidad de incorporar estas competencias para garantizar una adecuada gestión del microcurrículo en el área, con lo cual se promueven procesos de calidad en la formación de los profesionales de la información. 


\title{
Competencies of teaching and learning Library and
} Information Science into the digital society Johann Pirela-Morillo

\begin{abstract}
Six competencies are proposed to be developed by teachers of Library and Information Science (LIS), who are trainers of Information Professionals requested for driving up sustainable development process in the frame of current digital society. This proposal is theoretically based on REDECA approach (Network of design and assessment on scholarly competencies) as well as arguments put forward by Guzman, Marin \& Inciarte (2014) by which teaching at universities must move towards a new competence-based model for teacher training. The comparison among criteria indicated by the Latin American authors above, some learning strategies and the competency assessment used for teaching and learning in LIS were included in the methodology. The need for embodying these competencies so as to ensure a sound management and the promotion of quality training process of information professionals were stressed as findings.
\end{abstract}

\section{INTRODUCCIÓN}

$\mathrm{E}$ n el contexto de las actuales sociedades digitales, se requiere una formación profesional innovadora y articulada con las tendencias que emergen en los escenarios globales e interactivos, caracterizados por el uso intensivo de las tecnologías de información y comunicación (TIC), que configuran nuevos ecosistemas para el intercambio de mensajes, estructurados en torno a redes telemáticas, conexiones entre diversas fuentes y nodos, logrando con todo ello la creación de formas diferentes de producción y transferencia colaborativa del conocimiento. 
Estos entornos están exigiendo que los docentes desarrollen competencias que se acoplen a las nuevas realidades, sobre todo si se trata de promover procesos de enseñanza-aprendizaje en un área de conocimiento tan crucial en estos momentos como la Bibliotecología y la Ciencia de la información. Se trata entonces de plantear el desarrollo de nuevas competencias docentes para la enseñanza-aprendizaje de estas disciplinas y con ello contribuir a una formación profesional en sintonía con las realidades digitales, de las cuales están surgiendo también nuevas necesidades sociales, centradas en la inclusión, la participación y el valor estratégico que sigue teniendo el conocimiento, como un elemento de desarrollo y de progreso.

Para fundamentar nuestras ideas, acerca de cuáles son las competencias que deben desarrollar los docentes para la enseñanza-aprendizaje de la Bibliotecología y la Ciencia de la información en la sociedad digital, partimos, en primer lugar, del concepto de competencia. En este sentido, muchas son las definiciones planteadas, pero las que más se ajustan a la noción que pretendemos argumentar son las de Rougiers (2010) y Tobón (2010), según las cuales las competencias se traducen en la movilización conjunta de diversos saberes para generar actuaciones integrales que permiten resolver problemas con idoneidad, ética y mejora continua.

Trasladando esta concepción de las competencias a la enseñanzaaprendizaje de la Bibliotecología y la Ciencia de la información en la sociedad digital, podríamos plantear que se trata del conjunto de conocimientos, habilidades, destrezas y actitudes necesarias para que los docentes realicemos procesos de mediación pedagógica y didáctica, sustentados en recursos tecnológicos y con ello aportemos de manera significativa para que los estudiantes desarrollen aprendizajes significativos y funcionales, mediante la construcción de conocimientos y de prácticas propios de los objetos, sujetos de estudio y escenarios de acción inherentes a los campos bibliotecológico y de la ciencia de la información. 


\section{La investigación bibliotecológica: problemas para...}

\section{COMPETENCIAS PARA ENSEÑAR-APRENDER EN BIBLIOTECOLOGÍA Y LA CIENCIA DE LA INFORMACIÓN}

Una referencia importante de las competencias para la enseñanza y el aprendizaje en la sociedad digital fue la que aportó UNESCO (2008), en relación con algunos estándares que deben considerarse para introducir las tecnologías de información y comunicación en ambientes educativos. Tales estándares apuntan a tres componentes básicos: incremento de la comprensión tecnológica en estudiantes, ciudadanos y fuerza laboral; aumento de la capacidad de los profesionales en formación para utilizar conocimientos construidos con mediación de recursos digitales y aumento de las habilidades y destrezas para que los estudiantes utilicen el conocimiento, sustentado en TIC; y agregación de valor por parte de los ciudadanos y ciudadanas a la sociedad y a la economía, aplicando el conocimiento y los recursos tecnológicos en la resolución de problemas complejos y reales.

Pirela (2005), había planteado algunas ideas en torno a la necesidad de articular la enseñanza de la Bibliotecología en el contexto de las denominadas también cibersociedades. El énfasis de tales ideas se colocó en la adopción de modelos formativos sustentados en el uso crítico de las tecnologías, conjugados con la necesidad de avanzar hacia la adopción de modelos pedagógicos y didácticos centrados en el desarrollo de procesos de pensamiento para dotar a los estudiantes de las herramientas para aprender a aprender más allá de la Universidad, todo ello enmarcado además en criterios de pertinencia, innovación e impacto de los procesos formativos.

Pero la discusión acerca de cuáles serían las competencias de los docentes en esta sociedad caracterizada por el uso intensivo de las tecnologías digitales, no solo deben apuntar al uso y apropiación educativa de tales tecnologías, sino que debe considerar también las dimensiones y componentes que conforman el ciclo de procesos que van de la planificación didáctica con todas las variables e indicadores que implica hasta la gestión del aprendizaje, su evaluación y retroalimentación permanente, utilizando una variada gama de recursos, técnicas e instrumentos; sobre todo cuando se trabaja en el marco de los currículos por competencias para la formación del profesional de la información. 
Siguiendo este planteamiento y asumiendo una perspectiva del desarrollo de competencias docentes para la sociedad digital, más allá de lo instrumental y lo estrictamente técnico-operativo del manejo de las tecnologías, consideramos que para garantizar una formación efectiva de los profesionales de Bibliotecología y Ciencia de la Información se requiere que las Escuelas y Programas desde donde se diseñan y administran los currículos tomen muy en cuenta el carácter estratégico de la tríada: formación de los docentes, gestión del microcurrículo y logro de la calidad de la formación de los ciudadanos-profesionales, para cuya realización es necesario además que los profesores adquieran y desarrollen las competencias que estén en sintonía con las características y particularidades de las sociedades de la información y el conocimiento. En este sentido, se propone considerar las competencias propuestas docentes por el grupo REDECA (Red para el desarrollo y evaluación de competencias académicas), en la cual participan un conjunto de universidades iberoamericanas, en especial de los países: México, Venezuela y España.

Según algunos miembros de esta Red, entre ellos: Guzmán, Marín e Inciarte (2014), señalan que estas competencias son:

a. El desarrollo de la formación docente de forma continua.

b. La realización de procesos de transposición didáctica.

c. El desarrollo de la docencia mediante dispositivos de formación y evaluación por competencias.

d. La gestión de la progresión en la adquisición de las competencias.

e. La aplicación de formas adecuadas de comunicación educativa.

f. La valoración del logro de las competencias.

Tales competencias pueden trasladarse al ámbito de la enseñanzaaprendizaje de la Bibliotecología y la Ciencia de la Información, para estar a tono con las propuestas curriculares diseñadas 


\section{La investigación bibliotecológica: problemas para...}

FORMACIÓN DOCENTE CONTINUA EN BIBLIOTECOLOGÍA Y CIENCIA DE LA INFORMACIÓN.

En cuanto al desarrollo de la formación continua, los docentes debemos poseer habilidades para la gestión del proceso de análisis y reflexión colegiada de la docencia, visualizando la brecha existente entre las competencias que poseemos y las que deseamos alcanzar. En este sentido, debemos negociar con nuestros pares la construcción de un programa de formación, incorporando la participación de los colegas con los cuales compartimos el compromiso de formar profesionales de la información, de una manera sistemática y bajo criterios de corresponsabilidad.

La formación continua de los docentes de Bibliotecología y Ciencia de la información debe estructurase en el marco de los principios del aprendizaje colaborativo y la posibilidad de configurar redes de saberes sobre conocimientos y metodologías pedagógicas y didácticas, conformando de esta forma alianzas y comunidades académicas que compartan experiencias sobre las variadas y múltiples formas de abordar los procesos formativos, con perspectiva crítica y creativa. De modo que los procesos de formación continua de los docentes debe orientarse en función de lo señalado por Moliner y Loren (2010), con miras a consolidar espacios de indagación y experimentación, de reflexión crítica sobre la propia cultura y práctica didáctica, lo cual además supone articular la potenciación de nuevas competencias junto al proceso de cambio y mejora de las instituciones formadoras de profesionales de la información.

Para el logro de estas posibilidades de comunicación e intercambio permanente entre pares, Caldera (2014), propuso que los docentes formadores de profesionales de la información, sobre todo aquellos que trabajan en la gestión de los microcurrículos de organización de la información y del conocimiento en las instituciones de educación superior de Venezuela, conformen una Red de enseñanza-aprendizaje-investigación-innovación para compartir buenas prácticas y lecciones aprendidas acerca de las experiencias que han resultado ser exitosas para desarrollar competencias en organización del conocimiento, entendidas como conjunto de 
conocimientos, habilidades, destrezas y actitudes que permiten garantizar la maximización del acceso a la información desde las diferentes unidades y servicios de información.

La propuesta del bibliotecólogo y docente venezolano apunta a la posibilidad de configurar espacios de intercambio y cooperación académica entre los profesores de esta importante área de la formación profesional, con lo cual también planteó la necesidad de intercambiar saberes pedagógicos que pueden ayudar a actualizar la formación de los docentes de manera permanente.

Otra experiencia significativa, que puede mencionarse como impulsora de procesos de formación docente continua, es la que se impulsa desde el Seminario de Didáctica de la Bibliotecología, coordinado por el Dr. Jaime Ríos Ortega del Instituto de Investigaciones Bibliotecológicas y de la información, de la Universidad Nacional Autónoma de México, espacio que busca consolidar un cuerpo de conocimientos teórico-prácticos para orientar la enseñanza-aprendizaje de la Bibliotecología según criterios de pertinencia, creatividad e impacto; todo lo cual redundará en la formación de profesionales de la información para el ámbito latinoamericano, bajo principios de

REALIZACIÓN DE PROCESOS DE TRANSPOSICIÓN DIDÁCTICA EN BIBLIOTECOLOGÍA Y CIENCIA DE LA INFORMACIÓN

La realización de los procesos de transposición didáctica, como segunda competencia propuesta, parte del conocimiento teórico-epistemológico de las disciplinas y las áreas que conforman la ciencia Bibliotecológica y de la información. La transposición didáctica también se vincula con los procesos colegiados para el fortalecimiento del compromiso con la mejora y desarrollo de la institución y su contexto educativo, reconociendo de manera crítica la organización académico-administrativa del currículo que opera. Esta competencia implica el reconocimiento de manera crítica de la distribución y organización de los saberes que integra en su sistema cognitivo, con objeto de transforma los saberes en objetos de enseñanza. 


\section{La investigación bibliotecológica: problemas para...}

De acuerdo con Chevallard, un contenido de saber que se ha designado como saber susceptible de ser enseñado sufre un conjunto de transformaciones adaptativas que lo hacen apto de ocupar un lugar frente a los objetos de enseñanza. La transposición didáctica es, entonces, un proceso que transforma un objeto de saber a enseñar en un objeto de enseñanza. El proceso implica el despliegue de un conjunto de operaciones cognitivas, afectivas y procedimentales que permiten al docente la apropiación del conocimiento teórico y práctico que se va a enseñar.

El concepto de transposición didáctica de Chevallard, según Cardelli (2004), implica implica un proceso manipulativo con el saber en direcciones definidas y con fines determinados; lo cual le imprime al proceso didáctico intencionalidad y trascendencia. Cuando un profesor enseña conocimientos y prácticas de Bibliotecología y Ciencia de la información lo hace atendiendo a los elementos socio-culturales que distinguen cada uno de los contextos donde se situa la experiencia didáctica. De esta forma y siguiendo las ideas del autor, el enfoque didáctico de Chevallard distingue el movimiento que lleva de un saber, en tanto que objeto producido por la cultura dominante a un saber a enseñar a un saber de enseñanza, mediante procesos de preparación, apropiación e interpretación.

De manera pues que realizar procesos de transposición didáctica en Bibliotecología y Ciencia de la información, como en todas las áreas del conocimiento, implica en primer lugar el reconocimiento de la estructura bajo la cual está organizado el saber que se pretende enseñar, su naturaleza, grado de profundidad y las características que lo configuran, en tanto que si se trata de conocimientos conceptuales, procedimentales-técnicos y tecnológicos y actitudinales. El acto de transponer el conocimiento bibliotecológico y de la ciencia de la información supone primero una mediación crítica que el docente debe hacer con el saber y práctica institucionalizada y aceptada por la comunidad académica, para entonces convertirlo en saber de enseñanza. 
DiSEÑO DE LA DOCENCIA BIBLIOTECOLÓGICA Y DE CIENCIA DE LA INFORMACIÓN MEDIANTE DISPOSITIVOS DE FORMACIÓN Y EVALUACIÓN POR COMPETENCIAS

En relación con el diseño de la docencia, mediante dispositivos de formación y evaluación por competencias, tenemos la organización de su hacer docente a partir de un modelo pedagógico que considere de contenidos y propósitos formativos, mediante la utilización de medios, métodos y materiales de apoyo al desarrollo y evaluación de las competencias que van adquiriendo y logrando los estudiantes. Algunos de estos métodos y estrategias son: el portafolio docente, las secuencias didácticas y las realizaciones o exhibiciones.

Klenowski (2005), señaló que desde 1992, Arter y Spandel definieron el concepto de portafolio como una colección de trabajos que nos cuenta la historia de los esfuerzos, progreso y logros en una determinada área. Dentro de esta definición se distinguen elementos que tiene que ver con la idea de mostrar evidencias y objetivar los avances y progresión de los logros. De modo que el trabajo con los portafolios incorpora la autorreflexión, reforzando el aprendizaje y monitoreo acerca de su propio crecimiento.

En palabras de Guzmán, Marín e Inciarte (2014), el objetivo del portafolio es la construcción es promover distintas formas de reflexión y autoevaluación en los profesores, por medio de las cuales aprendan la búsqueda de las evidencias que documente los logros y problemas que han enfrentado en su labor como docente. De esta forma, el portafolio se convierte en un instrumento fundamental no solo para el acopio de productos y actividades que resultan de la sistematización de las experiencias docentes, sino que también muestra los grados de avance en la creatividad y rigor con la cual se estructuran, logrando configurar un banco de estrategias didácticas que pueden utilizarse para visualizar el progreso en la adquisición y desarrollo de las competencias.

El diseño de secuencias didácticas es otro de los dispositivos que pueden utilizar los docentes para desarrollar competencias en los estudiantes. Estos dispositivos se estructuran con base en los marcos institucionales, lo splanes de estudios y las intenciones formativas. En 


\section{La investigación bibliotecológica: problemas para...}

las secuencias se plantean situaciones problemas de las que se derivan actividades de aprendizaje, articuladas con evidencias de desempeño y con dispositivos de evaluación. Otros de los dispositivos son las realizaciones y exhibiciones, que definen también como productos que se generan de los procesos formativos y de la consolidación del aprendizaje adquirido.

\section{GESTIÓN DE LA ADQUISICIÓN DE LAS COMPETENCIAS}

En el marco de esta competencia docente para profesores de Bibliotecología y Ciencia de la información que trabajan por competencias, es importante considerar itinerarios de formación y niveles de desempeño en ellogrodelos conocimientos, habilidades, destrezasyactitudes en los profesionales en formación. La gestión de la adquisición de las competencias implica la realización de procesos de observación y evaluación en situaciones de aprendizaje, llevando a cabo controles periódicos para tomar decisiones respecto a la progresión de las competencias.

Para concretar esta competencia, los docentes deben aplicar técnicas de enseñanza centradas en prácticas reflexivas, como las historias de vida, los protocolos de casos, las situaciones didácticas, los portafolios, las metáforas, los incidentes críticos, sociodramas y las situaciones de integración. Mención especial merecen acá la técnica de incidentes críticos, por medio de los cuales se describen conductas prototípicas de los alumnos que se implican en actividades de aprendizaje o los momentos de práctica en los cuales surgen eventos inesperados que desestabilizan el comportamiento de los profesores y de los estudiantes.

Los incidentes críticos, por su naturaleza de promover el pensamiento divergente, con el cual también se potencian los procesos de problematización. De modo que se constituyen en herramientas valiosas, sobre todo si se trata de enfrentar a los estudiantes con situaciones de aprendizaje retador, que requiera de echar mano de los conocimientos teóricos pero también de soluciones prácticas. 


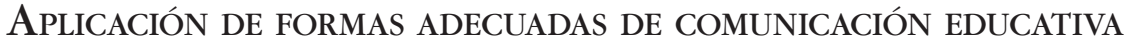

En cuanto a la competencia de aplicación de formas activas de comunicación didáctica tenemos la imperiosa necesidad de llevar a la práctica los modos cada vez más dinámicos y lúdicos que se abren tras el uso crítico de las tecnologías de información y comunicación como mediadoras del aprendizaje y del desarrollo de competencias por parte de los estudiantes.

Esta competencia, referida a la comunicación educativa comprende tres componentes centrales:

1. El dominio de las TIC como recursos de apoyo al aprendizaje.

2. El desarrollo de la competencia en manejo de la información, denominada también competencia informacional o en términos más abarcadores e integrales, competencia en gestión del conocimiento mediado por TIC.

3. El desarrollo de la competencia en medios, con la cual se busca que adopte una posición crítica frente a los medios y sea capaz de colocar conocimiento en los circuitos de información.

Desde estas nuevas formas de comunicación educativa se busca que el profesor asuma nuevos roles y desafíos, como por ejemplo, el fomento de sistemas que faciliten la creación de conexiones para aprender, la validación de la calidad de las conexiones que construye el estudiante, la mediación para el desarrollo de competencias informacionales y tecnológicas y el fomento del deseo de construir sentido.

Por su parte, el alumno debe convertirse en gestor de su propio conocimiento con mediación tecnológica, construyendo ambientes personales y colectivos de aprendizajes, generando un pensamiento crítico y reflexivo en conexión con la sociedad del conocimiento, creando y formando parte de comunidades virtuales de aprendizaje, tomando decisiones acerca de qué y cómo aprender con mediación tecnológica y dirigiendo su aprendizaje en conexión con otros actores. 


\section{La investigación bibliotecológica: problemas para...}

\section{VAlORACIÓN DEL LOGRO DE LAS COMPETENCIAS}

La última y no menos importante de las competencias que debe dominar de forma efectiva el docente de Bibliotecología y Ciencia de la información, para gestionar el micro-currículo a partir de un enfoque de calidad es la valoración del logro de las competencias que los estudiantes han adquirido y desarrollado, y esto lo alcanza el profesor si aplica dispositivos, estrategias e instrumentos para la evaluación del logro de las competencias de los estudiantes; utilizando dispositivos, estrategias e instrumentos para la acreditación de la asignatura, la satisfacción de las expectativas del profesor y de los estudiantes y por último valorando el impacto de la experiencia personal de la experiencia didáctica.

Las técnicas e instrumentos de evaluación compatibles con la formación por competencias plantean como principios conceptuales y metodológicos las ideas de integralidad y cooperación. El carácter integral de la evaluación viene dado porque la evaluación aborda el desempeño de los estudiantes en su totalidad, diversidad y riqueza. Lo cooperativo se traduce en el proceso de evaluación mediante la participación de todos los actores que intervienen en el proceso de evaluación. Por ello, las estrategias y los instrumentos evaluativos apuntan hacia hacer palpable el concepto de evaluación consensuada y democrática.

Sobre la base de tales principios, se propone diversificar las estrategias de evaluación, incorporando las siguientes estrategias: el mapa mental, el informe escrito, el debate sobre películas, visitas a unidades de información, el socio-drama y evaluativo oral. Como instrumentos evaluativos se emplean: el formato para el diario de visitas a unidades de información, la lista de cotejo para evaluar el socio-drama y la rúbrica para evaluar el mapa mental.

Para la valoración de las competencias, los profesores deben apoyarse en el uso de rúbricas en las cuales se desagreguen los criterios de evaluación con sus correspondientes niveles de dominio. Un ejemplo de rúbrica como instrumento de evaluación se muestra en el cuadro núm. 1. La rúbrica fue diseñada para evaluar la construcción 
de mapas mentales, elaborados por estudiantes de Bibliotecología y Ciencia de la información, de la asignatura: Práctica Profesional I de la Universidad del Zulia.

Cuadro núm. 1.

Rúbrica para evaluar un mapa mental

\begin{tabular}{|c|c|c|c|}
\hline Criterios & Básico & Intermedio & Avanzado \\
\hline $\begin{array}{l}\text { Creatividad e } \\
\text { innovación }\end{array}$ & $\begin{array}{l}\text { Se presentan imá- } \\
\text { genes relacionadas } \\
\text { con las dimensio- } \\
\text { nes profesionales } \\
\text { de acuerdo con una } \\
\text { visión elemental. }\end{array}$ & $\begin{array}{l}\text { Se presentan en la } \\
\text { composición del ma- } \\
\text { pa de imágenes de } \\
\text { las dimensiones pro- } \\
\text { fesionales de acuerdo } \\
\text { con una visión aso- } \\
\text { ciativa y relacional de } \\
\text { ámbitos laborales. }\end{array}$ & $\begin{array}{l}\text { Se construye un ma- } \\
\text { pamentalconbaseen } \\
\text { imágenes poco con- } \\
\text { vencionales, referi- } \\
\text { das a las dimensiones } \\
\text { profesionales, consi- } \\
\text { derando fotografías } \\
\text { tomadas por el pro- } \\
\text { pio estudiante enám- } \\
\text { bitosespecíficos. }\end{array}$ \\
\hline $\begin{array}{l}\text { Capacidad de } \\
\text { simbolización }\end{array}$ & $\begin{array}{l}\text { Relación directa } \\
\text { entre la dimensión } \\
\text { y sus particularida- } \\
\text { des y la estructura } \\
\text { de simbolización. }\end{array}$ & $\begin{array}{l}\text { Las imágenes selec- } \\
\text { cionadas para el ma- } \\
\text { pa reflejan de manera } \\
\text { clara, precisa y cohe- } \\
\text { rente las dimensiones } \\
\text { profesionales. }\end{array}$ & $\begin{array}{l}\text { El mapa presenta } \\
\text { una estructura de } \\
\text { simbolización que } \\
\text { no requiere explicar- } \\
\text { la sino que se explica } \\
\text { por si misma al co- } \\
\text { nectar todos los ele- } \\
\text { mentos de la dimen- } \\
\text { sión profesional. }\end{array}$ \\
\hline $\begin{array}{l}\text { Capacidad de sín- } \\
\text { tesis }\end{array}$ & $\begin{array}{l}\text { En el mapa se in- } \\
\text { tegran todos los } \\
\text { elementos de la } \\
\text { dimensión profe- } \\
\text { sional. }\end{array}$ & $\begin{array}{l}\text { El mapa integra y co- } \\
\text { necta la dimensión } \\
\text { con otras dimensio- } \\
\text { nes profesionales. }\end{array}$ & $\begin{array}{l}\text { El mapa integra la } \\
\text { dimensión con otras } \\
\text { dimensiones y con } \\
\text { las competencias del } \\
\text { perfil. }\end{array}$ \\
\hline Expresión oral & $\begin{array}{l}\text { Uso de un vocabu- } \\
\text { lario académico, } \\
\text { coherente y orga- } \\
\text { nizado. }\end{array}$ & $\begin{array}{l}\text { Se utiliza un vocabu- } \\
\text { lario académico y se } \\
\text { manejan mediana- } \\
\text { mente el vocabulario } \\
\text { técnico y profesional } \\
\text { del área. }\end{array}$ & $\begin{array}{l}\text { Se aprecia fluidez, } \\
\text { coherencia y uso del } \\
\text { vocabulario técnico } \\
\text { propios del área de } \\
\text { bibliotecología, ar- } \\
\text { chivología y ciencia } \\
\text { de la información. }\end{array}$ \\
\hline
\end{tabular}

Fuente: Elaboración propia. 
Otro tipo de instrumento de evaluación que se pueden utilizar son las listas de cotejo, en las cuales se establecen criterios para evidenciar los niveles de logro, en función de escalas a las cuales se les asigna una valoración. En el cuadro núm. 2 se muestra un ejemplo de lista de cotejo para evaluar los desempeños alcanzados a partir de la técnica de socio-drama.

Cuadro núm. 2.

Lista de cotejo para evaluar la técnica de socio-drama

\begin{tabular}{|l|l|l|l|l|}
\hline \multicolumn{1}{|c|}{ Criterios } & 1 & 2 & 3 & 4 \\
\hline $\begin{array}{l}\text { Adaptación del vestuario a la dimensión profesional que } \\
\text { modela. }\end{array}$ & & & \\
\hline Creatividad del concepto del socio-drama. & & & & \\
\hline Calidad de la utilería y recursos de apoyo utilizados. & & & & \\
\hline Dicción. & & & & \\
\hline $\begin{array}{l}\text { Coherencia del discurso y las competencias que apoyan } \\
\text { la dimensión profesional. }\end{array}$ & & & \\
\hline $\begin{array}{l}\text { Coherencia del discurso y los indicadores de logro que } \\
\text { apoyan la dimensión profesional. }\end{array}$ & & & & \\
\hline Dominio de la dimensión profesional que modela. & & & & \\
\hline $\begin{array}{l}\text { Ajuste al tiempo señalado para la interpretación de la } \\
\text { dimensión profesional que modela. }\end{array}$ & & & & \\
\hline
\end{tabular}

Fuente: Elaboración propia.

Finalmente, se tiene también la posibilidad de utilizar las fichas de registro de observación y de visitas didácticas como instrumento de evaluación en asignaturas de formación bibliotecológica de orientación práctica, las cuales requieren la realización de actividades fuera del aula. En este sentido, los diferentes tipos de bibliotecas se convierten en espacios académicos para el aprendizaje de contenidos procedimentales y actitudinales, en los cuales los profesionales de la información en formación pueden encontrar procesos y fenómenos reales que se trabajan desde el ámbito teórico-conceptual. El cuadro núm. 3 muestra un ejemplo de ficha de observación y registro de visitas didácticas a unidades y servicios de información. 
Cuadro núm. 3.

Ficha de observación y registro de visitas a bibliotecas

\section{Institución:}

Nombre del coordinador o director de la unidad o servicio de información:

Fecha de creación de la institución:

Fecha de creación de la unidad o servicio de información:

Servicios que se ofrecen en la institución o unidad de información:

Tipo de colecciones con las cuales trabaja:

Servicios y funciones que se realizan vinculados con la dimensión profesional correspondiente:

Tipo de usuarios de la unidad o servicio de información:

Comentarios:

Fuente: Elaboración propia.

Incorporar estas competencias docentes al ideario pedagógico, garantizaría una adecuada gestión del micro-currículo por parte de los profesores, considerando además las concepciones y pautas establecidas en los niveles meso y macro-curricular; de modo que se trata de contar con un profesional que sea competente para:

1. Asumirse como un intelectual capaz de adherirse a la gestión de un proyecto institucional y curricular. 


\section{La investigación bibliotecológica: problemas para...}

2. Diseñar su docencia, planifica su acción de manera crítica y creativa para ponerla en práctica eficazmente.

3. Reflexionar durante su acción para reajustar su práctica educativa, gestionando de este modo la progresión de los aprendizajes de sus alumnos.

4. Reflexionar posteriormente sobre la acción con el fin de evaluar el proceso y refinarlo.

De modo que el docente es un profesional que reflexiona antes, durante y después de su acción. En el antes, ubicamos la fase de planificación didáctica. El durante alude a la fase interactiva propiamente dicha desde donde se incide en el ámbito micro-curricular. El después tiene que ver con la fase post-interactiva, en la cual el docente reflexiona y analiza lo ocurrido en el proceso y se recapitula sobre lo vivido, este momento es una etapa crítica debido a que se construyen saberes acerca de su práctica.

\section{Conclusiones}

Luego de estudiar y analizar las competencias propuestas desde el grupo REDECA concluimos en la necesidad de incorporarlas a nuestro ideario pedagógico, por cuanto hacen parte de las últimas tendencias que se vienen manejando para alcanzar elevados niveles de significatividad, funcionalidad y calidad en la formación de profesionales. Si nos detenemos a desconstruir los argumentos sobre cuya base su plantean, encontramos términos y conceptos propios del lenguaje de las ciencias gerenciales en generales y de la gerencia y gestión curricular en particular.

En el marco de la propuesta se recurre al uso de verbos como realizar, diseñar, gestionar, coordinar y valorar, acciones estas que traen consigo un conjunto de operaciones y estrategias vinculadas con el manejo, uso racional y efectivo de los recursos de todo tipo, entendiéndose el proceso de gestión micro-curricular como un circuito de operaciones, interacciones y procedimientos, encaminados hacia el logro de la calidad de la formación. 
El tema de la gestión desde el ámbito micro-curricular para avanzar hacia la calidad de la educación superior es un asunto de vital importancia, sobre todo si se trata de activar procesos de reflexión y de acción innovadora, que tiendan a mejorar de manera continua la formación de los cuadros profesionales que la sociedad requiere para apalancar el desarrollo y e incorporación a los escenarios complejos de la globalidad, no sólo económica sino también cultural y educacional.

Para abordar este tema, asumimos las premisas de que la educación se encuentra íntimamente ligada al desarrollo y de que la docencia es una profesión compleja que obliga a repensar sistemáticamente el trabajo académico, por lo cual no basta con transmitir conocimientos bajo el amparo de la libertad de cátedra. Ambas premisas aluden a su vez al hecho de que para alcanzar la calidad de los procesos de formación debemos gestionar de manera efectiva el micro-currículo y ello implica el dominio de competencias docentes para manejar adecuadamente la transposición didáctica.

\section{BiBLIOGRAFÍA}

Cardelli, J (2004). "Reflexiones críticas sobre el concepto de transposición didáctica de Chevallard." Cuadernos de Antropología Social 19. Facultad de Filosofía y Letras. Universidad de Buenos Aires. Disponible en línea: http://www.scielo.org.ar/pdf/cas/n19/n19a04.pdf. (Consulta: 10-11-15).

Guzmán, I., R. Marín y A. Inciarte. (2014). Innovar para transformar la docencia universitaria. Un modelo para la formación por competencias. Maracaibo: Astrodata. Universidad del Zulia.

Klenowski, V. (2005). Desarrollo de portafolios para el aprendizaje y la evaluación. Madrid: Narcea. 
Moliner, L. y C. Loren. (2010). "La formación continua como proceso clave en la profesionalización docente. Buenas prácticas en Chile." Revista Latinoamericana de Educación Inclusiva 4(1). Disponible en línea: http:// www.rinace.net/rlei/numeros/vol4-num1/art1.pdf. (Consulta: 12-11-15).

Pirela M, J. (2005) "Tendencias y perspectivas para la enseñanza de la bibliotecología en la cibersociedad.” En: Memoria del XXIII Coloquio de Investigación Bibliotecológica y de la Información: problemas y métodos de investigación en bibliotecología e información. Una perspectiva interdisciplinaria. Centro Universitario de Investigaciones Bibliotecológicas (CUIB). Universidad Nacional Autónoma de México. UNAM.

Rougiers, X. (2010). Una pedagogía de la integración: competencias e integración de los conocimientos en la enseñanza. México: Fondo de Cultura económica.

Tobón, S. (2010). Formación integral y competencias: pensamiento complejo, currículo, didáctica y evaluación. Bogotá: Ecoe Ediciones.

UNESCO (2008). Estándares de competencias en TIC para docentes. Disponible en línea: http://www.oei.es/tic/ UNESCOEstandaresDocentes.pdf. (Consulta. 14-10-15) 
La investigación bibliotecológica: problemas para su enseñanza y aprendizaje. Coordinación editorial y revisión de pruebas, Carlos Ceballos Sosa; revisión de textos y formación editorial, Edgar Abraham Alameda Rangel. Instituto de Investigaciones Bibliotecológicas y de la Información / UNAM. México, D.F. Se terminó de producir en Ciudad Universitaria el mes de abril de 2016. 